\title{
Parvalbumin interneuron alterations in stress-related mood disorders: A systematic review
}

\author{
George Perlman, Arnaud Tanti ${ }^{*}, 1$, Naguib Mechawar
}

\section{A R T I C L E I N F O}

\section{Keywords:}

Parvalbumin

Stress

Depression

Interneuron

Perineuronal net

\begin{abstract}
A B S T R A C T
Stress-related psychiatric disorders including depression involve complex cellular and molecular changes in the brain, and GABAergic signaling dysfunction is increasingly implicated in the etiology of mood disorders. Parvalbumin (PV)-expressing neurons are fast-spiking interneurons that, among other roles, coordinate synchronous neuronal firing. Mounting evidence suggests that the PV neuron phenotype is altered by stress and in mood disorders. In this systematic review, we assessed PV interneuron alterations in psychiatric disorders as reported in human postmortem brain studies and animal models of environmental stress. This review aims to 1) comprehensively catalog evidence of PV cell function in mood disorders (humans) and stress models of mood disorders (animals); 2) analyze the strength of evidence of PV interneuron alterations in various brain regions in humans and rodents; 3 ) determine whether the modulating effect of antidepressant treatment, physical exercise, and environmental enrichment on stress in animals associates with particular effects on PV function; and 4) use this information to guide future research avenues. Its principal findings, derived mainly from rodent studies, are that stress-related changes in PV cells are only reported in a minority of studies, that positive findings are region-, age-, sex-, and stress recency-dependent, and that antidepressants protect from stress-induced apparent PV cell loss. These observations do not currently translate well to humans, although the postmortem literature on the topic remains limited.
\end{abstract}

\section{Introduction}

Parvalbumin (PV) neurons are a type of GABAergic interneuron defined by their expression of the calcium-binding protein parvalbumin. In the telencephalon, they can be subdivided into two types: basket cells, whose axons innervate the soma and proximal dendrites of principal cells; and chandelier cells, which synapse onto the initial axon segment of their targets (Hu et al., 2014). PV cells share common electrophysiological parameters and roles in microcircuits and are particularly implicated in plasticity and learning (Hu et al., 2014). Notably, their functional maturation controls the opening and closure of critical windows of enhanced plasticity during postnatal development (Bradshaw et al., 2018) and mature PV cells coordinate synchronous oscillatory firing of principal neurons through feed-forward inhibition (Hu et al., 2014), thereby regulating the balance of excitatory and inhibitory neurotransmission in the brain. The influence of PV cells on developmental neuroplasticity is strongly associated with the establishment of specialized condensed extracellular matrix structures called perineuronal nets (PNNs), which ensheath the somata, proximal dendrites, and initial axon segments of a large proportion of PV neurons. Among other roles, PNNs buffer oxidative stress and regulate the formation and function of synapses by interacting directly or indirectly with neurotrophic factors, receptors, and guidance cues (Wen et al., 2018). Indeed, PNNs seem to influence every aspect of PV neuron physiology and connectivity.

Consistent with a broad implication of GABAergic interneurons in neuropsychiatric disorders (Prévot and Sibille, 2020), disruptions in PV cells in the hippocampus (HC) and prefrontal cortex (PFC) have been associated with mood disorders (Page et al., 2019b; Zaletel et al., 2016). Postmortem brain studies have revealed reductions in PV interneurons in the hippocampus and prefrontal cortex of people with major depressive disorder (MDD) and bipolar disorder (BD) (Knable et al., 2004; Konradi et al., 2011; Rajkowska et al., 2007). These findings are consistent with findings showing that PV neurons are particularly impacted by chronic stress, a major risk factor for MDD and BD. Functional consequences of chronic stress on PV cells have been observed in many brain regions in animals, particularly in the HC (Hu et al., 2010),

* Corresponding author. McGill Group for Suicide Studies, Department of Psychiaty, McGill University, Douglas Mental Health University Institute, 6875 LaSalle blvd, Verdun, Qc, H4H 1R3, Canada

E-mail addresses: george.perlman@mail.utoronto.ca (G. Perlman), arnaud.tanti@inserm.fr (A. Tanti), naguib.mechawar@mcgill.ca (N. Mechawar).

1 Current affiliation: UMR 1253, iBrain, Université de Tours, Inserm, Tours, France. 


\begin{tabular}{|llll|}
\hline Nomenclature & UCMS & unpredictable chronic mild stress \\
PV & parvalbumin & IHC & immunohistochemistry \\
GABA & gamma-aminobutyric acid & mRNA & messenger ribonucleic acid \\
PNN & perineuronal net & CA1/CA2/CA3 cornu ammonis $1 / 2 / 3$ \\
HC & hippocampus & DG & dentate gyrus \\
PFC & prefrontal cortex & PrL & prelimbic cortex \\
MDD & major depressive disorder & WFL & Wisteria floribunda lectin \\
BD & bipolar disorder & WFA & Wisteria floribunda agglutinin \\
BLA & basolateral amygdala & SIPSC & spontaneous inhibitory postsynaptic current \\
GR & glucocorticoid receptor & IL & infralimbic cortex \\
HPA & hypothalamic-pituitary-adrenal & ACC & anterior cingulate cortex \\
OFC & orbitofrontal cortex & qPCR & quantitative polymerase chain reaction \\
mPFC & medial prefrontal cortex & E/I & excitation/inhibition \\
MS & maternal separation & mEPSC & miniature excitatory postsynaptic current \\
LB/LN & limited bedding/limited nesting & ERK & extracellular signal-related kinase \\
MSEW & maternal separation-early weaning & dlPFC & dorsolateral prefrontal cortex \\
SI & social isolation & BA9 & Brodmann area 9 \\
SDPS & social defeat-prolonged stress & BA24 & Brodmann area 24 \\
CVS & chronic variable stress & TRN & thalamic reticular nucleus \\
& & FACS & fluoresence-activated cell sorting \\
\hline
\end{tabular}

PFC (Wieck et al., 2013), and basolateral amygdala (BLA) (Guadagno et al., 2020). Depressed patients (Black et al., 2015; Michel et al., 2012) and individuals experiencing chronic or severe life stress (Salim, 2017; Schiavone et al., 2013) have higher levels of oxidative stress in the brain, which is negatively associated with the integrity of PV interneurons and their surrounding PNNs (Steullet et al., 2017). Further, a majority of PV interneurons in the rat infralimbic cortex express glucocorticoid receptors (GRs) whereas other interneuron populations in the region do not stain for GRs (McKlveen et al., 2019). These infralimbic PV cells show reduced GRs and increased activity following chronic stress in adults (McKlveen et al., 2016), suggesting a possible involvement of PV neurons in the disruption of the hypothalamic-pituitary-adrenal (HPA) axis' negative feedback loop in chronic stress conditions. This review examines the evidence implicating PV neurons in mood disorders, including studies conducted with animal stress models. A number of relevant parameters were taken into consideration following our literature search such as regional effects, sex, age, and various forms of environmental enrichment.

Abundant research in stress neurobiology has focused on the HC, amygdala, and PFC as they are particularly impacted in mood disorders. These three regions and communication between them are involved in cognitive and affective processes that are disturbed in mood disorders. In general, chronic stress reduces neurotrophic signaling in the $\mathrm{HC}$ and PFC (LiuWei et al., 2017; McEwen et al., 2016), resulting in impaired plasticity and dendrite retraction, whereas the opposite trend is observed in the BLA (Boyle, 2013). This pattern may underlie the cognitive and mood changes in depression; depressed patients and rodents displaying depressive-like behavior commonly show impaired executive function, learning, and memory, processes associated with the PFC and HC, whereas behavioral inhibition and reactivity to negative stimuli, functions associated with the amygdala, are increased (McKlveen et al., 2019). Moreover, the effects of stress on neurogenesis and synaptic rewiring can be subregion-specific. For example, the orbitofrontal cortex (OFC) and medial PFC (mPFC) respond differently to stress, as do the BLA and central amygdala.

Sex-specific responses to stress have also been reported in PV neurons in animal studies; recent findings have highlighted sex-specific stress-induced PV cell transcriptomic changes (Girgenti et al., 2019) as well as changes to parvalbumin expression and cell density that associate with cognitive outcomes (Goodwill et al., 2018). Unfortunately, most of the animal stress model literature concerns male rodents; certain stress paradigms (e.g., social defeat) are more suitable to males, and females' estrus cycle and associated hormonal fluctuations can confound results (Furman et al., 2019; Milner et al., 2013; Takahashi et al., 2017). The apparent ease of research with male animals comes at a scientific cost given that mood disorders are significantly more prevalent in women than in men. Furthermore, female animals tend to exhibit different neurobiological, cognitive, and behavioral outcomes in response to stress (Galea et al., 1997; Luine et al., 2017).

Further, developmental timing and stress recency also play major roles in determining the neurobiological response to stress (Gee and Casey, 2015). Stress acts differently on the brain depending on developmental stage and interferes with neurodevelopment - typically in a deleterious manner when the stressor is highly intense or frequent. Early life stress is particularly harmful as evidenced by its position as a major predictor of later psychiatric illness. This is likely due to the brain's greater malleability in response to stimuli in youth and the potential of stressors to interfere with neurodevelopment. Social isolation during early-life, for example, has notable effects on neurodevelopment. While it is beyond the scope of this review to extensively describe cellular alterations associated with early-life isolation, it is worth mentioning that several studies have indicated that social isolation early in life (postweaning) alone or in combination with another stressor such as maternal separation induces changes in PV expression and function as well as in the number of PNNs (Gildawie et al., 2021; Maćkowiak et al., 2019; Ueno et al., 2017). These effects may have a lasting impact on the emergence of psychopathologies, considering that PV cells may have an important role in the neural circuitry necessary for the maturation and expression of social behavior (Bicks et al., 2020).

The recency of stress is also a key modulator of its effect; rodents and humans alike show early hyper-reactivity to stress-associated stimuli, but these reactions dull over time when the animal is returned to a more congenial environment. The neurobiological signature of this diminishing response may be reflected in PV neurons.

There is ample evidence that PV cell structure and function can be modulated by interventions such as antidepressant drug administration, physical exercise, and environmental enrichment, all of which can counteract the deleterious effects of chronic stress. In this review, we included treatment with antidepressant drugs such as fluoxetine and ketamine as enrichment protocols because of their use in treating stressrelated mood disorders in humans. One notable example of enrichment impacting PV neurons is that of fluoxetine's effect on PNNs; numerous studies have demonstrated chronic fluoxetine treatment to reduce the densities of PNNs and PV cells in the HC (Karpova et al., 2011; 
Mukhopadhyay et al., 2021), PFC (Guirado et al., 2014; Ohira et al., 2013), and BLA (Karpova et al., 2011). Making PV cell dendrites more freely accessible for the formation and elimination of synapses may be one of the mechanisms underlying the antidepressant effects of fluoxetine.

Here, we systematically review the literature on PV interneurons in postmortem studies and animal models of mood disorders. We further include animal studies of enrichment paradigms that act as a buffer or protective influence against the behavioral and biological effects of stress. The most robust finding to emerge from animal studies is a tendency of stress-associated PV cell reductions in subregions of the PFC and HC that was in some cases preventable by subjecting the animals to antidepressant or anti-inflammatory drug regimen during stress. This trend was highly heterogeneous, however, and was mainly found in males. Human postmortem studies were considerably less numerous and lacked the weight and consistency to support robust conclusions. However, a trend of reduced PV expression was observed in the dorsolateral PFC of individuals with $\mathrm{BD}$.

\section{Methods}

\subsection{Animal stress models}

Models of early-life stress, a factor which strongly predisposes to psychopathologies, include maternal separation (MS) and limited bedding/limited nesting (LB/LN). The former involves isolating pups from their mothers for a period each day during early postnatal life and can also be combined with early weaning (MSEW). The latter involves providing mothers with insufficient bedding material to provide a nurturing environment for their pups. Models of stress administered during juvenility, adolescence and adulthood include social isolation, chronic restraint or immobilization, and chronic social defeat (Chu et al., 2016; Ieraci et al., 2016; Iñiguez et al., 2014; Murthy and Gould, 2020). Social isolation (SI) is a major risk factor for psychiatric illness in humans (Leigh-Hunt et al., 2017), and animal models mimic this by isolating rodents for periods of roughly 2 weeks to 3 months. In chronic restraint or immobilization protocols, rodents are placed in cylindrical tubes or have their limbs taped to their sides, making them unable to move for a period of each day. These interventions reliably elevate glucocorticoid levels and produce behavioral and neurobiological hallmarks of mood disorders (Chu et al., 2016; Zheng et al., 2018). Experiencing social adversity such as bullying is a risk factor for depression in humans (Björkqvist, 2001), and the chronic social defeat model aims to reproduce this in animals. In this paradigm a rodent is routinely subordinated to another in direct physical confrontations. One novel adaptation of subordination stress is the social defeat-prolonged stress (SDPS) paradigm, in which an animal is subordinated to another for five consecutive days and then socially isolated until testing. This manipulation is meant to mimic a traumatic trigger and the following lack of social support that is associated with depression (Spijker et al., 2020). Some other chronic stress paradigms used in rodents include chronic mild stress, chronic variable stress (CVS), and unpredictable chronic mild stress (UCMS) (Spijker et al., 2020). These involve subjecting rodents to a variety of stressors, typically physical or social. Physical stressors can include restraint, tail pinches, overnight illumination, and more. Examples of social stressors are isolation, crowded housing, and social defeat (Spijker et al., 2020; Umemori et al., 2015). Maternal stress during gestation in rodents is also used to model mood disorders given robust evidence that it increases the incidence of mood disorders in children (Brannigan et al., 2019) and produces depressive-like symptoms in animal offspring (Kim et al., 2015). Examples of stressors applied to mothers include immobilization and chronic variable stress.

\subsection{Postmortem studies}

Postmortem studies of human brains have yielded major insights into the molecular and functional manifestations of mood disorders (Bani-Fatemi et al., 2018). Brains harvested in a timely manner after death can be preserved and used for neurobiological studies. However, postmortem studies are susceptible to influence by a range of confounding factors such as postmortem interval, cause of death, history of medication, and comorbidities that make it difficult to have appropriately control-matched samples. Research groups with expertise in postmortem immunostaining and other approaches typically control for factors that may impact signal detection, such as postmortem interval, tissue $\mathrm{pH}$, and autofluorescence. Further, in light of these potential shortcomings, animal models are useful complements to human brain studies, with the obvious caveat of species differences.

\subsection{Approaches used to assess PV interneurons}

Immunohistochemistry (IHC) was the primary tool used to visualize $\mathrm{PV}$ interneurons in studies included in this review. It was used mainly to assess the total number or density of PV cells in various brain regions. Co-staining was also used in several studies to interrogate particular aspects of PV cell phenotype or activity. For example, c-Fos staining in PV cells was used to assess PV cell activation after a given stressor (Page et al., 2019). Electron microscopy can provide deeper insights into cellular functions of PV neurons, including subcellular receptor localization and dendritic features. Many studies included in this review also measured regional mRNA or protein expression of parvalbumin. While these do not fully elucidate local PV neuron function in a given brain region, they nevertheless add a layer of understanding to PV cell physiology in stressed animals. Of note, Donato et al., reported that PV expression (measured by IHC) correlates with GABA production (Donato et al., 2013).

Reductions in PV neuron numbers and in the expression of PV protein have been observed in the HC of stressed animals (Czeh et al., 2005; Filipović et al., 2013), and it has been debated whether these findings are due to PV cell death, attenuated maturation, or reduced PV expression (sometimes to undetectable levels), all of which could be interpreted as a reduction in the number of PV cells as measured by IHC. Two studies by Filipović et al., in 2011 and 2013 appeared to favor the second and third hypotheses, with their reports that adulthood social isolation-associated PV cell reductions in the dentate, CA1 and CA3 HC subfields were not accompanied by increased staining for apoptotic markers such as cytosolic cytochrome $c$ and mitochondrial p53 protein. However, a nonsignificant trend toward increased apoptotic markers in the HC in this study may indicate the contrary. Increases in oxidative stress markers have been reported in both the PFC and HC of adult socially isolated rats (Zlatković and Filipović, 2012) and in PV neurons of maternally separated animals' dentate gyrus (DG), CA1 and prelimbic cortex (PrL) (Soares et al., 2020).

Reductions in the expression of PV protein or mRNA in a given region may be due to cell death, compromised maturation, or a simple reduction in expression associated with cell stress. Given the lack of substantial data supporting the hypothesis of cell death we avoid using the expression "PV cell loss" in this paper, opting instead for "reduction in PV cell number or density" or "apparent PV cell loss".

Electrophysiological recordings of PV cells or pyramidal neurons onto which they synapse can yield insights into PV cell function. PV neurons coordinate oscillatory neuronal firing at theta frequency in local microcircuits in the mouse hippocampus, and optogenetically silencing them disrupts theta rhythm (Amilhon et al., 2015). PV cells have a unique electrophysiological signature, and thus their signaling onto pyramidal neurons can be gleaned by measuring spontaneous inhibitory postsynaptic currents (sIPSCs) on pyramidal neuron plasma membranes. Excitability can be evaluated by recording PV cells directly or sIPSCs on pyramidal neurons in response to current injection, chemogenetic or optogenetic stimulation, or drug administration.

Specialized extracellular matrix structures called perineuronal nets (PNNs) commonly ensheath PV neurons (Wen et al., 2018). PNNs serve 
various functions, including regulating synaptic transmission by interacting with neurotrophins, transcription factors, and cell surface molecules such as receptors, protecting their ensheathed neurons from oxidative stress, and regulating synaptic plasticity (Berretta et al., 2015; Wen et al., 2018). PNNs are established during postnatal development and their maturation is intimately associated with the opening and closure of critical periods of enhanced neuroplasticity (Wen et al., 2018). Recent evidence suggests that PNNs on PV neurons may be altered by early life stress in animals (Gildawie et al., 2019; Mukhopadhyay et al., 2021) and humans (Tanti et al., 2020), which are thought to reflect changes in PV cell excitability, plasticity, oxidative stress, and other metabolic functions (Wen et al., 2018). PNNs are typically labeled using a lectin called Wisteria floribunda lectin (WFL) or agglutinin (WFA), which binds a carbohydrate residue found in PNNs, in particular those surrounding PV neurons. This represents a shortcoming of PNN measurement, however, as WFA/WFL staining does not account for other molecular components of PNNs, some PNNs are not recognized by this lectin, and their makeup can vary according to the cell types they surround (McEwen et al., 2016), biasing the results obtained solely from WFL/WFA staining. Specific components of PNNs have been shown to control the localization of ion channels (Favuzzi et al., 2017) and to regulate axon growth (Foscarin et al., 2017), and changes to these components are not detected by WFA/WFL staining. Hopefully, in future studies other techniques such as mass spectrometry- and antibody-based detection of PNN elements, including carbohydrate residues and (Matthews et al., 2002; Konradi et al., 2011; Riga et al., 2017; Wang et al., 2018), will help to fill gaps in our understanding of PNN remodeling, with the limitation that PNN components can also be found in non-PNN structures.

Despite a growing number of studies trying to address changes in PNNs formation and composition in stress-related disorders, current approaches based on immunoreactivity are only partly informative. Ultimately further development is needed to understand how PNNs are dynamically formed and remodeled by experiences and stress through life, at the transcriptional and cellular level, using innovative in-vivo approaches combined with functional readouts to map their contribution to PV cell physiology. Only these integrative approaches will shed light on the role of impaired PNN development in psychopathology.

Ultimately, beyond the biological interpretation of density changes of specific cell types or changes in protein expression associated with an experimental condition or disease, methods of investigation based on immunostaining can be quantitatively flawed and prompt to bias. Tissue collection and preparation, choice of antibodies, immunolabeling protocols, and quantification all vary considerably between studies, and necessarily influence their results and interpretations. Such limitations are particularly amplified in postmortem studies, where sample preparation and quality can strongly impact the outcome of immunolabeling. Because of these limitations, assessing PV integrity through multiple experimental approaches combining immunolabeling, gene expression, and more functional assays such as electrophysiological recordings are necessarily much more informative and should be privileged.

\subsection{Inclusion/exclusion criteria}

We conducted a search across MEDLINE, Web of Science, and Pubmed on March 24, 2020 using a search strategy outlined in the Supplementary Materials. The initial screen yielded 4141 studies after duplicates were excluded. An updated search on December 7, 2020 spanning publications in 2020 and 2021 yielded 485 non-duplicate articles. Abstracts were screened to further narrow down the field by applying the following inclusion and exclusion criteria: studies of interest 1 ) assessed PV interneurons 2) in postmortem brain samples from patients with mood disorders or animal models (environmental stress) of mood disorders 3) in comparison to samples from psychiatrically healthy individuals or unstressed controls, respectively.

In order to limit the scope of this review, here we included postmortem studies of mood disorders but not other neuropsychiatric conditions such as schizophrenia and ADHD, despite the implication of stress and the dysfunction of PV neurons found in these latter conditions. This choice is in part motivated by the limited translatability of animal models of these disorders, their higher heritability, and their different nosography. However, a transdiagnostic examination of the associations between PV neurons and psychiatric disorders may be a fruitful avenue of research.

Control-matched animal studies examining the effects of antidepressant administration, environmental enrichment, and physical exercise interventions on PV interneurons were all included in the review (under enrichment). Because environmental stress models have superior construct validity in mimicking the causes of mood disorders in humans (Planchez et al., 2019), drug-induced models were excluded, including chronic administration of stress hormones such as corticosterone or inflammatory molecules such as lipopolysaccharide.

A full-text information search from the resulting 168 articles yielded 129 studies that were ultimately included in this review (Fig. S1).

\section{Results}

A summary of all extracted studies can be found in Tables 1-5, with those of particular significance in bold. For interpretation of animal studies, we grouped rodents into four age categories: early postnatal (birth to postnatal day 19 (P19)), juvenile (P20-P30), adolescent (P31-P60), and adult (P60+).

\subsection{Changes in $P V$ neuron populations}

The majority of studies that assessed PV interneuron changes due to stress measured their density or total number in a given brain region. Immunohistochemical studies tended to show apparent PV cell losses in subregions of the PFC and HC of stressed animals. In the PFC, while most studies reported no change in PV cell density, those in which stress did lead to a change overwhelmingly found a decrease in the prelimbic and infralimbic (IL) areas (Table 1). This trend held most strongly for adolescents, whereas adult animals showed reductions in PV cells in the IL but not in the PrL cortex and juveniles displayed minimal change (Brenhouse and Andersen, 2011; Clarke et al., 2019; Czeh et al., 2015; do Prado et al., 2015; Ganguly et al., 2015; Gildawie et al., 2019; Grassi-Oliveira et al., 2016; Helmeke et al., 2008; Heslin and Coutellier, 2018; Leussis et al., 2012; Lussier and Stevens, 2016; Moench et al., 2020; Ohta et al., 2020; Page and Coutellier, 2018a; Shepard et al., 2016; Soares et al., 2020; Ueno et al., 2017; Wang et al., 2019). Drug enrichment protocols protected against stress-associated apparent PV cell loss in some studies (Ganguly et al., 2015; Todorovic et al., 2018; Wieck et al., 2013), while enrichment alone did not tend to change the number of PV cells in the PrL and IL in unstressed animals (Sampedro-Piquero et al., 2016; Song et al., 2019; Yang et al., 2015) (Table 4). A few studies stained PV cells in the anterior cingulate cortex (ACC), the $\mathrm{mPFC}$, and the whole PFC, reporting mixed findings with no clear trend in any direction (Table 1). Likewise, enrichment studies produced varied effects in these regions (Jargalsaikhan et al., 2017; O'Connor et al., 2019; Todorovic et al., 2018).

As in the PFC, chronic stress paradigms tended to produce reductions in the densities of PV cells throughout the HC (Table 2). This held robustly in the dentate gyrus, CA1 and CA2/3, and inconsistently in the CA3 and whole hippocampus of adult animals, with weaker evidence suggesting decreases in adolescents as well. It was not clear how coadministration of antidepressant drugs affected the PV cell response to stress - in the dentate, while two studies found them to protect against stress-induced apparent PV cell loss (Czeh et al., 2005; Peric et al., 2018), another reported fluoxetine combined with social isolation to reduce the number of PV cells compared to social isolation alone (Filipović et al., 2011). Most studies of enrichment alone found no change (Anstotz et al., 2018; Gomes da Silva et al., 2010; Mukhopadhyay et al., 
Table 1

PV neuron alterations in the prefrontal cortex of stressed animals.

\begin{tabular}{|c|c|c|c|c|c|c|c|c|c|}
\hline Species & $\begin{array}{l}\text { Age during } \\
\text { manipulation }\end{array}$ & $\begin{array}{l}\text { Age at } \\
\text { measurement }\end{array}$ & Sex & Experimental Paradigm & Brain Region & Method & Measure & Outcome & Reference \\
\hline Mouse (C57/BL6) & Adolescent & Adolescent & $0^{\circ}$ & RS $6 \mathrm{~h} /$ day 21 days & Prelimbic cortex & $\mathrm{IHC}$ & $\begin{array}{l}\text { Total PV cell number; PV } \\
\text { cellular intensity }\end{array}$ & no change & $\begin{array}{l}\text { [27] Clarke et al. } \\
\text { (2019) }\end{array}$ \\
\hline Rat (Wistar) & $\begin{array}{l}\text { Adolescent- } \\
\text { adult }\end{array}$ & Adult & 0 & CMS 9 weeks & Prelimbic cortex & $\mathrm{IHC}$ & Total PV cell number & no change & $\begin{array}{l}\text { [33] Czeh et al. } \\
\text { (2018) }\end{array}$ \\
\hline Mouse (C57/BL6) & Adult & Adult & 0 & $\begin{array}{l}\text { RS } 1 \mathrm{~h} / \text { day for } 14 \text { days; } \\
\text { sacrifice immediately or } \\
1 \text { month later }\end{array}$ & Prelimbic cortex & $\mathrm{IHC}$ & Total PV cell number & no change & $\begin{array}{l}\text { [46] Friedman } \\
\text { et al. (2017) }\end{array}$ \\
\hline Rat (Sprague-Dawley) & Early postnatal & Adolescent & o & MS 4h/day & Prelimbic cortex & IHC & PV cell density & decreased & $\begin{array}{l}\text { [49] Ganguly } \\
\text { et al. (2015) }\end{array}$ \\
\hline Rat (Sprague-Dawley) & Early postnatal & $\begin{array}{l}\text { Juvenile; } \\
\text { adolescent; } \\
\text { adult }\end{array}$ & రోo & $\begin{array}{l}\text { MS } 4 \mathrm{~h} / \text { day; } 0,20 \text {, or } 50 \\
\text { days rest }\end{array}$ & Prelimbic cortex & IHC and WFA stain & $\begin{array}{l}\text { PV +/PNN + cell density; PV } \\
\text { cell density; PV + PNN } \\
\text { intensity; PNN + PV } \\
\text { intensity; PV intensity }\end{array}$ & $\begin{array}{l}\text { increased PV + PNN intensity at } \\
\text { P70 in males; no change in others }\end{array}$ & $\begin{array}{l}\text { [52] Gildawie } \\
\text { et al. (2019) }\end{array}$ \\
\hline Rat (Sprague-Dawley) & $\begin{array}{l}\text { Early } \\
\text { postnatal- } \\
\text { adolescent }\end{array}$ & Adult & ơ & $\begin{array}{l}\text { MS 4h/day; SI or pair } \\
\text { housing from P21-P35 }\end{array}$ & Prelimbic cortex & IHC and WFA stain & $\begin{array}{l}\text { PV cell number; PV } \\
\text { intensity; PNN number; PNN } \\
\text { intensity; PV+/PNN + cell } \\
\text { number; PNN + fraction of } \\
\text { PV cells; PNN + PV } \\
\text { intensity; PV + PNN } \\
\text { intensity }\end{array}$ & $\begin{array}{l}\text { PV cell number and PNN + fraction } \\
\text { of PV cells reduced in females by } \\
\text { MS + SI compared to SI alone; PNN } \\
\text { intensity reduced by MS + SI in } \\
\text { females compared to MS or SI alone; } \\
\text { PV + PNN intensity reduced by MS } \\
+ \text { SI in females compared to MS } \\
\text { alone }\end{array}$ & $\begin{array}{l}\text { [53] Gildawie } \\
\text { et al. (2021) }\end{array}$ \\
\hline Rat (Sprague-Dawley) & Early postnatal & Adolescent & ơo & MS 4h/day & Prelimbic cortex & $\mathrm{IHC}$ & Total PV cell number & $\begin{array}{l}\text { decreased in males, no change in } \\
\text { females }\end{array}$ & $\begin{array}{l}\text { [60] } \\
\text { Grassi-Oliveira } \\
\text { et al. (2016) }\end{array}$ \\
\hline Degu & Early postnatal & Juvenile & 0 & MS $3 \times 1$ h/day & Prelimbic cortex & $\mathrm{IHC}$ & PV cell density & no change & $\begin{array}{l}\text { [66] Helmeke } \\
\text { et al. (2008) }\end{array}$ \\
\hline Degu & Early postnatal & Adolescent & o & MS $3 \times 1 \mathrm{~h} /$ day & Prelimbic cortex & $\mathrm{IHC}$ & PV cell density & no change & $\begin{array}{l}\text { [66] Helmeke } \\
\text { et al. (2008) }\end{array}$ \\
\hline $\begin{array}{l}\text { Npas4 HET and wild- } \\
\text { type mice }\end{array}$ & - & Adult & o & $\begin{array}{l}\text { Maternal RS (GD7-19) } \\
30 \text { min twice per day }\end{array}$ & Prelimbic cortex & $\mathrm{IHC}$ & $\begin{array}{l}\text { Total PV cell number; total } \\
\text { PV+/c-Fos + cell number; } \\
\text { average NR1 puncta per PV } \\
\text { cell }\end{array}$ & no change & $\begin{array}{l}\text { [67] Heslin and } \\
\text { Coutellier (2018) }\end{array}$ \\
\hline Rat (Sprague-Dawley) & Early postnatal & $\begin{array}{l}\text { Adolescent; } \\
\text { adult }\end{array}$ & o & MS 4h/day & Prelimbic cortex & IHC & PV cell density & $\begin{array}{l}\text { decreased at } \mathrm{P} 40 \text {, no change at } \\
\mathrm{P} 100\end{array}$ & $\begin{array}{l}\text { [93] Leussis et al. } \\
\text { (2012) }\end{array}$ \\
\hline Mouse (C57/BL6) & Early postnatal & $\begin{array}{l}\text { Early postnatal; } \\
\text { juvenile; } \\
\text { adolescent; } \\
\text { adult }\end{array}$ & రోo & LB/LN 7 days & Prelimbic Cortex & $\mathrm{IHC}$ & PV cell density & increased in adults & $\begin{array}{l}\text { [118] Nieves } \\
\text { et al. (2020) }\end{array}$ \\
\hline Rat (Sprague-Dawley) & Early postnatal & Adult & o & MS $2 \times 3 \mathrm{~h} /$ day & Prelimbic cortex & IHC & PV cell density & no change & $\begin{array}{l}\text { [126] Ohta et al. } \\
(2020)\end{array}$ \\
\hline Mouse (C57/BL6) & Adolescent & $\begin{array}{l}\text { Adolescent; } \\
\text { adult }\end{array}$ & 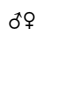 & $\begin{array}{l}\text { UCMS } 2 \text { weeks; } 6 \text { or } 40 \\
\text { days rest before sacrifice }\end{array}$ & Prelimbic cortex & IHC & Total PV cell number & decreased in males & $\begin{array}{l}\text { [130] Page and } \\
\text { Coutellier } \\
\text { (2018a) }\end{array}$ \\
\hline Mouse (C57/BL6) & Adult & Adult & 809 & UCMS 4 weeks & Prelimbic cortex & $\mathrm{IHC}$ & Total PV cell number & increased & $\begin{array}{l}\text { [155] Shepard } \\
\text { et al. (2016) }\end{array}$ \\
\hline Rat (Sprague-Dawley) & Early postnatal & Juvenile & 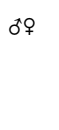 & MS 4h/day 19 days & Prelimbic Cortex & $\mathrm{IHC}$ & $\begin{array}{l}\text { 8-oxo-dG + fraction of PV } \\
\text { cells; PV + cell 8-oxo-dG } \\
\text { intensity; PV cell number; } \\
\text { PV intensity }\end{array}$ & $\begin{array}{l}\text { increased 8-oxo-dG + fraction; PV } \\
\text { intensity higher in females than } \\
\text { males }\end{array}$ & $\begin{array}{l}\text { [157] Soares } \\
\text { et al. (2020) }\end{array}$ \\
\hline Mouse (C57/BL6) & $\begin{array}{l}\text { Juvenile- } \\
\text { adolescent }\end{array}$ & Adolescent & $0^{\circ}$ & SI 5 weeks & $\begin{array}{l}\text { Prelimbic cortex } \\
\text { layers } 2 / 3 \text { and L5/ } \\
6\end{array}$ & IHC and WFA stain & $\begin{array}{l}\text { PV cell density; PNN + } \\
\text { fraction of PV cells; PV } \\
\text { fluorescence intensity; PV } \\
\text { soma area }\end{array}$ & decreased PV soma area & $\begin{array}{l}\text { [170] Ueno et al. } \\
(2017)\end{array}$ \\
\hline Mouse (C57/BL6) & Juvenile; adult & & 0 & CUS 7 days & Prelimbic cortex & IHC and WFA stain & & & inued on next page) \\
\hline
\end{tabular}




\begin{tabular}{|c|c|c|c|c|c|c|c|c|c|}
\hline Species & $\begin{array}{l}\text { Age during } \\
\text { manipulation }\end{array}$ & $\begin{array}{l}\text { Age at } \\
\text { measurement }\end{array}$ & Sex & Experimental Paradigm & Brain Region & Method & Measure & Outcome & Reference \\
\hline & & $\begin{array}{l}\text { Adolescent; } \\
\text { adult }\end{array}$ & & & & & $\begin{array}{l}\text { PV cell density; PNN }+ \\
\text { fraction of PV cells; PV + } \\
\text { fraction of PNNs; PV } \\
\text { fluorescence; PV soma area }\end{array}$ & & $\begin{array}{l}\text { [171] Ueno et al. } \\
\text { (2018) }\end{array}$ \\
\hline Mouse (C57/BL6) & $\begin{array}{l}\text { Adolescent- } \\
\text { adult }\end{array}$ & Adult & o & $\begin{array}{l}\text { CSIS } 7 \text { weeks. After } \\
\text { stress, mice housed } \\
\text { individually for } 1 \text { year }\end{array}$ & Prelimbic cortex & $\mathrm{IHC}$ & PV cell density & decreased & $\begin{array}{l}\text { [179] Wang et al. } \\
\text { (2019) }\end{array}$ \\
\hline Rat (Sprague-Dawley) & Early postnatal & Juvenile & o & MS 4h/day & Prelimbic cortex & IHC; Western blot & $\begin{array}{l}\text { PV cell density; PV protein } \\
\text { content }\end{array}$ & no change & $\begin{array}{l}\text { [19] Brenhouse } \\
\text { and Andersen } \\
\text { (2011) }\end{array}$ \\
\hline Rat (Sprague-Dawley) & Early postnatal & Adolescent & o & MS 4h/day & Prelimbic cortex & IHC; Western blot & $\begin{array}{l}\text { PV cell density; PV protein } \\
\text { content }\end{array}$ & decreased protein and density & $\begin{array}{l}\text { [19] Brenhouse } \\
\text { and Andersen } \\
\text { (2011) }\end{array}$ \\
\hline Rat (Sprague-Dawley) & Early postnatal & Adolescent & 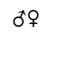 & MS 4h/day & Prelimbic cortex & Western blot & PV protein content & decreased in males & $\begin{array}{l}\text { [35] do Prado } \\
\text { et al. (2015) }\end{array}$ \\
\hline Rat (Sprague-Dawley) & Early postnatal & $\begin{array}{l}\text { Adolescent; } \\
\text { adult }\end{array}$ & toㅇ & MS 4h/day & Prelimbic cortex & Western blot & $\mathrm{PV}$ protein content & $\begin{array}{l}\text { decreased at P40, no change at } \\
\text { P100 }\end{array}$ & $\begin{array}{l}\text { [93] Leussis et al. } \\
\text { (2012) }\end{array}$ \\
\hline Rat (Sprague-Dawley) & Adult & Adult & ơ & RS 3h/day for 10 days & Prelimbic cortex & qPCR & PV mRNA expression & no change & $\begin{array}{l}\text { [112] Moench } \\
\text { et al. (2020) }\end{array}$ \\
\hline Rat (Sprague-Dawley) & Adult & Adult & to & $\begin{array}{l}\text { Acute elevated platform } \\
\text { stress }\end{array}$ & Prelimbic cortex & qPCR & PV mRNA expression & no change & $\begin{array}{l}\text { [112] Moench } \\
\text { et al. (2020) }\end{array}$ \\
\hline Rat (Sprague-Dawley) & Adult & Adult & toㅇ & $\begin{array}{l}\text { RS } 3 \mathrm{~h} / \text { day for } 10 \text { days; } \\
\text { elevated platform stress } \\
\text { on day } 11\end{array}$ & Prelimbic cortex & qPCR & PV mRNA expression & no change & $\begin{array}{l}\text { [112] Moench } \\
\text { et al. (2020) }\end{array}$ \\
\hline Rat (Sprague-Dawley) & Adult & Adult & ơ & $\begin{array}{l}\text { RS } 3 \mathrm{~h} / \text { day for } 10 \text { days; } 7 \\
\text { days rest }\end{array}$ & Prelimbic cortex & qPCR & PV mRNA expression & increased & $\begin{array}{l}\text { [112] Moench } \\
\text { et al. (2020) }\end{array}$ \\
\hline Rat (Sprague-Dawley) & Adult & Adult & to & $\begin{array}{l}\text { RS } 3 \mathrm{~h} / \text { day for } 10 \text { days; } \\
\text { elevated platform stress } \\
\text { on day } 17\end{array}$ & Prelimbic cortex & qPCR & PV mRNA expression & increased in males & $\begin{array}{l}\text { [112] Moench } \\
\text { et al. (2020) }\end{array}$ \\
\hline $\begin{array}{l}\text { PV-Cre Mouse (C57/ } \\
\text { BL6) }\end{array}$ & Adolescent & Adolescent & o & $\begin{array}{l}\text { LH } 1 \mathrm{~h} \text { for } 2 \text { days; mice } \\
\text { classified as helpless or } \\
\text { resilient }\end{array}$ & Prelimbic cortex & Electrophysiology & $\begin{array}{l}\text { mEPSC and mIPSC } \\
\text { amplitude and frequency } \\
\text { onto PV cells }\end{array}$ & $\begin{array}{l}\text { decreased mEPSC amplitude in } \\
\text { helpless, no change in others }\end{array}$ & $\begin{array}{l}\text { [137] Perova } \\
\text { et al. (2015) }\end{array}$ \\
\hline Mouse (C57/BL6) & Adolescent & Adolescent & o & RS 6h/day 3 weeks & Infralimbic cortex & IHC & $\begin{array}{l}\text { Total PV cell number; PV } \\
\text { cellular intensity }\end{array}$ & no change & $\begin{array}{l}\text { [27] Clarke et al. } \\
\text { (2019) }\end{array}$ \\
\hline Rat (Wistar) & $\begin{array}{l}\text { Adolescent- } \\
\text { adult }\end{array}$ & Adult & o & CMS 9 weeks & Infralimbic cortex & $\mathrm{IHC}$ & Total PV cell number & $\begin{array}{l}\text { decreased in anhedonic but not } \\
\text { resilient rats }\end{array}$ & $\begin{array}{l}\text { [33] Czeh et al. } \\
\text { (2018) }\end{array}$ \\
\hline Rat (Sprague-Dawley) & Early postnatal & Adolescent & o & MS 4h/day & Infralimbic cortex & $\mathrm{IHC}$ & PV cell density & decreased & $\begin{array}{l}\text { [49] Ganguly } \\
\text { et al. (2015) }\end{array}$ \\
\hline Rat (Sprague-Dawley) & Early postnatal & $\begin{array}{l}\text { Juvenile; } \\
\text { adolescent; } \\
\text { adult }\end{array}$ & రోْ & $\begin{array}{l}\text { MS } 4 \mathrm{~h} / \text { day; } 0,20 \text {, or } 50 \\
\text { days rest }\end{array}$ & Infralimbic cortex & IHC and WFA stain & $\begin{array}{l}\text { PV +/PNN + cell density; PV } \\
\text { cell density; PV + PNN } \\
\text { intensity; PNN + PV } \\
\text { intensity; PV intensity }\end{array}$ & no change & $\begin{array}{l}\text { [52] Gildawie } \\
\text { et al. (2019) }\end{array}$ \\
\hline Rat (Sprague-Dawley) & $\begin{array}{l}\text { Early } \\
\text { postnatal- } \\
\text { adolescent }\end{array}$ & Adult & toㅇ & $\begin{array}{l}\text { MS 4h/day; SI or pair } \\
\text { housing from P21-P35 }\end{array}$ & Infralimbic cortex & IHC and WFA stain & $\begin{array}{l}\text { PV cell number; PV } \\
\text { intensity; PNN number; PNN } \\
\text { intensity; PV +/PNN + cell } \\
\text { number; PNN + fraction of } \\
\text { PV cells; PNN + PV } \\
\text { intensity; PV + PNN } \\
\text { intensity }\end{array}$ & $\begin{array}{l}\text { PNN intensity and PV }+ \text { PNN } \\
\text { intensity reduced in females by MS } \\
+ \text { SI compared to MS or SI alone }\end{array}$ & $\begin{array}{l}\text { [53] Gildawie } \\
\text { et al. (2021) }\end{array}$ \\
\hline Rat (Sprague-Dawley) & Early postnatal & Adolescent & ợ & MS 4h/day & Infralimbic cortex & $\mathrm{IHC}$ & Total PV cell number & decreased in males & $\begin{array}{l}\text { [60] } \\
\text { Grassi-Oliveira } \\
\text { et al. (2016) }\end{array}$ \\
\hline Degu & Early postnatal & Juvenile & o & MS $3 \times 1$ h/day & Infralimbic cortex & IHC & PV cell density & no change & $\begin{array}{l}\text { [66] Helmeke } \\
\text { et al. (2008) }\end{array}$ \\
\hline Degu & Early postnatal & Adolescent & 0 & MS $3 \times 1 \mathrm{~h} /$ day & Infralimbic cortex & IHC & PV cell density & no change & \\
\hline
\end{tabular}




\begin{tabular}{|c|c|c|c|c|c|c|c|c|c|}
\hline Species & $\begin{array}{l}\text { Age during } \\
\text { manipulation }\end{array}$ & $\begin{array}{l}\text { Age at } \\
\text { measurement }\end{array}$ & Sex & Experimental Paradigm & Brain Region & Method & Measure & Outcome & Reference \\
\hline & & & & & & & & & $\begin{array}{l}\text { [66] Helmeke } \\
\text { et al. (2008) }\end{array}$ \\
\hline $\begin{array}{l}\text { Npas4 HET and wild- } \\
\text { type mice }\end{array}$ & - & Adult & o & $\begin{array}{l}\text { Maternal RS (GD7-19) } \\
30 \text { min twice per day }\end{array}$ & Infralimbic cortex & $\mathrm{IHC}$ & $\begin{array}{l}\text { Total PV cell number; total } \\
\text { PV+/c-Fos + cell number; } \\
\text { average NR1 puncta per PV } \\
\text { cell }\end{array}$ & $\begin{array}{l}\text { decreased PV cell number and PV+/ } \\
\text { c-Fos + cell number in } \\
\text { heterozygotes vs wild type; no } \\
\text { change due to stress }\end{array}$ & $\begin{array}{l}\text { [67] Heslin and } \\
\text { Coutellier (2018) }\end{array}$ \\
\hline Mouse (C57/BL6) & Early postnatal & $\begin{array}{l}\text { Early postnatal; } \\
\text { juvenile; } \\
\text { adolescent; } \\
\text { adult }\end{array}$ & రోo & LB/LN 7 days & Infralimbic cortex & $\mathrm{IHC}$ & PV cell density & no change & $\begin{array}{l}\text { [118] Nieves } \\
\text { et al. (2020) }\end{array}$ \\
\hline Rat (Sprague-Dawley) & $\begin{array}{l}\text { Adolescent- } \\
\text { adult }\end{array}$ & Adult & 0 & CVS 14 days & Infralimbic cortex & $\mathrm{IHC}$ & $\begin{array}{l}\mathrm{PV}+/ \text { Glucocorticoid } \\
\text { receptor + number }\end{array}$ & decreased & $\begin{array}{l}\text { [105] McKlveen } \\
\text { et al. (2016) }\end{array}$ \\
\hline Rat (Sprague-Dawley) & Early postnatal & Adult & 0 & MS $2 \times 3 \mathrm{~h} /$ day & Infralimbic cortex & $\mathrm{IHC}$ & PV cell density & decreased & $\begin{array}{l}\text { [126] Ohta et al. } \\
(2020)\end{array}$ \\
\hline Mouse (C57/BL6) & Adolescent & $\begin{array}{l}\text { Adolescent; } \\
\text { adult }\end{array}$ & $\delta \%$ & $\begin{array}{l}\text { UCMS } 2 \text { weeks; } 6 \text { or } 40 \\
\text { days rest before sacrifice }\end{array}$ & Infralimbic cortex & $\mathrm{IHC}$ & Total PV cell number & no change & $\begin{array}{l}\text { [130] Page and } \\
\text { Coutellier } \\
\text { (2018a) }\end{array}$ \\
\hline Mouse (C57/BL6) & Adult & Adult & రోo & UCMS 4 weeks & Infralimbic cortex & $\mathrm{IHC}$ & Total PV cell number & increased in females & $\begin{array}{l}\text { [155] Shepard } \\
\text { et al. (2016) }\end{array}$ \\
\hline Rat (Sprague-Dawley) & Early postnatal & Juvenile & రోo & MS 4h/day 19 days & Infralimbic Cortex & $\mathrm{IHC}$ & $\begin{array}{l}\text { 8-oxo-dG + fraction of PV } \\
\text { cells; PV + cell 8-oxo-dG } \\
\text { intensity; PV cell number; } \\
\text { PV intensity }\end{array}$ & no change & $\begin{array}{l}\text { [159] Soares } \\
\text { et al. (2020) }\end{array}$ \\
\hline Mouse (C57/BL6) & $\begin{array}{l}\text { Juvenile- } \\
\text { adolescent }\end{array}$ & Adolescent & 0 & SI 5 weeks & $\begin{array}{l}\text { Infralimbic cortex } \\
\text { layers } 2 / 3 \text { and L5/ } \\
6\end{array}$ & IHC and WFA stain & $\begin{array}{l}\text { PV cell density; PNN + } \\
\text { fraction of PV cells; PV } \\
\text { fluorescence intensity; PV } \\
\text { soma area }\end{array}$ & no change & $\begin{array}{l}\text { [170] Ueno et al. } \\
\text { (2017) }\end{array}$ \\
\hline Mouse (C57/BL6) & Juvenile; adult & $\begin{array}{l}\text { Adolescent; } \\
\text { adult }\end{array}$ & o & $\begin{array}{l}\text { CUS } 7 \text { days starting at } \\
\text { P21 or P71 }\end{array}$ & Infralimbic cortex & IHC and WFA stain & $\begin{array}{l}\text { PV cell density; PNN + } \\
\text { fraction of PV cells; PV + } \\
\text { fraction of PNNs; PV } \\
\text { fluorescence; PV soma area }\end{array}$ & no change & $\begin{array}{l}\text { [171] Ueno et al. } \\
\text { (2018) }\end{array}$ \\
\hline Mouse (C57/BL6) & $\begin{array}{l}\text { Adolescent- } \\
\text { adult }\end{array}$ & Adult & 0 & $\begin{array}{l}\text { CSIS } 7 \text { weeks. After } \\
\text { stress, mice housed } \\
\text { individually for } 1 \text { year }\end{array}$ & Infralimbic cortex & $\mathrm{IHC}$ & PV cell density & decreased & $\begin{array}{l}\text { [179] Wang et al. } \\
\text { (2019) }\end{array}$ \\
\hline Rat (Sprague-Dawley) & Early postnatal & Adolescent & ơ & MS 4h/day & Infralimbic cortex & Western blot & $\mathrm{PV}$ protein content & decreased in males & $\begin{array}{l}\text { [35] do Prado } \\
\text { et al. (2015) }\end{array}$ \\
\hline Rat (Wistar) & $\begin{array}{l}\text { Adolescent- } \\
\text { adult }\end{array}$ & Adult & 0 & CMS 9 weeks & $\begin{array}{l}\text { Anterior Cingulate } \\
\text { cortex }\end{array}$ & IHC & Total PV cell number & no change & $\begin{array}{l}\text { [33] Czeh et al. } \\
\text { (2018) }\end{array}$ \\
\hline Degu & Early postnatal & Juvenile & 0 & MS $3 \times 1 \mathrm{~h} /$ day & $\begin{array}{l}\text { Anterior Cingulate } \\
\text { cortex }\end{array}$ & $\mathrm{IHC}$ & PV cell density & no change & $\begin{array}{l}\text { [66] Helmeke } \\
\text { et al. (2008) }\end{array}$ \\
\hline Degu & Early postnatal & Adolescent & o & MS $3 \times 1 \mathrm{~h} /$ day & $\begin{array}{l}\text { Anterior Cingulate } \\
\text { cortex }\end{array}$ & IHC & PV cell density & increased & $\begin{array}{l}\text { [66] Helmeke } \\
\text { et al. (2008) }\end{array}$ \\
\hline Mouse (C57/BL6) & $\begin{array}{l}\text { Juvenile- } \\
\text { adolescent }\end{array}$ & Adolescent & o & SI 5 weeks & $\begin{array}{l}\text { Dorsal Anterior } \\
\text { Cingulate cortex } \\
\text { layers } 2 / 3 \text { and L5/ } \\
6\end{array}$ & IHC and WFA stain & $\begin{array}{l}\text { PV cell density; PNN + } \\
\text { fraction of PV cells; PV } \\
\text { fluorescence intensity; PV } \\
\text { soma area }\end{array}$ & $\begin{array}{l}\text { decreased layer } 2 / 3 \text { PNN }+ \text { fraction } \\
\text { of PV cells and PV fluorescence } \\
\text { intensity }\end{array}$ & $\begin{array}{l}\text { [170] Ueno et al. } \\
\text { (2017) }\end{array}$ \\
\hline Mouse (C57/BL6) & Juvenile; adult & $\begin{array}{l}\text { Adolescent, } \\
\text { adult }\end{array}$ & 0 & $\begin{array}{l}\text { CUS } 7 \text { days starting at } \\
\text { P21 or P71 }\end{array}$ & $\begin{array}{l}\text { Dorsal Anterior } \\
\text { Cingulate cortex }\end{array}$ & IHC and WFA stain & $\begin{array}{l}\text { PV cell density; PNN }+ \\
\text { fraction of PV cells; PV }+ \\
\text { fraction of PNNs; PV } \\
\text { fluorescence; PV soma area }\end{array}$ & no change & $\begin{array}{l}\text { [171] Ueno et al. } \\
\text { (2018) }\end{array}$ \\
\hline Mouse (C57/BL6) & $\begin{array}{l}\text { Adolescent- } \\
\text { adult }\end{array}$ & Adult & 0 & $\begin{array}{l}\text { CSIS } 7 \text { weeks. After } \\
\text { stress, mice housed } \\
\text { individually for } 1 \text { year }\end{array}$ & $\begin{array}{l}\text { Anterior Cingulate } \\
\text { cortex }\end{array}$ & IHC & PV cell density & decreased & $\begin{array}{l}\text { [179] Wang et al. } \\
\text { (2019) }\end{array}$ \\
\hline \multirow[t]{2}{*}{ Degu } & Early postnatal & Juvenile & o & MS $3 \times 1 \mathrm{~h} /$ day & $\begin{array}{l}\text { Precentral Medial } \\
\text { cortex }\end{array}$ & $\mathrm{IHC}$ & PV cell density & no change & $\begin{array}{l}\text { [66] Helmeke } \\
\text { et al. (2008) }\end{array}$ \\
\hline & & & & & & & & & (continued on next page) \\
\hline
\end{tabular}




\begin{tabular}{|c|c|c|c|c|c|c|c|c|c|}
\hline Species & $\begin{array}{l}\text { Age during } \\
\text { manipulation }\end{array}$ & $\begin{array}{l}\text { Age at } \\
\text { measurement }\end{array}$ & Sex & Experimental Paradigm & Brain Region & Method & Measure & Outcome & Reference \\
\hline Degu & Early postnatal & Adolescent & $0^{\dagger}$ & MS $3 \times 1$ h/day & $\begin{array}{l}\text { Precentral Medial } \\
\text { cortex }\end{array}$ & IHC & PV cell density & increased & $\begin{array}{l}\text { [66] Helmeke } \\
\text { et al. (2008) }\end{array}$ \\
\hline Mouse (C57/B16) & $\begin{array}{l}\text { Juvenile- } \\
\text { adolescent }\end{array}$ & Adult & $0^{*}$ & $\begin{array}{l}\text { SI P21-35, group } \\
\text { housing until } \\
\text { measurement at P60-65 }\end{array}$ & $\begin{array}{l}\text { Dorsomedial PFC } \\
\text { (including } \\
\text { prelimbic and } \\
\text { anterior cingulate } \\
\text { regions) }\end{array}$ & Electrophysiology & $\begin{array}{l}200 \text { pA-elicited spike } \\
\text { frequency; sIPSC frequency }\end{array}$ & reduced (both) & $\begin{array}{l}\text { [12] Bicks et al., } \\
\text { [2020] }\end{array}$ \\
\hline Mouse (C57/BL6) & Adult & Adult & $\delta 9$ & UCMS 4 weeks & $\begin{array}{l}\text { Medial Prefrontal } \\
\text { cortex }\end{array}$ & $\mathrm{IHC}$ & $\begin{array}{l}\text { Total PV+/c-Fos + cell } \\
\text { number }\end{array}$ & increased & $\begin{array}{l}\text { [133] Page et al. } \\
\text { (2019b) }\end{array}$ \\
\hline $\begin{array}{l}\text { Npas4 HET and wild- } \\
\text { type mice }\end{array}$ & Adolescent & Adult & $0^{*}$ & $\begin{array}{l}\text { CMS } 2 \text { weeks; } 4 \text { weeks } \\
\text { rest }\end{array}$ & $\begin{array}{l}\text { Medial Prefrontal } \\
\text { cortex }\end{array}$ & IHC and WFA stain & $\begin{array}{l}\text { Total PV cell number; PNN } \\
+ \text { fraction of PV cells }\end{array}$ & $\begin{array}{l}\text { increased PNN + fraction in wild- } \\
\text { type mice }\end{array}$ & $\begin{array}{l}\text { [131] Page et al., } \\
\text { 2018b }\end{array}$ \\
\hline Rat (Sprague-Dawley) & Adult & Adult & $0^{+}$ & RS $6 \mathrm{~h} /$ day for 10 days & $\begin{array}{l}\text { Medial Prefrontal } \\
\text { cortex }\end{array}$ & IHC and WFA stain & $\begin{array}{l}\text { Total PV cell number; Total } \\
\text { PNN }+/ \mathrm{PV}+\text { cell number }\end{array}$ & increased total PV cell number & $\begin{array}{l}\text { [138] Pesarico } \\
\text { et al., } 2019\end{array}$ \\
\hline $\begin{array}{l}\text { GAD67(+/GFP) (HET) } \\
\text { mice }\end{array}$ & - & Juvenile & $0^{0}$ & $\begin{array}{l}\text { Maternal RS: } 45 \min 3 x \text { / } \\
\text { day from GD15 to } \\
\text { GD17.5; BrdU injection } \\
\text { IP once at GD12 or } \\
\text { GD15 }\end{array}$ & $\begin{array}{l}\text { Medial Prefrontal } \\
\text { Cortex }\end{array}$ & $\mathrm{IHC}$ & $\mathrm{PV}+/ \mathrm{GFP}+$ cell density & decreased & $\begin{array}{l}\text { [169] Uchida } \\
\text { et al. (2014) }\end{array}$ \\
\hline $\begin{array}{l}\text { GAD67(+/GFP) (HET) } \\
\text { mice (C57/BL6) }\end{array}$ & - & Juvenile & $0^{*}$ & $\begin{array}{l}\text { Maternal RS: } 3 \times 45 \mathrm{mins} / \\
\text { day under halogen light } \\
\text { during day from GD15- } \\
\text { GD17.5; newborns given } \\
\text { to surrogate mothers on } \\
\text { P0 }\end{array}$ & $\begin{array}{l}\text { Medial Prefrontal } \\
\text { cortex }\end{array}$ & IHC and WFA stain & $\begin{array}{l}\text { Densities of PV cells, PNN + } \\
\text { PV cells, PNN- PV cells, } \\
\text { Aggrecan+/PV + cells, } \\
\text { Aggrecan- PV cells; WFA } \\
\text { intensity of PV cells; } \\
\text { Aggrecan intensity of PV } \\
\text { cells }\end{array}$ & $\begin{array}{l}\text { Decreased densities; no change in } \\
\text { intensities }\end{array}$ & $\begin{array}{l}\text { [180] Wang et al. } \\
\text { (2018) }\end{array}$ \\
\hline Mouse (C57/BL6) & - & Juvenile & o & $\begin{array}{l}\text { Maternal RS: } 3 \times 45 \mathrm{mins} / \\
\text { day under halogen light } \\
\text { during day from GD15- } \\
\text { GD17.5; newborns given } \\
\text { to surrogate mothers on } \\
\text { P0 }\end{array}$ & $\begin{array}{l}\text { Medial Prefrontal } \\
\text { cortex }\end{array}$ & IHC and WFA stain & $\begin{array}{l}\text { Densities of PV cells, PNN + } \\
\text { PV cells, PNN- PV cells, } \\
\text { Aggrecan+/PV + cells, } \\
\text { Aggrecan- PV cells; WFA } \\
\text { intensity of PV cells; } \\
\text { Aggrecan intensity of PV } \\
\text { cells }\end{array}$ & no change & $\begin{array}{l}\text { [180] Wang et al. } \\
\text { (2018) }\end{array}$ \\
\hline Mouse (C57/BL6) & Early postnatal & Adult & $\delta 9$ & $\mathrm{LB} / \mathrm{LN}$ & $\begin{array}{l}\text { Medial Prefrontal } \\
\text { cortex }\end{array}$ & qPCR & PV mRNA expression & no change & $\begin{array}{l}\text { [59] Goodwill } \\
\text { et al. (2018) }\end{array}$ \\
\hline $\begin{array}{l}\text { GAD67(+/GFP) (HET) } \\
\text { mice (CD1) }\end{array}$ & - & Juvenile, adult & $0^{\circ}$ & $\begin{array}{l}\text { Maternal RS: beginning } \\
\text { on GD12, } 45 \mathrm{~min} 3 \mathrm{x} / \mathrm{day} \\
\text { during daylight under } \\
\text { bright lights }\end{array}$ & $\begin{array}{l}\text { Medial Prefrontal } \\
\text { Cortex }\end{array}$ & $\mathrm{IHC}$ & $\begin{array}{l}\text { PV + fraction of GAD67: } \\
\text { GFP + cells }\end{array}$ & decreased at P24, increased at P150 & $\begin{array}{l}\text { [100] Lussier and } \\
\text { Stevens (2016) }\end{array}$ \\
\hline $\begin{array}{l}\text { GAD67(+/GFP) (HET) } \\
\text { mice (CD1) }\end{array}$ & - & Juvenile, adult & $0^{\circ}$ & $\begin{array}{l}\text { Maternal RS: beginning } \\
\text { on GD12, } 45 \mathrm{~min} 3 \mathrm{x} / \mathrm{day} \\
\text { during daylight under } \\
\text { bright lights }\end{array}$ & $\begin{array}{l}\text { Medial Prefrontal } \\
\text { Cortex }\end{array}$ & QPCR & PV:GAD1 mRNA ratio & $\begin{array}{l}\text { no change at P24, decreased at } \\
\text { P150 }\end{array}$ & $\begin{array}{l}\text { [100] Lussier and } \\
\text { Stevens (2016) }\end{array}$ \\
\hline Rat (Wistar) & Adult & Adult & $0^{0}$ & $\begin{array}{l}\text { CUS } 16 \text { days or CMS } 8 \\
\text { weeks }\end{array}$ & $\begin{array}{l}\text { Medial Prefrontal } \\
\text { cortex }\end{array}$ & IHC & $\begin{array}{l}\text { PV numerical density, } \\
\text { relative PV optical density }\end{array}$ & no change & $\begin{array}{l}\text { [187] Zadrozna } \\
\text { et al. (2011) }\end{array}$ \\
\hline Mouse (C57/BL6) & Adolescent & $\begin{array}{l}\text { Adolescent, } \\
\text { adult }\end{array}$ & $\delta \circ$ & $\begin{array}{l}\text { UCMS } 2 \text { weeks; } 6 \text { or } 40 \\
\text { days rest before sacrifice }\end{array}$ & $\begin{array}{l}\text { Medial Prefrontal } \\
\text { cortex }\end{array}$ & IHC and WFA stain & PNN + fraction of PV cells & no change & $\begin{array}{l}\text { [131] Page et al., } \\
\text { 2018b }\end{array}$ \\
\hline Mouse (C57/BL6) & Juvenile & Adult & 0 & 2 weeks SI & $\begin{array}{l}\text { Medial Prefrontal } \\
\text { Cortex }\end{array}$ & Electrophysiology & $\begin{array}{l}\text { sIPSC frequency and } \\
\text { amplitude on PH and non- } \\
\text { PH layer } 5 \text { pyramidal } \\
\text { neurons }\end{array}$ & $\begin{array}{l}\text { increased frequency in } \mathrm{PH} \\
\text { pyramidal neurons }\end{array}$ & $\begin{array}{l}\text { [185] Yamamuro } \\
\text { et al. (2020) }\end{array}$ \\
\hline Mouse (C57/BL6) & Adolescent & Adult & $0^{+}$ & 2 weeks SI & $\begin{array}{l}\text { Medial Prefrontal } \\
\text { Cortex }\end{array}$ & Electrophysiology & $\begin{array}{l}\text { sIPSC frequency and } \\
\text { amplitude on PH and non- } \\
\text { PH layer } 5 \text { pyramidal } \\
\text { neurons }\end{array}$ & no change & $\begin{array}{l}\text { [185] Yamamuro } \\
\text { et al. (2020) }\end{array}$ \\
\hline Rat (Wistar) & & & $0^{+}$ & SI 2,4 , or 7 weeks & Prefrontal cortex & IHC & PV cell density & (continued on next page) & \\
\hline
\end{tabular}




\begin{tabular}{|c|c|c|c|c|c|c|c|c|c|}
\hline Species & $\begin{array}{l}\text { Age during } \\
\text { manipulation }\end{array}$ & $\begin{array}{l}\text { Age at } \\
\text { measurement }\end{array}$ & Sex & Experimental Paradigm & Brain Region & Method & Measure & Outcome & Reference \\
\hline & $\begin{array}{l}\text { Juvenile- } \\
\text { adolescent; } \\
\text { juvenile-adult }\end{array}$ & $\begin{array}{l}\text { Adolescent, } \\
\text { adult }\end{array}$ & & & & & & $\begin{array}{l}\text { decreased at } 4 \text { and } 7 \text { weeks' SI but } \\
\text { not } 2\end{array}$ & $\begin{array}{l}\text { [152] Schiavone } \\
\text { et al. (2012) }\end{array}$ \\
\hline $\begin{array}{l}\text { Npas } 4 \mathrm{HET} \text { and wild- } \\
\text { type mice }\end{array}$ & Adolescent & Adult & o & $\begin{array}{l}\text { CMS } 2 \text { weeks; } 4 \text { weeks } \\
\text { rest }\end{array}$ & $\begin{array}{l}\text { Ventral Prefrontal } \\
\text { cortex (infralimbic } \\
\text { and dorsal } \\
\text { peduncular } \\
\text { cortices) }\end{array}$ & IHC and WFA stain & $\begin{array}{l}\text { Total PV cell number; PNN } \\
+ \text { fraction of PV cells }\end{array}$ & $\begin{array}{l}\text { increased PNN + fraction in wild- } \\
\text { type mice }\end{array}$ & $\begin{array}{l}\text { [131] Page et al., } \\
\text { 2018b }\end{array}$ \\
\hline $\begin{array}{l}\text { Npas } 4 \text { HET and wild- } \\
\text { type mice }\end{array}$ & Adolescent & Adult & o & $\begin{array}{l}\text { CMS } 2 \text { weeks; } 4 \text { weeks } \\
\text { rest }\end{array}$ & $\begin{array}{l}\text { Dorsal Prefrontal } \\
\text { cortex (anterior } \\
\text { cingulate and } \\
\text { prelimbic cortices) }\end{array}$ & IHC and WFA stain & $\begin{array}{l}\text { Total PV cell number; PNN } \\
+ \text { fraction of PV cells }\end{array}$ & no change & $\begin{array}{l}\text { [131] Page et al., } \\
\text { 2018b }\end{array}$ \\
\hline Mouse (BALB/c) & Adult & Adult & đoㅇ & UCMS 2 weeks & Prefrontal cortex & qPCR; IHC & $\begin{array}{l}\text { PV mRNA expression; Total } \\
\text { PV cell number; PV+/pERK } \\
+ \text { cell number; VGlut1 } \\
\text { puncta number per PV cell }\end{array}$ & $\begin{array}{l}\text { Increased PV mRNA, PV cell } \\
\text { number, and PV }+/ \mathrm{pERK}+\text { cell } \\
\text { number in females but not males. } \\
\text { Increased VGlut1 puncta/PV cell in } \\
\text { males and females }\end{array}$ & $\begin{array}{l}\text { [156] Shepard } \\
\text { and Coutellier } \\
\text { (2017) }\end{array}$ \\
\hline Mouse (BALB/c) & Adult & Adult & ơ & UCMS 4 weeks & Prefrontal cortex & qPCR; IHC & $\begin{array}{l}\text { PV mRNA expression; Total } \\
\text { PV cell number; VGlut1 } \\
\text { puncta number per PV cell }\end{array}$ & $\begin{array}{l}\text { Increased VGlut1 puncta/PV cell in } \\
\text { females }\end{array}$ & $\begin{array}{l}\text { [156] Shepard } \\
\text { and Coutellier } \\
\text { (2017) }\end{array}$ \\
\hline Mouse (C57/BL6) & Early postnatal & $\begin{array}{l}\text { Early postnatal, } \\
\text { juvenile }\end{array}$ & 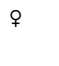 & $\mathrm{LB} / \mathrm{LN}$ & Prefrontal cortex & qPCR & PV mRNA expression & decreased at P21 & $\begin{array}{l}\text { [59] Goodwill } \\
\text { et al. (2018) }\end{array}$ \\
\hline $\begin{array}{l}\text { Npas4 HET and wild- } \\
\text { type mice }\end{array}$ & - & Adult & 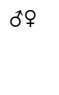 & $\begin{array}{l}\text { Maternal RS (GD7-19) } \\
30 \text { min 2x/day }\end{array}$ & Prefrontal cortex & qPCR & PV mRNA expression & $\begin{array}{l}\text { increased in heterozygotes vs wild } \\
\text { type in males but not females; no } \\
\text { change due to stress }\end{array}$ & $\begin{array}{l}\text { [67] Heslin and } \\
\text { Coutellier (2018) }\end{array}$ \\
\hline Rat (Wistar) & Adult & Adult & o & CMS 7 weeks & Prefrontal cortex & qPCR & PV mRNA expression & no change & $\begin{array}{l}\text { [145] Rossetti } \\
\text { et al. (2018) }\end{array}$ \\
\hline Mouse (C57/BL6) & Adult & Adult & ơ & UCMS 2 or 4 weeks & Prefrontal cortex & $\mathrm{qPCR}$ & PV mRNA expression & increased in females but not males & $\begin{array}{l}\text { [155] Shepard } \\
\text { et al. (2016) }\end{array}$ \\
\hline Rat (Sprague-Dawley) & Adult & Adult & $0^{*}$ & CUS 36 days & Prefrontal cortex & Western blot & $\mathrm{PV}$ protein content & no change & $\begin{array}{l}\text { [6] Banasr et al. } \\
\text { (2017) }\end{array}$ \\
\hline Rat (Sprague-Dawley) & Early postnatal & $\begin{array}{l}\text { Juvenile, } \\
\text { adolescent }\end{array}$ & ơ & MS 4h/day & Prefrontal cortex & Western blot & PV protein content & $\begin{array}{l}\text { decreased in female juveniles and } \\
\text { male adolescents }\end{array}$ & $\begin{array}{l}\text { [68] Holl et al. } \\
\text { (2014) }\end{array}$ \\
\hline Rat (Sprague-Dawley) & $\begin{array}{l}\text { Early } \\
\text { postnatal; } \\
\text { adolescent }\end{array}$ & Adolescent & \% & MS 4h/day; LH task P41 & Prefrontal cortex & Western blot & PV protein content & decreased & $\begin{array}{l}\text { [97] Lukkes et al. } \\
\text { (2017) }\end{array}$ \\
\hline Rat (Sprague-Dawley) & $\begin{array}{l}\text { Early } \\
\text { postnatal; } \\
\text { adolescent }\end{array}$ & Adolescent & q & $\begin{array}{l}\text { MS 4h/day; LH task P41; } \\
\text { allowed to witness } \\
\text { another rat in task } 1 \text { day } \\
\text { before they did it. }\end{array}$ & Prefrontal cortex & Western blot & PV protein content & no change & $\begin{array}{l}\text { [97] Lukkes et al. } \\
\text { (2017) }\end{array}$ \\
\hline Rat (Sprague-Dawley) & $\begin{array}{l}\text { Early } \\
\text { postnatal; } \\
\text { adolescent }\end{array}$ & Adolescent & \% & $\begin{array}{l}\text { MS 4h/day; LH tests } \\
\text { P40-41 then sacrifice }\end{array}$ & Prefrontal cortex & Western blot & PV protein content & $\begin{array}{l}\text { decreased in anhedonic MS vs non- } \\
\text { anhedonic MS rats }\end{array}$ & $\begin{array}{l}\text { [98] Lukkes et al. } \\
\text { (2018) }\end{array}$ \\
\hline Rat (Sprague-Dawley) & $\begin{array}{l}\text { Juvenile- } \\
\text { adolescent }\end{array}$ & Adolescent & q & SI 3 weeks & Prefrontal cortex & Western blot & $\mathrm{PV}$ protein content & no change & $\begin{array}{l}\text { [98] Lukkes et al. } \\
\text { (2018) }\end{array}$ \\
\hline $\begin{array}{l}\text { Ncf1 DA allele rats (low } \\
\text { ROS production), } \\
\text { and Ncf1 E3 rats } \\
\text { (high ROS } \\
\text { production) }\end{array}$ & Juvenile-adult & Adult & o & SI 7 weeks & Prefrontal cortex & Western blot & PV protein content & $\begin{array}{l}\text { decreased by SI in E3 but not DA } \\
\text { rats }\end{array}$ & $\begin{array}{l}\text { [152] Schiavone } \\
\text { et al. (2012) }\end{array}$ \\
\hline Mouse (C57/BL6) & Adolescent & Adolescent & 6o & $\begin{array}{l}\text { RS } 6 \mathrm{~h} / \text { day for } 2 \text { or } 7 \\
\text { days }\end{array}$ & $\begin{array}{l}\text { Frontal } \\
\text { Association cortex } \\
\text { layers } 2 / 3\end{array}$ & Microscopy & $\begin{array}{l}\mathrm{PV} \text { cell dendritic spine } \\
\text { formation and elimination } \\
\text { rate }\end{array}$ & $\begin{array}{l}\text { increased formation and } \\
\text { elimination at } 2 \text { days }\end{array}$ & $\begin{array}{l}{[120] \mathrm{Ng} \text { et al. }} \\
(2018)\end{array}$ \\
\hline $\begin{array}{l}\text { PV-Cre; Ai9-tdTomato } \\
\text { mice (C57/BL6) }\end{array}$ & Adolescent & Adolescent & ơ 9 & $\begin{array}{l}\text { CNO injection then RS } \\
6 \mathrm{~h} / \text { day for } 2 \text { or } 7 \text { days }\end{array}$ & & & & $\begin{array}{l}\text { decreased elimination at days } 2 \text { and } \\
7\end{array}$ & $\begin{array}{l}\text { [120] Ng et al. } \\
(2018)\end{array}$ \\
\hline
\end{tabular}


2021; Sampedro-Piquero et al., 2016; Serra et al., 2020; Umemori et al., 2015), with single studies finding an increase (Serra et al., 2020) and a decrease (Yang et al., 2015) in PV cells in the region. Enrichment studies in CA1 sometimes reported an increasing effect (Filipović et al., 2013; Gomes da Silva et al., 2010; Nguyen et al., 2013; Peric et al., 2018), with one study finding a reduction (Guirado et al., 2014). Physical exercise (Peric et al., 2018; Pesarico et al., 2019; Serra et al., 2020) and antidepressants (Czeh et al., 2005; Filipović et al., 2017; Peric et al., 2018) had increasing or stress-protective effects on CA2/3 PV cells.

In contrast to the PFC and HC, stress protocols tended to increase the number of PV cells in the BLA (Giachino et al., 2007; Gildawie et al., 2019; Nieves et al., 2020; Pesarico et al., 2019). Studies of the somatosensory cortex suggested a possible decrease in PV cell density in adolescents (Chen et al., 2018) and adults (Lee et al., 2015), although there are too few studies to draw conclusions with confidence (Table 3 ).

\subsection{PV expression}

Several studies quantified the expression of parvalbumin mRNA via qPCR and PV protein via Western blotting or as the intensity of IHC stains. PV expression has been shown correlate with PV cells' GABA levels and maturity (Donato et al., 2013), thus its expression provides insight into regional excitation/inhibition (E/I) balance and the local population demographics of PV cells. The general trend suggests that stress tends to decrease, rather than increase, PV protein and mRNA in the PFC of rodents in a subregion-dependent manner.

In the PrL cortex, stressors tended to decrease PV protein expression in adolescents rather than adults or juveniles (Brenhouse and Andersen, 2011; do Prado et al., 2015; Leussis et al., 2012; Moench et al., 2020), however this was matched by null findings (Clarke et al., 2019; Gildawie et al., 2019; Ueno et al., 2017, 2018).

Most studies of the IL cortex reported no change in PV protein (Clarke et al., 2019; Gildawie et al., 2019; Soares et al., 2020; Ueno et al., 2017, 2018) except one account in which MS decreased male but not female adolescent PV protein expression, an effect which was not changed by EE after weaning (do Prado et al., 2015). One study of the OFC found that LB/LN reduced PV mRNA expression in adult males and females (Goodwill et al., 2018), hinting that PV cells in the region may be worthy of further study in the context of early life stress.

In the whole PFC, several studiesd suggested that animals lose PV protein or mRNA after stress (Goodwill et al., 2018; Holl et al., 2014; Lukkes et al., 2017, 2018; Schiavone et al., 2009; Sun et al., 2016), although this finding was not consistent (Banasr et al., 2017; Goodwill et al., 2018; Heslin and Coutellier, 2018; Holm et al., 2011; Rossetti et al., 2018), and one research group has reported increased mRNA in stressed animals (Shepard et al., 2016; Shepard and Coutellier, 2017). PV protein and mRNA expression were unchanged by an enrichment protocol alone (Schiavone et al., 2009; Sun et al., 2016) and when combined with a chronic stress regimen (Lukkes et al., 2017; Schiavone et al., 2009; Sun et al., 2016), suggesting a possible stress-buffering effect. Acute single ketamine treatments exerted ambiguous effects on PV expression that were unlike other enrichment protocols (O'Connor et al., 2019; Wang et al., 2014; Zhou et al., 2014), indicating that it may have a unique interaction with stress on PV neurons, likely tied to either its neurochemistry or to its unique position as an acute enriching treatment.

There was little evidence of changes in mRNA or protein in the whole hippocampus (Banasr et al., 2017; Bath et al., 2016; Brenhouse and Andersen, 2011; Kim et al., 2020; Lussier and Stevens, 2016; Rossetti et al., 2018; Ueno et al., 2018) or in its subregions (Clarke et al., 2019; Krugers et al., 1996; Nowak et al., 2010; Soares et al., 2020) and the studies showing an effect reported mixed directionality (Bath et al., 2016; Kim et al., 2020; Lussier and Stevens, 2016; Riga et al., 2017; Rossetti et al., 2018; Ueno et al., 2017). The few studies including enrichment paradigms showed contradictory effects (Donato et al., 2013; Gomes da Silva et al., 2010; Kong et al., 2017; McHugh et al., 
Table 2

PV neuron alterations in the hippocampus of stressed animals.

\begin{tabular}{|c|c|c|c|c|c|c|c|c|c|}
\hline Species & $\begin{array}{l}\text { Age during } \\
\text { manipulation }\end{array}$ & $\begin{array}{l}\text { Age at } \\
\text { measurement }\end{array}$ & Sex & Experimental paradigm & Brain Region & Method & Measure & Outcome & Reference \\
\hline Mouse (C57/BL6) & $\begin{array}{l}\text { Early } \\
\text { postnatal }\end{array}$ & $\begin{array}{l}\text { Early } \\
\text { postnatal, } \\
\text { juvenile, } \\
\text { adolescent }\end{array}$ & o & LB/LN P4-P11 & Dentate Gyrus & $\mathrm{IHC}$ & PV cell density & Increased at P21 & $\begin{array}{l}\text { [8] Bath et al. } \\
\text { (2016) }\end{array}$ \\
\hline Rat (Lister-hooded) & Adolescent & Adolescent & $\delta ?$ & CUS 3 days & $\begin{array}{l}\text { Infrapyramidal } \\
\text { Dentate Gyrus }\end{array}$ & IHC & PV cell density & increased in males & $\begin{array}{l}\text { [20] Brydges } \\
\text { et al. (2018) }\end{array}$ \\
\hline Rat (Lister-hooded) & Adolescent & Adolescent & đơ & CUS 3 days & $\begin{array}{l}\text { Suprapyramidal } \\
\text { Dentate Gyrus }\end{array}$ & IHC & PV cell density & no change & $\begin{array}{l}\text { [20] Brydges } \\
\text { et al. (2018) }\end{array}$ \\
\hline Rat (Wistar) & Adult & Adult & o & CMS 9 weeks & $\begin{array}{l}\text { Dorsal Dentate } \\
\text { Gyrus }\end{array}$ & $\mathrm{IHC}$ & PV cell density & decreased & $\begin{array}{l}\text { [30] Csabai et al. } \\
\text { (2017) }\end{array}$ \\
\hline Rat (Wistar) & Adult & Adult & o & CMS 9 weeks & $\begin{array}{l}\text { Ventral Dentate } \\
\text { Gyrus }\end{array}$ & $\mathrm{IHC}$ & Total PV cell number & no change & $\begin{array}{l}\text { [32] Czeh et al. } \\
\text { (2015) }\end{array}$ \\
\hline Rat (Wistar) & Adult & Adult & o & CMS 9 weeks & $\begin{array}{l}\text { Dorsal Dentate } \\
\text { Gyrus }\end{array}$ & $\mathrm{IHC}$ & Total PV cell number & no change & $\begin{array}{l}\text { [32] Czeh et al. } \\
\text { (2015) }\end{array}$ \\
\hline PV-Cre Mouse & $\begin{array}{l}\text { Adolescent- } \\
\text { adult }\end{array}$ & Adult & not stated & $\begin{array}{l}\text { SI } 8 \text { weeks; } 16 \text { days rest and } \\
\text { behavioral tests }\end{array}$ & $\begin{array}{l}\text { Ventral Dentate } \\
\text { Gyrus }\end{array}$ & $\mathrm{IHC}$ & PV cell density & no change & $\begin{array}{l}\text { [34] Deng et al. } \\
\text { (2020) }\end{array}$ \\
\hline Rat (Sprague-Dawley) & $\begin{array}{l}\text { Early } \\
\text { postnatal }\end{array}$ & Early postnatal & o & $\begin{array}{l}\text { Handling and MS: } 15 \text { or } \\
180 \text { min/day from P2-P14 }\end{array}$ & Dentate Gyrus & $\mathrm{IHC}$ & Total PV cell number & no change & $\begin{array}{l}\text { [37] Dricks } \\
(2016)\end{array}$ \\
\hline Rat (Wistar) & Adult & Adult & o & SI 3 weeks & Dentate Gyrus & $\mathrm{IHC}$ & Total PV cell number & decreased & $\begin{array}{l}\text { [44] Filipović } \\
\text { et al. (2017) }\end{array}$ \\
\hline Rat (Wistar) & Adult & Adult & o & $\begin{array}{l}\text { Acute ( } 2 \mathrm{~h} \text { cold or } \mathrm{RS} \text { ) or } \\
\text { chronic ( } 21 \text { days } \mathrm{SI} \text { ) stress, or } \\
\text { chronic stress with acute } \\
\text { stress at the end of isolation }\end{array}$ & Dentate Gyrus & $\mathrm{IHC}$ & $\begin{array}{l}\text { PV-immunoreactive } \\
\text { number }\end{array}$ & $\begin{array}{l}\text { decreased by isolation and } \\
\text { combined isolation }+ \text { acute } \\
\text { stressors }\end{array}$ & $\begin{array}{l}\text { [43] Filipović } \\
\text { et al. (2013) }\end{array}$ \\
\hline Rat (Sprague-Dawley) & $\begin{array}{l}\text { Early } \\
\text { postnatal }\end{array}$ & Adolescent & o & $\begin{array}{l}\text { MS: 3h/day from P2-P14, or } \\
\text { early handling P2-P14 } \\
\text { (moved to different cage } \\
\text { 15min/day) }\end{array}$ & $\begin{array}{l}\text { Dentate Gyrus: } \\
\text { Molecular layer, } \\
\text { Granule cell layer, } \\
\text { and Polymorphic } \\
\text { layer }\end{array}$ & $\mathrm{IHC}$ & PV cell density & $\begin{array}{l}\text { decreased in MS vs no } \\
\text { handling in molecular layer }\end{array}$ & $\begin{array}{l}\text { [51] Giachino } \\
\text { et al. (2007) }\end{array}$ \\
\hline Mouse (C57/BL6) & Adolescent & Adult & o & $\begin{array}{l}\text { Maternal stress: GD9 poly I:C } \\
\text { injection (mimics infection); } \\
\text { offspring exposed to } 10 \text { days } \\
\text { variable unpredictable stress } \\
\text { from P30-P40 }\end{array}$ & $\begin{array}{l}\text { Ventral Dentate } \\
\text { Gyrus }\end{array}$ & $\mathrm{IHC}$ & Total PV cell number & $\begin{array}{l}\text { decreased by poly I:C and } \\
\text { stress but not either alone }\end{array}$ & $\begin{array}{l}\text { [54] Giovanoli } \\
\text { et al., } 2014\end{array}$ \\
\hline Mouse (C57/BL6) & Adolescent & Adult & o & $\begin{array}{l}\text { Maternal stress: GD9 poly I:C } \\
\text { injection (mimics infection); } \\
\text { offspring exposed to } 10 \text { days } \\
\text { variable unpredictable stress } \\
\text { from P30-P40 }\end{array}$ & $\begin{array}{l}\text { Dorsal Dentate } \\
\text { Gyrus }\end{array}$ & IHC & Total PV cell number & no change & $\begin{array}{l}\text { [54] Giovanoli } \\
\text { et al., } 2014\end{array}$ \\
\hline Rat (Wistar) & $\begin{array}{l}\text { Juvenile- } \\
\text { adult }\end{array}$ & Adult & o & SI 8 weeks & Dentate Gyrus & $\mathrm{IHC}$ & PV cell density & no change & $\begin{array}{l}\text { [61] Greene } \\
\text { et al., } 2001\end{array}$ \\
\hline Rat (Sprague-Dawley) & $\begin{array}{l}\text { Juvenile- } \\
\text { adult }\end{array}$ & Adult & \% & SI 11 weeks & Dentate Gyrus & IHC & PV cell density & decreased & $\begin{array}{l}\text { [65] Harte et al. } \\
\text { (2007) }\end{array}$ \\
\hline Rat (Sprague-Dawley) & $\begin{array}{l}\text { Adolescent- } \\
\text { adult }\end{array}$ & Adult & o & RS 6h/day 3 weeks & Dentate Gyrus & IHC & PV cell density & decreased & $\begin{array}{l}\text { [70] Hu et al. } \\
\text { (2010) }\end{array}$ \\
\hline Rat (Sprague-Dawley) & Adult & Adult & $0^{\circ}$ & $\begin{array}{l}\text { Gulf war illness model: } 4 \\
\text { weeks daily: } 5 \text { min RS, } \\
\text { pyridostigmine bromide } \\
1.3 \mathrm{mg} / \mathrm{kg} \text { oral, DEET } 200 \mathrm{ul} \\
40 \mathrm{mg} / \mathrm{kg} \text { dermal, and } \\
\text { permethrin } 200 \mathrm{ul} 0.13 \mathrm{mg} / \\
\mathrm{kg} \text { dermal. }\end{array}$ & Dentate Gyrus & IHC & Total PV cell number & decreased & $\begin{array}{l}\text { [107] Megahed } \\
\text { et al. (2014) }\end{array}$ \\
\hline Mouse (C57/BL6) & $\begin{array}{l}\text { Early } \\
\text { postnatal }\end{array}$ & Adult & o & $\begin{array}{l}\text { MSEW: MS 4h/day from } \\
\text { P2-P5, then 8h/day from }\end{array}$ & $\begin{array}{l}\text { Ventral Dentate } \\
\text { Gyrus }\end{array}$ & IHC & PV cell density & decreased & $\begin{array}{l}\text { [116] Murthy } \\
\text { et al. (2019) }\end{array}$ \\
\hline
\end{tabular}




\begin{tabular}{|c|c|c|c|c|c|c|c|c|c|}
\hline Species & $\begin{array}{l}\text { Age during } \\
\text { manipulation }\end{array}$ & $\begin{array}{l}\text { Age at } \\
\text { measurement }\end{array}$ & Sex & Experimental paradigm & Brain Region & Method & Measure & Outcome & Reference \\
\hline & & & & $\begin{array}{l}\text { P6-P16. MS pups weaned at } \\
\text { P17, controls at P21 }\end{array}$ & & & & & \\
\hline Rat (Wistar) & Adult & Adult & o & CMS 8 weeks & Dentate Gyrus hilus & IHC & PV cell density & no change & $\begin{array}{l}\text { [122] } \\
\text { Nieto-Gonzalez } \\
\text { et al. (2015) }\end{array}$ \\
\hline Rat (Wistar) & Adult & Adult & o & CMS 8 weeks & $\begin{array}{l}\text { Dentate Gyrus } \\
\text { granule cell layer }\end{array}$ & IHC & PV cell density & no change & $\begin{array}{l}\text { [122] } \\
\text { Nieto-Gonzalez } \\
\text { et al. (2015) }\end{array}$ \\
\hline Rat (Wistar) & Adult & Adult & o & CMS 8 weeks & Dentate Gyrus & $\mathrm{IHC}$ & PV cell density & no change & $\begin{array}{l}\text { [122] } \\
\text { Nieto-Gonzalez } \\
\text { et al. (2015) }\end{array}$ \\
\hline Rat (Wistar) & Adult & Adult & o & CUS 16 days or CMS 8 weeks & Dentate Gyrus & $\mathrm{IHC}$ & $\begin{array}{l}\text { PV cell density; PV cell } \\
\text { surface area; PV } \\
\text { fluorescence intensity }\end{array}$ & no change & $\begin{array}{l}\text { [123] Nowak } \\
\text { et al. (2010) }\end{array}$ \\
\hline Rat (Sprague-Dawley) & $\begin{array}{l}\text { Early } \\
\text { postnatal }\end{array}$ & Juvenile & 우우 & MS 4h/day 19 days & Dentate Gyrus & IHC & $\begin{array}{l}\text { 8-oxo-dG + fraction of } \\
\text { PV cells; PV + cell 8-oxo- } \\
\text { dG intensity; PV cell } \\
\text { number; PV intensity }\end{array}$ & $\begin{array}{l}\text { increased 8-oxo-dG + } \\
\text { fraction; increased PV+ 8- } \\
\text { oxo-dG in females vs males } \\
\text { and increased PV intensity } \\
\text { in males vs females }\end{array}$ & $\begin{array}{l}\text { [159] Soares } \\
\text { et al. (2020) }\end{array}$ \\
\hline $\begin{array}{l}\text { GAD67(+/GFP) (HET) } \\
\text { mice }\end{array}$ & - & Juvenile & o & $\begin{array}{l}\text { Maternal RS: } 45 \mathrm{~min} 3 \mathrm{x} / \text { day } \\
\text { from E15 to E17.5; BrdU } \\
\text { injection IP once at E12 or } \\
\text { E15 }\end{array}$ & Dentate Gyrus & $\mathrm{IHC}$ & $\mathrm{PV}+/ \mathrm{GFP}+$ cell density & no change & $\begin{array}{l}\text { [169] Uchida } \\
\text { et al. (2014) }\end{array}$ \\
\hline Mouse (C57/BL6) & $\begin{array}{l}\text { Juvenile- } \\
\text { adolescent }\end{array}$ & Adolescent & o & SI 5 weeks & Dentate Gyrus & $\begin{array}{l}\text { IHC and WFA } \\
\text { stain }\end{array}$ & $\begin{array}{l}\text { PV cell density; PNN + } \\
\text { fraction of PV cells; PV } \\
\text { fluorescence intensity; } \\
\text { PV soma area }\end{array}$ & decreased (all) & $\begin{array}{l}\text { [170] Ueno et al. } \\
\text { (2017) }\end{array}$ \\
\hline Mouse (C57/BL6) & $\begin{array}{l}\text { Adolescent- } \\
\text { adult }\end{array}$ & Adult & o & $\begin{array}{l}\text { CSIS } 7 \text { weeks. After stress, } \\
\text { mice housed individually for } \\
1 \text { year }\end{array}$ & Dentate Gyrus & IHC & PV cell density & decreased & $\begin{array}{l}\text { [179] Wang } \\
\text { et al. (2019) }\end{array}$ \\
\hline Mouse (C57/BL6) & $\begin{array}{l}\text { Early } \\
\text { postnatal }\end{array}$ & Adult & o & $\begin{array}{l}\text { MSEW: MS 4h/day from } \\
\text { P2-P5, then 8h/day from } \\
\text { P6-P16. MS pups weaned at } \\
\text { P17, controls at P21 }\end{array}$ & $\begin{array}{l}\text { Ventral Dentate } \\
\text { Gyrus }\end{array}$ & $\mathrm{IHC}$ & $\begin{array}{l}\text { c-Fos + fraction of PV } \\
\text { cells }\end{array}$ & no change & $\begin{array}{l}\text { [116] Murthy } \\
\text { et al. (2019) }\end{array}$ \\
\hline Rat (Sprague-Dawley) & $\begin{array}{l}\text { Juvenile- } \\
\text { Adult }\end{array}$ & Adult & o & $\begin{array}{l}\text { Forced swim, } 330 \text {-min } \\
\text { elevated platform sessions, } \\
2 \mathrm{~h} \mathrm{RS.} 32 \text { days rest followed } \\
\text { by } 4 \text { days of odor exposure } \\
\text { preceding } 45 \mathrm{~s} \text { underwater } \\
\text { restraint trauma. } 4 \text { weeks } \\
\text { later, odor re-exposure then } \\
\text { elevated plus maze before } \\
\text { sacrifice }\end{array}$ & $\begin{array}{l}\text { Dorsal Dentate } \\
\text { Gyrus }\end{array}$ & IHC & $\begin{array}{l}\mathrm{PV}+/ \mathrm{c}-\mathrm{Fos}+\text { cell } \\
\text { density }\end{array}$ & no change & $\begin{array}{l}{[142]} \\
\text { Regev-Tsur et al. } \\
(2020)\end{array}$ \\
\hline Rat (Sprague-Dawley) & $\begin{array}{l}\text { Juvenile- } \\
\text { Adult }\end{array}$ & Adult & o & $\begin{array}{l}\text { Forced swim, } 330 \text {-min } \\
\text { elevated platform sessions, } \\
2 \mathrm{~h} \mathrm{RS} \text {. } 32 \text { days rest followed } \\
\text { by } 4 \text { days of odor exposure } \\
\text { preceding } 45 \mathrm{~s} \text { underwater } \\
\text { restraint trauma. } 4 \text { weeks } \\
\text { later, odor re-exposure then } \\
\text { elevated plus maze before } \\
\text { sacrifice }\end{array}$ & $\begin{array}{l}\text { Ventral Dentate } \\
\text { Gyrus }\end{array}$ & $\mathrm{IHC}$ & $\begin{array}{l}\mathrm{PV}+/ \mathrm{c}-\mathrm{Fos}+\text { cell } \\
\text { density }\end{array}$ & no change & $\begin{array}{l}{[142]} \\
\text { Regev-Tsur et al. } \\
(2020)\end{array}$ \\
\hline Mouse (C57/BL6) & $\begin{array}{l}\text { Early } \\
\text { postnatal }\end{array}$ & Adult & o & $\begin{array}{l}\text { MSEW: MS 4h/day from } \\
\text { P2-P5, then 8h/day from }\end{array}$ & $\begin{array}{l}\text { Ventral Dentate } \\
\text { Gyrus Granule Cell } \\
\text { Layer }\end{array}$ & IHC & WFA intensity in PV cells & increased & $\begin{array}{l}\text { [116] Murthy } \\
\text { et al. (2019) }\end{array}$ \\
\hline
\end{tabular}









\begin{tabular}{|c|c|c|c|c|c|c|c|c|c|}
\hline Species & $\begin{array}{l}\text { Age during } \\
\text { manipulation }\end{array}$ & $\begin{array}{l}\text { Age at } \\
\text { measurement }\end{array}$ & Sex & Experimental paradigm & Brain Region & Method & Measure & Outcome & Reference \\
\hline & & & & $\begin{array}{l}\text { offspring exposed to } 10 \text { days } \\
\text { variable unpredictable stress } \\
\text { from P30-P40 }\end{array}$ & & & & & \\
\hline Mouse (C57/BL6) & Adolescent & Adult & o & $\begin{array}{l}\text { Maternal stress: GD9 poly I:C } \\
\text { injection (mimics infection); } \\
\text { offspring exposed to } 10 \text { days } \\
\text { variable unpredictable stress } \\
\text { from P30-P40 }\end{array}$ & Dorsal CA1-3 & $\mathrm{IHC}$ & Total PV cell number & no change & $\begin{array}{l}\text { [54] Giovanoli } \\
\text { et al., } 2014\end{array}$ \\
\hline Rat (Wistar) & $\begin{array}{l}\text { Juvenile- } \\
\text { adult }\end{array}$ & Adult & o & SI 8 weeks & CA1 & IHC & PV cell density & no change & $\begin{array}{l}\text { [61] Greene } \\
\text { et al., } 2001\end{array}$ \\
\hline Rat (Sprague-Dawley) & $\begin{array}{l}\text { Juvenile- } \\
\text { adult }\end{array}$ & Adult & \% & SI 11 weeks & CA1 & $\mathrm{IHC}$ & PV cell density & no change & $\begin{array}{l}\text { [65] Harte et al. } \\
\text { (2007) }\end{array}$ \\
\hline Rat (Sprague-Dawley) & $\begin{array}{l}\text { Adolescent- } \\
\text { adult }\end{array}$ & Adult & o & RS 6h/day 3 weeks & CA1 & IHC & PV cell density & decreased & $\begin{array}{l}\text { [70] Hu et al. } \\
\text { (2010) }\end{array}$ \\
\hline Rat (Wistar) & Adult & Adult & o & $\begin{array}{l}\text { SDPS: } 5 \text { days defeat then SI } \\
\text { until measurement }\end{array}$ & CA1 & $\mathrm{IHC}$ & $\begin{array}{l}\text { PV cell density } 72 \mathrm{~h} \text { and } \\
2,4 \text {, and } 8 \text { weeks after } \\
\text { last defeat }\end{array}$ & no change & $\begin{array}{l}\text { [86] Koskinen } \\
\text { et al. (2019) }\end{array}$ \\
\hline Rat (Tryon Maze Dull) & Adult & Adult & o & CSD 8 days & $\begin{array}{l}\text { CA1 pyramidal cell } \\
\text { layer }\end{array}$ & $\mathrm{IHC}$ & $\begin{array}{l}\text { Relative Optical Density } \\
\text { of PV stain }\end{array}$ & no change & $\begin{array}{l}\text { [87] Krugers } \\
\text { et al. (1996) }\end{array}$ \\
\hline Rat (Sprague-Dawley) & Adult & Adult & o & $\begin{array}{l}\text { Gulf war illness model: } 4 \\
\text { weeks daily: } 5 \text { min RS, } \\
\text { pyridostigmine bromide } \\
1.3 \mathrm{mg} / \mathrm{kg} \text { oral, DEET } 200 \mathrm{ul} \\
40 \mathrm{mg} / \mathrm{kg} \text { dermal, and } \\
\text { permethrin } 200 \mathrm{ul} 0.13 \mathrm{mg} / \\
\mathrm{kg} \text { dermal. }\end{array}$ & $\mathrm{CA} 1 / 3$ & $\mathrm{IHC}$ & Total PV cell number & no change & $\begin{array}{l}\text { [107] Megahed } \\
\text { et al. (2014) }\end{array}$ \\
\hline C57/BL6 mice & $\begin{array}{l}\text { Early } \\
\text { postnatal }\end{array}$ & Adult & o & $\begin{array}{l}\text { MSEW: MS 4h/day from } \\
\text { P2-P5, then 8h/day from } \\
\text { P6-P16. MS pups weaned at } \\
\text { P17, controls at P21 }\end{array}$ & Ventral CA1 & $\mathrm{IHC}$ & PV cell density & no change & $\begin{array}{l}\text { [116] Murthy } \\
\text { et al. (2019) }\end{array}$ \\
\hline $\begin{array}{l}\text { GAD67(+/GFP) (HET) } \\
\text { mice }\end{array}$ & - & Juvenile & o & $\begin{array}{l}\text { Maternal RS: } 45 \mathrm{~min} 3 \mathrm{x} / \text { day } \\
\text { from E15 to E17.5; BrdU } \\
\text { injection IP once at E12 or } \\
\text { E15 }\end{array}$ & CA1 & $\mathrm{IHC}$ & $\mathrm{PV}+/ \mathrm{GFP}+$ cell density & decreased & $\begin{array}{l}\text { [169] Uchida } \\
\text { et al. (2014) }\end{array}$ \\
\hline Mouse (C57/BL6) & $\begin{array}{l}\text { Juvenile- } \\
\text { adolescent }\end{array}$ & Adolescent & o & SI 5 weeks & CA1 & $\begin{array}{l}\text { IHC and WFA } \\
\text { stain }\end{array}$ & $\begin{array}{l}\text { PV cell density; PNN + } \\
\text { fraction of PV cells; PV } \\
\text { fluorescence intensity; } \\
\text { PV soma area }\end{array}$ & $\begin{array}{l}\text { decreased PNN }+ \text { fraction } \\
\text { of PV cells and PV } \\
\text { fluorescence }\end{array}$ & $\begin{array}{l}\text { [170] Ueno et al. } \\
\text { (2017) }\end{array}$ \\
\hline Mouse (C57/BL6) & $\begin{array}{l}\text { Adolescent- } \\
\text { adult }\end{array}$ & Adult & o & $\begin{array}{l}\text { CSIS } 7 \text { weeks. After stress, } \\
\text { mice housed individually for } \\
1 \text { year }\end{array}$ & CA1 & $\mathrm{IHC}$ & PV cell density & decreased & $\begin{array}{l}\text { [179] Wang } \\
\text { et al. (2019) }\end{array}$ \\
\hline Rat (Sprague-Dawley) & $\begin{array}{l}\text { Early } \\
\text { postnatal }\end{array}$ & Juvenile & \$o & MS 4h/day 19 days & CA1 & $\mathrm{IHC}$ & $\begin{array}{l}\text { 8-oxo-dG + fraction of } \\
\text { PV cells; PV + cell 8-oxo- } \\
\text { dG intensity; PV cell } \\
\text { number; PV intensity }\end{array}$ & $\begin{array}{l}\text { increased 8-oxo-dG }+ \\
\text { fraction; increased PV }+8 \text { - } \\
\text { oxo-dG in females vs males } \\
\text { and increased PV intensity } \\
\text { in males vs females }\end{array}$ & $\begin{array}{l}\text { [159] Soares } \\
\text { et al. (2020) }\end{array}$ \\
\hline Rat (Wistar) & Adult & Adult & o & $\begin{array}{l}\text { SDPS: } 5 \text { days defeat then SI } \\
\text { until measurement }\end{array}$ & CA1 & $\mathrm{IHC}$ & $\begin{array}{l}\mathrm{PV}+/ \mathrm{CSPG}+\text { cell } \\
\text { density } 72 \mathrm{~h} \text { and } 2,4, \\
\text { and } 8 \text { weeks after last } \\
\text { defeat }\end{array}$ & $\begin{array}{l}\text { decreased at } 72 \mathrm{~h} \text {; } \\
\text { increased at } 8 \text { weeks }\end{array}$ & $\begin{array}{l}\text { [86] Koskinen } \\
\text { et al. (2019) }\end{array}$ \\
\hline C57/BL6 mice & $\begin{array}{l}\text { Early } \\
\text { postnatal }\end{array}$ & Adult & o & $\begin{array}{l}\text { MSEW: MS 4h/day from } \\
\text { P2-P5, then 8h/day from } \\
\text { P6-P16. MS pups weaned at } \\
\text { P17, controls at P21 }\end{array}$ & Ventral CA1 & $\begin{array}{l}\text { IHC and WFA } \\
\text { stain }\end{array}$ & WFA intensity in PV cells & no change & $\begin{array}{l}\text { [116] Murthy } \\
\text { et al. (2019) }\end{array}$ \\
\hline Rat (Wistar) & Adult & Adult & o & CUS 16 days or CMS 8 weeks & CA1 & $\mathrm{IHC}$ & & no change & \\
\hline
\end{tabular}

\section{kg dermal.}

E15

mice housed individually for
1 year

SDPS: 5 days defeat then SI

P17, controls at P21

CA

IHC 


\begin{tabular}{|c|c|c|c|c|c|c|c|c|c|}
\hline Species & $\begin{array}{l}\text { Age during } \\
\text { manipulation }\end{array}$ & $\begin{array}{l}\text { Age at } \\
\text { measurement }\end{array}$ & Sex & Experimental paradigm & Brain Region & Method & Measure & Outcome & Reference \\
\hline & & & & & & & $\begin{array}{l}\text { PV cell density; PV cell } \\
\text { surface area; PV } \\
\text { fluorescence intensity }\end{array}$ & & $\begin{array}{l}\text { [123] Nowak } \\
\text { et al. (2010) }\end{array}$ \\
\hline Rat (Wistar) & Adult & Adult & $0^{*}$ & $\begin{array}{l}\text { SDPS: } 5 \text { days defeat then } 3 \\
\text { months SI; controls pair } \\
\text { housed for } 3 \text { months }\end{array}$ & Dorsal CA1 & $\mathrm{IHC}$ & $\begin{array}{l}\mathrm{PV}+\text { fraction of CSPG }+ \\
\text { cells; CSPG intensity in } \\
\text { PV cells }\end{array}$ & increased PV + fraction & $\begin{array}{l}\text { [144] Riga et al. } \\
\text { (2017) }\end{array}$ \\
\hline Rat (Wistar) & Adult & Adult & o & $\begin{array}{l}\text { SDPS: } 5 \text { days defeat then } 3 \\
\text { months SI; controls pair } \\
\text { housed for } 3 \text { months }\end{array}$ & $\begin{array}{l}\text { CA1 stratum } \\
\text { pyramidale }\end{array}$ & $\mathrm{IHC}$ & $\begin{array}{l}\text { CSPG + fraction of PV } \\
\text { cells; PV intensity in } \\
\text { CSPG + cells }\end{array}$ & increased PV intensity & $\begin{array}{l}\text { [144] Riga et al. } \\
\text { (2017) }\end{array}$ \\
\hline Rat (Wistar) & Adult & Adult & $0^{*}$ & $\begin{array}{l}\text { SDPS: } 5 \text { days defeat then } 3 \\
\text { months SI; controls pair } \\
\text { housed for } 3 \text { months }\end{array}$ & $\begin{array}{l}\text { CA1 stratum } \\
\text { pyramidale }\end{array}$ & $\mathrm{IHC}$ & $\begin{array}{l}\text { Fraction of high-PV } \\
\text { expressing and } \\
\text { intermediate-low-PV } \\
\text { expressing PV+/CSPG+ } \\
\text { and PV+/CSPG- cells }\end{array}$ & $\begin{array}{l}\text { increased high-PV } \\
\text { expressing and decreased } \\
\text { intermediate-low-PV } \\
\text { expressing PV+/CSPG + } \\
\text { cells }\end{array}$ & $\begin{array}{l}\text { [144] Riga et al. } \\
\text { (2017) }\end{array}$ \\
\hline Rat (Sprague-Dawley) & $\begin{array}{l}\text { Adolescent- } \\
\text { adult }\end{array}$ & Adult & o & RS 6h/day 3 weeks & CA1 & Electrophysiology & $\begin{array}{l}\text { sIPSC frequency and } \\
\text { amplitude on pyramidal } \\
\text { neurons }\end{array}$ & increased frequency & $\begin{array}{l}\text { [70] Hu et al. } \\
(2010)\end{array}$ \\
\hline C57/BL6 mice & $\begin{array}{l}\text { Early } \\
\text { postnatal }\end{array}$ & Adult & o & $\begin{array}{l}\text { MSEW: MS 4h/day from } \\
\text { P2-P5, then 8h/day from } \\
\text { P6-P16. MS pups weaned at } \\
\text { P17, controls at P21 }\end{array}$ & Ventral CA1 & $\mathrm{IHC}$ & $\begin{array}{l}\text { c-Fos + fraction of PV } \\
\text { cells }\end{array}$ & no change & $\begin{array}{l}\text { [116] Murthy } \\
\text { et al. (2019) }\end{array}$ \\
\hline Rat (Wistar) & Adult & Adult & 0 & $\begin{array}{l}\text { SDPS: } 5 \text { days defeat then } 3 \\
\text { months SI; controls pair } \\
\text { housed for } 3 \text { months }\end{array}$ & $\begin{array}{l}\text { CA1 stratum } \\
\text { pyramidale }\end{array}$ & Electrophysiology & $\begin{array}{l}\text { sIPSC frequency and } \\
\text { amplitude on pyramidal } \\
\text { neurons }\end{array}$ & decreased frequency & $\begin{array}{l}\text { [144] Riga et al. } \\
\text { (2017) }\end{array}$ \\
\hline Rat (Wistar) & Adult & Adult & o & CMS 9 weeks & Dorsal CA2/3 & $\mathrm{IHC}$ & PV cell density & decreased & $\begin{array}{l}\text { [30] Csabai et al. } \\
\text { (2017) }\end{array}$ \\
\hline Rat (Wistar) & Adult & Adult & o & CMS 9 weeks & Ventral CA2/3 & $\mathrm{IHC}$ & Total PV cell number & no change & $\begin{array}{l}\text { [32] Czeh et al. } \\
\text { (2015) }\end{array}$ \\
\hline Rat (Wistar) & Adult & Adult & 0 & CMS 9 weeks & Dorsal CA2/3 & $\mathrm{IHC}$ & Total PV cell number & decreased & $\begin{array}{l}\text { [32] Czeh et al. } \\
\text { (2015) }\end{array}$ \\
\hline PV-Cre Mouse & $\begin{array}{l}\text { Adolescent- } \\
\text { adult }\end{array}$ & Adult & not stated & $\begin{array}{l}\text { SI } 8 \text { weeks; } 16 \text { days rest and } \\
\text { behavioral tests }\end{array}$ & Ventral CA2/3 & $\mathrm{IHC}$ & PV cell density & decreased & $\begin{array}{l}\text { [34] Deng et al. } \\
\text { (2020) }\end{array}$ \\
\hline Rat (Sprague-Dawley) & $\begin{array}{l}\text { Early } \\
\text { postnatal }\end{array}$ & Early postnatal & o & $\begin{array}{l}\text { Handling and MS: } 15 \text { or } \\
180 \text { min/day from P2-P14 }\end{array}$ & $\mathrm{CA} 2 / 3$ & $\mathrm{IHC}$ & Total PV cell number & no change & $\begin{array}{l}\text { [37] Dricks } \\
\text { (2016) }\end{array}$ \\
\hline Rat (Wistar) & Adult & Adult & o & SI 3 weeks & CA2 & $\mathrm{IHC}$ & Total PV cell number & decreased & $\begin{array}{l}\text { [44] Filipović } \\
\text { et al. (2017) }\end{array}$ \\
\hline Rat (Sprague-Dawley) & $\begin{array}{l}\text { Juvenile- } \\
\text { adult }\end{array}$ & Adult & $\%$ & SI 11 weeks & $\mathrm{CA} 2 / 3$ & IHC & PV cell density & decreased & $\begin{array}{l}\text { [65] Harte et al. } \\
(2007)\end{array}$ \\
\hline Rat (Sprague-Dawley) & $\begin{array}{l}\text { Adolescent- } \\
\text { adult }\end{array}$ & Adult & o & RS 6h/day 3 weeks & $\mathrm{CA} 2 / 3$ & $\mathrm{IHC}$ & PV cell density & decreased & $\begin{array}{l}\text { [70] Hu et al. } \\
\text { (2010) }\end{array}$ \\
\hline Mouse (C57/BL6) & Adolescent & Adolescent & o & RS 6h/day 3 weeks & CA3 & $\mathrm{IHC}$ & $\begin{array}{l}\text { Total PV cell number; PV } \\
\text { cellular intensity }\end{array}$ & increased PV cell number & $\begin{array}{l}\text { [27] Clarke et al. } \\
2019\end{array}$ \\
\hline Rat (Wistar) & Adult & Adult & o & SI 3 weeks & CA3 & $\mathrm{IHC}$ & Total PV cell number & decreased & $\begin{array}{l}\text { [44] Filipović } \\
\text { et al. (2017) }\end{array}$ \\
\hline Rat (Wistar) & Adult & Adult & o & $\begin{array}{l}\text { Acute ( } 2 \mathrm{~h} \text { cold or RS) or } \\
\text { chronic ( } 21 \text { days } \mathrm{SI}) \text { stress, or } \\
\text { chronic stress with acute } \\
\text { stress at the end of isolation }\end{array}$ & CA3 & $\mathrm{IHC}$ & $\begin{array}{l}\text { PV-immunoreactive } \\
\text { number }\end{array}$ & $\begin{array}{l}\text { decreased by isolation and } \\
\text { combined isolation }+ \text { acute } \\
\text { stressors }\end{array}$ & $\begin{array}{l}\text { [43] Filipović } \\
\text { et al. (2013) }\end{array}$ \\
\hline Rat (Wistar) & $\begin{array}{l}\text { Juvenile- } \\
\text { adult }\end{array}$ & Adult & o & SI 8 weeks & CA3 & $\mathrm{IHC}$ & PV cell density & no change & $\begin{array}{l}\text { [61] Greene } \\
\text { et al., } 2001\end{array}$ \\
\hline Rat (Tryon Maze Dull) & Adult & Adult & o & CSD 8 days & $\begin{array}{l}\text { CA3 pyramidal cell } \\
\text { layer }\end{array}$ & $\mathrm{IHC}$ & $\begin{array}{l}\text { Relative Optical Density } \\
\text { of PV stain }\end{array}$ & no change & $\begin{array}{l}\text { [87] Krugers } \\
\text { et al. (1996) }\end{array}$ \\
\hline \multirow[t]{2}{*}{ Mouse (C57/BL6) } & $\begin{array}{l}\text { Early } \\
\text { postnatal }\end{array}$ & Adult & o & $\begin{array}{l}\text { MSEW: MS 4h/day from } \\
\text { P2-P5, then } 8 \mathrm{~h} / \text { day from }\end{array}$ & Ventral CA3 & $\mathrm{IHC}$ & PV cell density & no change & $\begin{array}{l}\text { [116] Murthy } \\
\text { et al. (2019) }\end{array}$ \\
\hline & & & & & & & & $(\mathrm{col}$ & (continued on next page) \\
\hline
\end{tabular}




\begin{tabular}{|c|c|c|c|c|c|c|c|c|c|}
\hline Species & $\begin{array}{l}\text { Age during } \\
\text { manipulation }\end{array}$ & $\begin{array}{l}\text { Age at } \\
\text { measurement }\end{array}$ & Sex & Experimental paradigm & Brain Region & Method & Measure & Outcome & Reference \\
\hline & & & & $\begin{array}{l}\text { P6-P16. MS pups weaned at } \\
\text { P17, controls at P21 }\end{array}$ & & & & & \\
\hline Rat (Wistar) & Adult & Adult & o & CUS 16 days or CMS 8 weeks & CA3 & $\mathrm{IHC}$ & $\begin{array}{l}\text { PV cell density; PV cell } \\
\text { surface area; PV } \\
\text { fluorescence intensity }\end{array}$ & no change & $\begin{array}{l}\text { [123] Nowak } \\
\text { et al. (2010) }\end{array}$ \\
\hline Rat (Sprague-Dawley) & $\begin{array}{l}\text { Early } \\
\text { postnatal }\end{array}$ & Juvenile & 6̊ำ & MS 4h/day 19 days & CA3 & $\mathrm{IHC}$ & $\begin{array}{l}\text { 8-oxo-dG + fraction of } \\
\text { PV cells; PV + cell 8-oxo- } \\
\text { dG intensity; PV cell } \\
\text { number; PV intensity }\end{array}$ & $\begin{array}{l}\text { increased PV+ 8-oxo-dG in } \\
\text { females vs males and } \\
\text { increased PV intensity in } \\
\text { males vs females }\end{array}$ & $\begin{array}{l}\text { [159] Soares } \\
\text { et al. (2020) }\end{array}$ \\
\hline $\begin{array}{l}\text { GAD67(+/GFP) (HET) } \\
\text { mice }\end{array}$ & - & Juvenile & o & $\begin{array}{l}\text { Maternal RS: } 45 \mathrm{~min} 3 \mathrm{x} / \text { day } \\
\text { from E15 to E17.5; BrdU } \\
\text { injection IP once at E12 or } \\
\text { E15 }\end{array}$ & CA3 & $\mathrm{IHC}$ & $\mathrm{PV}+/ \mathrm{GFP}+$ cell density & no change & $\begin{array}{l}\text { [169] Uchida } \\
\text { et al. (2014) }\end{array}$ \\
\hline Mouse (C57/BL6) & $\begin{array}{l}\text { Juvenile- } \\
\text { adolescent }\end{array}$ & Adolescent & o & SI 5 weeks & CA3 & $\begin{array}{l}\text { IHC and WFA } \\
\text { stain }\end{array}$ & $\begin{array}{l}\text { PV cell density; PNN + } \\
\text { fraction of PV cells; PV } \\
\text { fluorescence intensity; } \\
\text { PV soma area }\end{array}$ & $\begin{array}{l}\text { decreased PV fluorescence } \\
\text { and PV soma area }\end{array}$ & $\begin{array}{l}\text { [170] Ueno et al. } \\
\text { (2017) }\end{array}$ \\
\hline Mouse (C57/BL6) & $\begin{array}{l}\text { Adolescent- } \\
\text { adult }\end{array}$ & Adult & o & $\begin{array}{l}\text { CSIS } 7 \text { weeks. After stress, } \\
\text { mice housed individually for } \\
1 \text { year }\end{array}$ & CA3 & $\mathrm{IHC}$ & PV cell density & decreased & $\begin{array}{l}\text { [179] Wang } \\
\text { et al. (2019) }\end{array}$ \\
\hline PV-Cre Mouse & $\begin{array}{l}\text { Adolescent- } \\
\text { adult }\end{array}$ & Adult & not stated & $\begin{array}{l}\text { SI } 8 \text { weeks; } 16 \text { days rest and } \\
\text { behavioral tests }\end{array}$ & $\begin{array}{l}\text { Ventral } \\
\text { Hippocampus }\end{array}$ & IHC & PV cell density & decreased & $\begin{array}{l}\text { [34] Deng et al. } \\
(2020)\end{array}$ \\
\hline PV-Cre Mouse & $\begin{array}{l}\text { Adolescent- } \\
\text { adult }\end{array}$ & Adult & not stated & $\begin{array}{l}\text { SI } 8 \text { weeks; } 16 \text { days rest and } \\
\text { behavioral tests }\end{array}$ & $\begin{array}{l}\text { Dorsal } \\
\text { Hippocampus }\end{array}$ & $\mathrm{IHC}$ & PV cell density & no change & $\begin{array}{l}\text { [34] Deng et al. } \\
\text { (2020) }\end{array}$ \\
\hline Rat (Sprague-Dawley) & $\begin{array}{l}\text { Early } \\
\text { postnatal }\end{array}$ & Early postnatal & o & $\begin{array}{l}\text { Handling and MS: } 15 \text { or } \\
180 \text { min/day from P2-P14 }\end{array}$ & Hippocampus & $\mathrm{IHC}$ & Total PV cell number & no change & $\begin{array}{l}\text { [37] Dricks } \\
(2016)\end{array}$ \\
\hline Rat (Sprague-Dawley) & Adult & Adult & o & $\begin{array}{l}\text { Gulf war illness model: } 4 \\
\text { weeks daily: } 5 \text { min RS, } \\
\text { pyridostigmine bromide } \\
1.3 \mathrm{mg} / \mathrm{kg} \text { oral, DEET } 200 \mathrm{ul} \\
40 \mathrm{mg} / \mathrm{kg} \text { dermal, and } \\
\text { permethrin } 200 \mathrm{ul} 0.13 \mathrm{mg} / \\
\mathrm{kg} \text { dermal. }\end{array}$ & Hippocampus & $\mathrm{IHC}$ & Total PV cell number & decreased & $\begin{array}{l}\text { [107] Megahed } \\
\text { et al. (2014) }\end{array}$ \\
\hline Rat (Sprague-Dawley) & Adult & Adult & o & RS: $6 \mathrm{~h} /$ day for 10 days & Hippocampus & $\begin{array}{l}\text { IHC and WFA } \\
\text { stain }\end{array}$ & $\begin{array}{l}\text { Total PV cell number; } \\
\text { total PNN }+/ P V+\text { cell } \\
\text { number }\end{array}$ & no change & $\begin{array}{l}\text { [139] Pesarico } \\
\text { et al., } 2019\end{array}$ \\
\hline Mouse (C57/BL6) & $\begin{array}{l}\text { Juvenile; } \\
\text { adult }\end{array}$ & $\begin{array}{l}\text { Adolescent; } \\
\text { adult }\end{array}$ & o & CUS 7 days & Hippocampus & $\begin{array}{l}\text { IHC and WFA } \\
\text { stain }\end{array}$ & $\begin{array}{l}\text { PV cell density; PNN + } \\
\text { fraction of PV cells; PV } \\
\text { + fraction of PNNs; PV } \\
\text { fluorescence; PV soma } \\
\text { area }\end{array}$ & no change & $\begin{array}{l}\text { [171] Ueno et al. } \\
\text { (2018) }\end{array}$ \\
\hline Rat (Sprague-Dawley) & Adolescent & Adolescent & o & $\begin{array}{l}\text { Daily FS } 10 \text { days, RS } 1 \mathrm{~h} \text { on } \\
\text { days } 1,2 \text {, and } 10\end{array}$ & $\begin{array}{l}\text { Ventral } \\
\text { Hippocampus }\end{array}$ & $\mathrm{IHC}$ & Total PV cell number & decreased & $\begin{array}{l}\text { [57] Gomes et al. } \\
\text { (2019) }\end{array}$ \\
\hline Rat (Sprague-Dawley) & Adult & Adult & o & $\begin{array}{l}\text { Daily FS } 10 \text { days, RS } 1 \mathrm{~h} \text { on } \\
\text { days } 1,2 \text {, and } 10\end{array}$ & $\begin{array}{l}\text { Ventral } \\
\text { Hippocampus }\end{array}$ & $\mathrm{IHC}$ & Total PV cell number & decreased & $\begin{array}{l}\text { [57] Gomes et al. } \\
\text { (2019) }\end{array}$ \\
\hline Rat (Sprague-Dawley) & Adolescent & $\begin{array}{l}\text { Adolescent; } \\
\text { adult }\end{array}$ & o & $\begin{array}{l}\text { Daily FS } 10 \text { days, RS } 1 \mathrm{~h} \text { on } \\
\text { days } 1,2 \text {, and } 10\end{array}$ & $\begin{array}{l}\text { Ventral } \\
\text { Hippocampus }\end{array}$ & $\begin{array}{l}\text { IHC and WFA } \\
\text { stain }\end{array}$ & $\begin{array}{l}\text { Total PV/PNN + cell } \\
\text { number }\end{array}$ & decreased in adolescents & $\begin{array}{l}\text { [57] Gomes et al. } \\
\text { (2019) }\end{array}$ \\
\hline Rat (Wistar) & Adult & Adult & o & $\begin{array}{l}\text { SDPS: } 5 \text { days defeat then } 3 \\
\text { months SI; controls pair } \\
\text { housed for } 3 \text { months. ChABC } \\
\text { or penicillinase bilateral } \\
\text { injection to dorsal } \\
\text { hippocampus }>2 \text { months } \\
\text { after last CSD day }\end{array}$ & $\begin{array}{l}\text { Dorsal } \\
\text { Hippocampus }\end{array}$ & $\mathrm{IHC}$ & $\mathrm{PV}+/ \mathrm{PNN}+$ cell density & $\begin{array}{l}\text { increased by CSD in } \\
\text { penicillinase- but not } \\
\text { chABC-treated rats; } \\
\text { decreased by chABC } \\
\text { treatment compared to } \\
\text { penicillinase in both } \\
\text { stressed and unstressed rats }\end{array}$ & $\begin{array}{l}\text { [144] Riga et al. } \\
\text { (2017) }\end{array}$ \\
\hline Mouse (CD1) & & & రo우 & & & $\mathrm{IHC}$ & PV cell density & & \\
\hline
\end{tabular}




\begin{tabular}{|c|c|c|c|c|c|c|c|c|c|}
\hline Species & $\begin{array}{l}\text { Age during } \\
\text { manipulation }\end{array}$ & $\begin{array}{l}\text { Age at } \\
\text { measurement }\end{array}$ & Sex & Experimental paradigm & Brain Region & Method & Measure & Outcome & Reference \\
\hline & $\begin{array}{l}\text { Early } \\
\text { postnatal }\end{array}$ & $\begin{array}{l}\text { Early } \\
\text { postnatal, } \\
\text { juvenile }\end{array}$ & & $\begin{array}{l}24 \mathrm{~h} \mathrm{MS} \text { on P4 with no food } \\
\text { or water }\end{array}$ & $\begin{array}{l}\text { Dorsal } \\
\text { Hippocampus }\end{array}$ & & & $\begin{array}{l}\text { decreased in left but not } \\
\text { right dorsal hippocampus } \\
\text { at both P14 and P28 }\end{array}$ & $\begin{array}{l}\text { [78] Katahira } \\
\text { et al. (2018) }\end{array}$ \\
\hline Rat (Sprague-Dawley) & $\begin{array}{l}\text { Early } \\
\text { postnatal }\end{array}$ & $\begin{array}{l}\text { Juvenile, } \\
\text { adolescent }\end{array}$ & o & MS 4h/day from P2-P20 & Hippocampus & IHC; Western blot & $\begin{array}{l}\text { PV cell density; PV } \\
\text { protein content }\end{array}$ & no change & $\begin{array}{l}\text { [19] Brenhouse } \\
\text { and Andersen } \\
\text { (2011) }\end{array}$ \\
\hline Rat (Sprague-Dawley) & $\begin{array}{l}\text { Early } \\
\text { postnatal }\end{array}$ & Adolescent & ơ우 & MS 3h/day 3 weeks & Hippocampus & IHC; Western blot & $\begin{array}{l}\text { PV immunoreactivity; } \\
\text { PV cluster number; PV } \\
\text { protein expression }\end{array}$ & $\begin{array}{l}\text { decreased } \\
\text { immunoreactivity and } \\
\text { cluster number }\end{array}$ & $\begin{array}{l}\text { [80] Kim et al. } \\
(2020)\end{array}$ \\
\hline GAD67-GFP Mouse (CD1) & - & Juvenile, adult & o & $\begin{array}{l}\text { Maternal stress: beginning on } \\
\text { GD12, mothers received } \\
\text { restraint stress } 45 \mathrm{~min} 3 \mathrm{x} / \\
\text { d during daylight under } \\
\text { bright lights. Litters weaned } \\
\text { at P24 }\end{array}$ & Hippocampus & IHC; qPCR & $\begin{array}{l}\text { PV + fraction of GAD67: } \\
\text { GFP + cells; PV:GAD1 } \\
\text { mRNA ratio }\end{array}$ & $\begin{array}{l}\text { decreased PV }+ \text { fraction at } \\
\text { both ages, increased PV } \\
\text { mRNA at P150 }\end{array}$ & $\begin{array}{l}\text { [100] Lussier } \\
\text { and Stevens } \\
\text { (2016) }\end{array}$ \\
\hline Rat (Wistar) & Adult & Adult & $0^{\circ}$ & CMS 7 weeks & $\begin{array}{l}\text { Ventral } \\
\text { Hippocampus }\end{array}$ & $\begin{array}{l}\text { qPCR; Western } \\
\text { blot }\end{array}$ & $\begin{array}{l}\text { PV mRNA expression; } \\
\text { PV protein content }\end{array}$ & no change & $\begin{array}{l}\text { [145] Rossetti } \\
\text { et al. (2018) }\end{array}$ \\
\hline Rat (Wistar) & Adult & Adult & o & CMS 7 weeks & $\begin{array}{l}\text { Dorsal } \\
\text { Hippocampus }\end{array}$ & $\begin{array}{l}\text { qPCR; Western } \\
\text { blot }\end{array}$ & $\begin{array}{l}\text { PV mRNA expression; } \\
\text { PV protein content }\end{array}$ & $\begin{array}{l}\text { decreased mRNA and } \\
\text { protein }\end{array}$ & $\begin{array}{l}\text { [145] Rossetti } \\
\text { et al. (2018) }\end{array}$ \\
\hline Mouse (C57/BL6) & $\begin{array}{l}\text { Early } \\
\text { postnatal }\end{array}$ & $\begin{array}{l}\text { Early } \\
\text { postnatal, } \\
\text { juvenile, } \\
\text { adolescent }\end{array}$ & o & LB/LN P4-P11 & Hippocampus & qPCR & PV mRNA expression & increased at P12 and P16 & $\begin{array}{l}\text { [8] Bath et al. } \\
\text { (2016) }\end{array}$ \\
\hline Rat (Sprague-Dawley) & $\begin{array}{l}\text { Adolescent- } \\
\text { adult }\end{array}$ & Adult & 0 & CUS 36 days & Hippocampus & Western blot & PV protein content & no change & $\begin{array}{l}\text { [6] Banasr et al. } \\
\text { (2017) }\end{array}$ \\
\hline Rat (Wistar) & Adult & Adult & o & $\begin{array}{l}\text { SDPS: } 5 \text { days defeat then } 3 \\
\text { months SI; controls pair } \\
\text { housed for } 3 \text { months. ChABC } \\
\text { or penicillinase bilateral } \\
\text { injection to dorsal } \\
\text { hippocampus }>2 \text { months } \\
\text { after last CSD day }\end{array}$ & $\begin{array}{l}\text { Dorsal } \\
\text { Hippocampus }\end{array}$ & Electrophysiology & $\begin{array}{l}\text { sIPSC frequency on } \\
\text { pyramidal neurons }\end{array}$ & $\begin{array}{l}\text { decreased by SDPS in } \\
\text { penicillinase-treated rats; } \\
\text { increased by chABC } \\
\text { compared to penicillinase } \\
\text { in SDPS rats }\end{array}$ & $\begin{array}{l}\text { [144] Riga et al. } \\
\text { (2017) }\end{array}$ \\
\hline $\begin{array}{l}\text { GAD67(+/GFP) (HET) } \\
\text { mice }\end{array}$ & - & Juvenile & o & $\begin{array}{l}\text { Maternal RS: } 45 \mathrm{~min} 3 \mathrm{x} / \text { day } \\
\text { from E15 to E17.5; BrdU } \\
\text { injection IP once at E12 or } \\
\text { E15 }\end{array}$ & Subiculum & $\mathrm{IHC}$ & $\mathrm{PV}+/ \mathrm{GFP}+$ cell density & no change & $\begin{array}{l}\text { [169] Uchida } \\
\text { et al. (2014) }\end{array}$ \\
\hline Rat (Sprague-Dawley) & $\begin{array}{l}\text { Early } \\
\text { postnatal }\end{array}$ & Adolescent & o & $\begin{array}{l}\text { MS: 3h/day from P2-P14, or } \\
\text { early handling P2-P14 } \\
\text { (moved to different cage } \\
\text { 15min/day) }\end{array}$ & Ammon's Horn & $\mathrm{IHC}$ & PV cell density & no change & $\begin{array}{l}\text { [51] Giachino } \\
\text { et al. (2007) }\end{array}$ \\
\hline
\end{tabular}

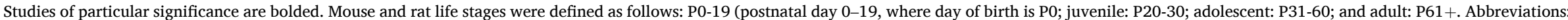

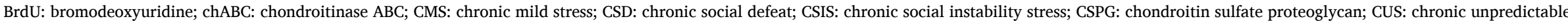

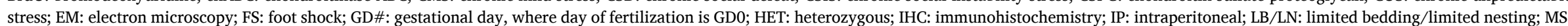

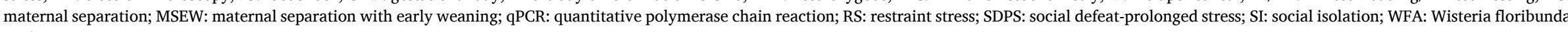
agglutinin. 
2009; Prévot and Sibille, 2020). As in the hippocampus, most evidence suggested no change in BLA PV expression after stress (Clarke et al., 2019; Gildawie et al., 2019; Lukkes et al., 2017; Santiago et al., 2018; Umemori et al., 2015).

Other brain regions such as the whole amygdala (Lukkes et al., 2018), nucleus accumbens (Schiavone et al., 2009), and perirhinal and dorsolateral entorhinal cortices (Ueno et al., 2017) showed evidence of the same pattern as found in the PFC: a stress-induced decrease in PV expression that could be countered by enrichment protocols. This evidence was generated by single studies, however, and elicits further validation.

\subsection{Sex differences}

Many studies have reported sex differences in PV cell phenotypes resulting from chronic stress. This may be due to known sexually divergent responses to stress (Altemus et al., 2014; Furman et al., 2019; Luine et al., 2017), but it also may be due to the unsuitability of chronic stress models' to assess female rodents given their ineffectiveness at eliciting depressive-like phenotypes in females compared to males (Murthy and Gould, 2018). Animal studies of PrL and IL areas of the PFC suggest that females may not show the same reductions in PV cell populations observed in males after stress. While many studies reported consistent outcomes between males and females (Leussis et al., 2012; Nieves et al., 2020; Shepard et al., 2016; Soares et al., 2020), several found stress-induced apparent loss of PV cells (Grassi-Oliveira et al., 2016; Page and Coutellier, 2018a) and protein (do Prado et al., 2015) in males only. In one MS study, while only males showed reductions in PrL and IL PV cell numbers, both sexes performed worse on a spatial memory task compared to unstressed controls, suggesting that females may have different neurobiological adaptations to stress (Grassi-Oliveira et al., 2016). No sex differences were observed in the $3 \mathrm{mPFC}$ studies that included female animals, however (Goodwill et al., 2018; Page and Coutellier, 2018a; Page et al., 2019).

Few investigations have assessed the effects of stress or enrichment on PV cells in the HC of female animals, though these studies mostly replicate findings in males. One study found that social isolation in juvenility and adolescence reduced the density of adult female rat PV cells in the dentate and CA2/3 areas (Harte et al., 2007), consistent with stress effects on males. However, another MS study found increased staining for the oxidative stress marker 8-oxo-dG in dentate, CA1 and CA2/3 PV cells of juvenile females than males (Soares et al., 2020). Two MS studies reported no sex difference in PV cell density, immunoreactive number, or protein expression in the whole HC (Katahira et al., 2018; Kim et al., 2020).

The BLA was spared from a lack of animal studies on females, and two of these studies pointed toward increases in PV cells in males but not females (Gildawie et al., 2019; Guadagno et al., 2020). Females also presented more PV cells staining for the oxidative stress marker 8-oxo-dG (Soares et al., 2020), suggesting a possible mechanism for their reduced numbers.

\subsection{PNNS}

The effects of stress on PNNs coating PV interneurons were of major interest for this review, given the influence of these structures on synaptic transmission, oxidative stress buffering capacity, and excitation/ inhibition balance of the neurons they ensheath - functions that are dysregulated in key brain regions in mood disorders (Duman et al., 2016; Hare and Duman, 2020; Ng et al., 2008; Page and Coutellier, 2019a). Spijker et al. recently published a review (2020) presenting an interesting model in which animal age and stress recency modulate the effect of stress on the densities of PNNs and PV cells in the HC. Citing several studies also included in this review, they argued that animals stressed as adolescents show long-term PV cell and PNN reductions (Gomes et al., 2019; Ueno et al., 2017). Animals stressed as adults, however, show an initial apparent loss of PNNs and PV cells which recovers over several weeks to eventually reach greater hippocampal densities of PV and PV+/PNN + cells compared to non-stressed animals (Koskinen et al., 2019; Riga et al., 2017). The present systematic review finds that this pattern mostly holds up in the HC, but it remains unclear if it applies to animals stressed as pups (Murthy et al., 2019).

We did not find strong support for the stress incubation model's application to PNNs in the PFC. PNNs coating PV cells in the PrL and IL regions of the PFC were minimally affected by stress (Gildawie et al., 2019; Ueno et al., 2017, 2018). One study of the mPFC presented evidence of stress in adolescence producing a delayed increase in PNN coverage of PV cells in males (Page et al., 2019b), however others found no effect (Page and Coutellier, 2018a; Pesarico et al., 2019). Fluoxetine studies likewise reported minimal effects on PNNs in the PFC (Karpova et al., 2011; Mukhopadhyay et al., 2021); a single study found a small decrease in PNNs coating PV cells in the MPFC after 2 weeks of fluoxetine administration in adults (Guirado et al., 2014).

Studies of PNNs ensheathing PV cells in the HC suggest a high degree of subregion dependence, although a dearth of studies assessing all possible combinations of animal age, stress recency, stressor type, and subregion leaves many holes in our understanding. Area CA1 showed the strongest evidence for early PNN reductions (Ueno et al., 2017) and late augmentations (Koskinen et al., 2019; Riga et al., 2017), although this was not entirely consistent (Murthy et al., 2019). This pattern was not well supported in the dentate gyrus (Murthy et al., 2019), areas CA2/3 (Ueno et al., 2017), or the whole hippocampus (Gomes et al., 2019; Pesarico et al., 2019; Ueno et al., 2018). An impressive number of studies assessed the effects of fluoxetine treatment on PNNs in the HC, reporting mixed findings with the most robust evidence being a decrease in PNNs on PV cells in area CA1 (Guirado et al., 2014; Karpova et al., 2011; Mukhopadhyay et al., 2021; Umemori et al., 2015), an effect that may not last long-term (Mukhopadhyay et al., 2021; Umemori et al., 2015). Fluoxetine given to adults appears to reduce PV cell and PNN densities in CA3 without changing the percentage of PV cells covered by PNNs (Guirado et al., 2014; Ohira et al., 2013).

Not enough information is available to grasp the effects of stress on PNNs in the BLA. Some studies reported single measures such as the fraction of PV cells surrounded by PNNs without complementary measures such as the overall densities of PV cells and PNNs that would elucidate whether PNNs are reduced specifically on PV cells or globally, or if PV cell numbers are increased without an accompanying increase in PNNs. Many studies reported no or mostly no effect of stressors or enrichment on PNNs coating PV cells in the region (Gildawie et al., 2019; Guadagno et al., 2020; Pesarico et al., 2019; Vazquez-Sanroman et al., 2021). One study found that juvenile-adolescent social isolation reduced the fraction of PV cells staining for PNNs, and that stress increased while enrichment decreased the activity of PNN-coated PV cells in the region (Vazquez-Sanroman et al., 2021). A paper by Umemori and colleagues suggests that PNN coverage of PV and non-PV cells were reduced by perinatal fluoxetine administration to mothers (Umemori et al., 2015). Of interest, Guadagno et al. (2020) recently reported hemisphere-dependent changes in PNNs on BLA PV cells in males but not females subjected to LB/LN.

\subsection{Functional consequences}

Stress during infancy appeared to produce opposite immediate and delayed effects on excitatory inputs to PrL PV cells. In one study, a 2-day LH protocol acutely reduced the amplitudes of miniature excitatory postsynaptic currents (mEPSCs) on PV cells in adolescent males classified as helpless by their behavior (Perova et al., 2015). On the other hand, Wieck et al. (2013) found that MS increased the proportion of adolescents' PV cells expressing the NMDA receptor subunit NR2A. Adolescent social isolation was found to reduce the E/I ratio of PV cells in the dorsomedial PFC (comprising the ACC and PrL) of adult male mice (Bicks et al., 2020). Another study found no effect of maternal restraint 
Table 3

PV neuron alterations in other brain regions of stressed animals.

\begin{tabular}{|c|c|c|c|c|c|c|c|c|c|}
\hline Species & $\begin{array}{l}\text { Age during } \\
\text { manipulation }\end{array}$ & $\begin{array}{l}\text { Age at } \\
\text { measurement }\end{array}$ & Sex & Experimental paradigm & Brain Region & Method & Measure & Outcome & Reference \\
\hline Mouse (C57/BL6) & Adolescent & Adolescent & o & RS 6h/day 3 weeks & $\begin{array}{l}\text { Basolateral } \\
\text { Amygdala }\end{array}$ & $\mathrm{IHC}$ & $\begin{array}{l}\text { Total PV cell number; PV } \\
\text { cellular intensity }\end{array}$ & no change & $\begin{array}{l}\text { [27] Clarke et al. } \\
\text { (2019) }\end{array}$ \\
\hline Rat (Sprague-Dawley) & $\begin{array}{l}\text { Early } \\
\text { postnatal }\end{array}$ & Adolescent & o & $\begin{array}{l}\text { MS 3h/day or early handling } \\
15 \text { min/day from P2-P14 }\end{array}$ & $\begin{array}{l}\text { Basolateral } \\
\text { Amygdala Basal } \\
\text { Nucleus }\end{array}$ & $\mathrm{IHC}$ & PV cell density & no change & $\begin{array}{l}\text { [51] Giachino et al. } \\
\text { (2007) }\end{array}$ \\
\hline Rat (Sprague-Dawley) & $\begin{array}{l}\text { Early } \\
\text { postnatal }\end{array}$ & Adolescent & c & $\begin{array}{l}\text { MS 3h/day or early handling } \\
15 \mathrm{~min} / \text { day from P2-P14 }\end{array}$ & $\begin{array}{l}\text { Basolateral } \\
\text { Amygdala Lateral } \\
\text { Nucleus }\end{array}$ & $\mathrm{IHC}$ & PV cell density & $\begin{array}{l}\text { increased by early } \\
\text { handling and MS }\end{array}$ & $\begin{array}{l}\text { [51] Giachino et al. } \\
\text { (2007) }\end{array}$ \\
\hline Mouse (C57/BL6) & $\begin{array}{l}\text { Early } \\
\text { postnatal }\end{array}$ & $\begin{array}{l}\text { Early postnatal; } \\
\text { juvenile; } \\
\text { adolescent; } \\
\text { adult }\end{array}$ & to & LB/LN 7 days & $\begin{array}{l}\text { Basolateral } \\
\text { Amygdala }\end{array}$ & $\mathrm{IHC}$ & PV cell density & $\begin{array}{l}\text { increased in } \\
\text { juveniles }\end{array}$ & $\begin{array}{l}\text { [118] Nieves et al. } \\
(2020)\end{array}$ \\
\hline Rat (Long-Evans) & $\begin{array}{l}\text { Early } \\
\text { postnatal }\end{array}$ & Early postnatal & đoㅇ & LB/LN P8-P12 & $\begin{array}{l}\text { Anterior/Mid } \\
\text { Basolateral } \\
\text { Amygdala }\end{array}$ & $\mathrm{IHC}$ & $\begin{array}{l}\text { PV cell density; PV stain } \\
\text { intensity }\end{array}$ & no change & $\begin{array}{l}\text { [150] Santiago et al. } \\
\text { (2018) }\end{array}$ \\
\hline Rat (Long-Evans) & $\begin{array}{l}\text { Early } \\
\text { postnatal }\end{array}$ & Early postnatal & to & LB/LN P8-P12 & $\begin{array}{l}\text { Posterior } \\
\text { Basolateral } \\
\text { Amygdala }\end{array}$ & IHC & $\begin{array}{l}\text { PV cell density; PV stain } \\
\text { intensity }\end{array}$ & no change & $\begin{array}{l}\text { [150] Santiago et al. } \\
\text { (2018) }\end{array}$ \\
\hline Rat (Long-Evans) & $\begin{array}{l}\text { Early } \\
\text { postnatal }\end{array}$ & Juvenile & ơ & LB/LN P8-P12 & $\begin{array}{l}\text { Anterior/Mid } \\
\text { Basolateral } \\
\text { Amygdala }\end{array}$ & $\mathrm{IHC}$ & $\begin{array}{l}\text { PV cell density; PV stain } \\
\text { intensity }\end{array}$ & no change & $\begin{array}{l}\text { [150] Santiago et al. } \\
\text { (2018) }\end{array}$ \\
\hline Rat (Long-Evans) & $\begin{array}{l}\text { Early } \\
\text { postnatal }\end{array}$ & Juvenile & to & LB/LN P8-P12 & $\begin{array}{l}\text { Posterior } \\
\text { Basolateral } \\
\text { Amygdala }\end{array}$ & $\mathrm{IHC}$ & $\begin{array}{l}\text { PV cell density; PV stain } \\
\text { intensity }\end{array}$ & no change & $\begin{array}{l}\text { [150] Santiago et al. } \\
\text { (2018) }\end{array}$ \\
\hline Mouse (C57/BL6) & $\begin{array}{l}\text { Adolescent- } \\
\text { adult }\end{array}$ & Adult & o & $\begin{array}{l}\text { CSIS } 7 \text { weeks. After stress, } \\
\text { mice housed individually for } 1 \\
\text { year }\end{array}$ & $\begin{array}{l}\text { Basolateral } \\
\text { Amygdala }\end{array}$ & $\mathrm{IHC}$ & PV cell density & no change & $\begin{array}{l}\text { [179] Wang et al. } \\
\text { (2019) }\end{array}$ \\
\hline Rat (Sprague-Dawley) & $\begin{array}{l}\text { Early } \\
\text { postnatal }\end{array}$ & Juvenile & đof & MS 4h/day 19 days & $\begin{array}{l}\text { Basolateral } \\
\text { Amygdala }\end{array}$ & $\mathrm{IHC}$ & $\begin{array}{l}\text { 8-oxo-dG + fraction of PV } \\
\text { cells; PV + cell 8-oxo-dG } \\
\text { intensity; PV cell number; } \\
\text { PV intensity }\end{array}$ & $\begin{array}{l}\text { increased PV } \\
\text { intensity; 8-oxo-dG } \\
+ \text { fraction increased } \\
\text { in females vs males }\end{array}$ & $\begin{array}{l}\text { [159] Soares et al. } \\
(2020)\end{array}$ \\
\hline Rat (Sprague-Dawley) & Adult & Adult & o & RS: $6 \mathrm{~h} /$ day for 10 days & $\begin{array}{l}\text { Basolateral } \\
\text { Amygdala }\end{array}$ & IHC and WFA stain & $\begin{array}{l}\text { Total PV cell number; Total } \\
\text { PV+/PNN + cell number }\end{array}$ & $\begin{array}{l}\text { increased PV cell } \\
\text { number }\end{array}$ & $\begin{array}{l}\text { [138] Pesarico et al., } \\
2019\end{array}$ \\
\hline Rat (Sprague-Dawley) & $\begin{array}{l}\text { Early } \\
\text { postnatal }\end{array}$ & Juvenile & 6ㅇ & MS 4h/day from P2-P20 & $\begin{array}{l}\text { Basolateral } \\
\text { Amygdala }\end{array}$ & IHC and WFA stain & $\begin{array}{l}\mathrm{PV}+/ \mathrm{PNN}+\text { cell density; PV } \\
\text { cell density; PV + PNN } \\
\text { intensity; PNN + PV } \\
\text { intensity; PV intensity }\end{array}$ & no change & $\begin{array}{l}\text { [52] Gildawie et al. } \\
\text { (2019) }\end{array}$ \\
\hline Rat (Sprague-Dawley) & $\begin{array}{l}\text { Early } \\
\text { postnatal }\end{array}$ & Adolescent & toㅇ & MS 4h/day from P2-P20 & $\begin{array}{l}\text { Basolateral } \\
\text { Amygdala }\end{array}$ & IHC and WFA stain & $\begin{array}{l}\mathrm{PV}+/ \mathrm{PNN}+\text { cell density; PV } \\
\text { cell density; PV + PNN } \\
\text { intensity; PNN + PV } \\
\text { intensity; PV intensity }\end{array}$ & $\begin{array}{l}\text { increased PV cell } \\
\text { density in males }\end{array}$ & $\begin{array}{l}\text { [52] Gildawie et al. } \\
\text { (2019) }\end{array}$ \\
\hline Rat (Sprague-Dawley) & $\begin{array}{l}\text { Early } \\
\text { postnatal }\end{array}$ & Adult & toㅇ & MS 4h/day from P2-P20 & $\begin{array}{l}\text { Basolateral } \\
\text { Amygdala }\end{array}$ & IHC and WFA stain & $\begin{array}{l}\text { PV +/PNN + cell density; PV } \\
\text { cell density; PV + PNN } \\
\text { intensity; PNN + PV } \\
\text { intensity; PV intensity }\end{array}$ & no change & $\begin{array}{l}\text { [52] Gildawie et al. } \\
\text { (2019) }\end{array}$ \\
\hline Rat (Sprague-Dawley) & $\begin{array}{l}\text { Early } \\
\text { postnatal }\end{array}$ & Juvenile & o & $\mathrm{LB} / \mathrm{LN} 9$ days & $\begin{array}{l}\text { Left and Right } \\
\text { Basolateral } \\
\text { Amygdala }\end{array}$ & IHC; WFA stain & $\begin{array}{l}\text { PV cell density; PV+/PNN } \\
\text { + cell density; Fos + } \\
\text { proportion of PV cells; Fos } \\
\text { + proportion of PV+/PNN } \\
+ \text { cells }\end{array}$ & $\begin{array}{l}\text { increased PV }+/ \text { PNN } \\
+ \text { cell density in left } \\
\text { and right BLA, } \\
\text { increased Fos + } \\
\text { proportion of PV } \\
\text { cells in right BLA } \\
\text { only }\end{array}$ & $\begin{array}{l}\text { [62] Guadagno et al. } \\
\text { (2020) }\end{array}$ \\
\hline Rat (Sprague-Dawley) & $\begin{array}{l}\text { Early } \\
\text { postnatal }\end{array}$ & Juvenile & q & $\mathrm{LB} / \mathrm{LN} 9$ days & & IHC; WFA stain & $\begin{array}{l}\text { PV cell density; PV+/PNN } \\
+ \text { cell density; Fos + }\end{array}$ & no change & $\begin{array}{l}\text { [62] Guadagno et al. } \\
\text { (2020) }\end{array}$ \\
\hline
\end{tabular}




\begin{tabular}{|c|c|c|c|c|c|c|c|c|c|}
\hline Species & $\begin{array}{l}\text { Age during } \\
\text { manipulation }\end{array}$ & $\begin{array}{l}\text { Age at } \\
\text { measurement }\end{array}$ & Sex & Experimental paradigm & Brain Region & Method & Measure & Outcome & Reference \\
\hline & & & & & $\begin{array}{l}\text { Left and Right } \\
\text { Basolateral } \\
\text { Amygdala }\end{array}$ & & $\begin{array}{l}\text { proportion of PV cells; Fos } \\
+ \text { proportion of } \mathrm{PV}+/ \mathrm{PNN} \\
+ \text { cells }\end{array}$ & & \\
\hline Rat (Sprague-Dawley) & $\begin{array}{l}\text { Early } \\
\text { postnatal; } \\
\text { juvenile }\end{array}$ & Juvenile & o & $\begin{array}{l}\text { LB/LN } 9 \text { days; fear } \\
\text { conditioning P28-29 }\end{array}$ & $\begin{array}{l}\text { Left and Right } \\
\text { Basolateral } \\
\text { Amygdala }\end{array}$ & IHC; WFA stain & $\begin{array}{l}\text { Fos + proportion of PV cells; } \\
\text { Fos + proportion of PV }+/ \\
\text { PNN + cells }\end{array}$ & $\begin{array}{l}\text { decreased Fos }+ \\
\text { proportion of PV } \\
\text { cells in right BLA }\end{array}$ & $\begin{array}{l}\text { [62] Guadagno et al. } \\
\text { (2020) }\end{array}$ \\
\hline Rat (Sprague-Dawley) & $\begin{array}{l}\text { Early } \\
\text { postnatal; } \\
\text { juvenile }\end{array}$ & Juvenile & q & $\begin{array}{l}\text { LB/LN } 9 \text { days; fear } \\
\text { conditioning P28-29 }\end{array}$ & $\begin{array}{l}\text { Left and Right } \\
\text { Basolateral } \\
\text { Amygdala }\end{array}$ & IHC; WFA stain & $\begin{array}{l}\text { Fos + proportion of PV cells; } \\
\text { Fos + proportion of } \mathrm{PV}+/ \\
\text { PNN + cells }\end{array}$ & no change & $\begin{array}{l}\text { [62] Guadagno et al. } \\
\text { (2020) }\end{array}$ \\
\hline Rat (Sprague-Dawley) & Adolescent & Adult & q & $\begin{array}{l}\text { SI from P21-P42, then } 20 \text { days } \\
\text { of group housing (isolates } \\
\text { together, non-isolates } \\
\text { together). On P62, anxiogen } \\
\text { FG-7142 injection } 2 \mathrm{~h} \text { before } \\
\text { sacrifice to provoke c-Fos } \\
\text { expression in the amygdala }\end{array}$ & $\begin{array}{l}\text { Anterior } \\
\text { Basolateral } \\
\text { Amygdala }\end{array}$ & $\mathrm{IHC}$ & $\begin{array}{l}\text { Total PV cell number; total } \\
\text { PV+/c-Fos + cell number }\end{array}$ & $\begin{array}{l}\text { decreased } \mathrm{PV}+/ \mathrm{c}- \\
\text { Fos }+ \text { cell number }\end{array}$ & $\begin{array}{l}\text { [97] Lukkes et al. } \\
\text { (2012) }\end{array}$ \\
\hline Rat (Sprague-Dawley) & Adolescent & Adult & $\%$ & $\begin{array}{l}\text { SI from P21-P42, then } 20 \text { days } \\
\text { of group housing (isolates } \\
\text { together, non-isolates } \\
\text { together). On P62, anxiogen } \\
\text { FG-7142 injection } 2 \mathrm{~h} \text { before } \\
\text { sacrifice to provoke c-Fos } \\
\text { expression in the amygdala }\end{array}$ & $\begin{array}{l}\text { Posterior } \\
\text { Basolateral } \\
\text { Amygdala }\end{array}$ & $\mathrm{IHC}$ & $\begin{array}{l}\text { Total PV cell number; total } \\
\text { PV+/c-Fos + cell number }\end{array}$ & no change & $\begin{array}{l}\text { [97] Lukkes et al. } \\
\text { (2012) }\end{array}$ \\
\hline Rat (Sprague-Dawley) & Adult & Adult & o & $\begin{array}{l}\text { RS: } 6 \mathrm{~h} / \text { day for } 10 \text { days. Acute } \\
\text { RS } 2 \mathrm{~h} \text { on day } 11 \text { then sacrifice }\end{array}$ & $\begin{array}{l}\text { Basolateral } \\
\text { Amygdala }\end{array}$ & $\mathrm{IHC}$ & $\begin{array}{l}\text { PV cell density; c-Fos + } \\
\text { fraction of PV cells }\end{array}$ & $\begin{array}{l}\text { c-Fos }+ \text { fraction of } \\
\text { PV cells increased by } \\
\text { acute stress and } \\
\text { chronic }+ \text { acute } \\
\text { stress, decreased by } \\
\text { chronic restraint } \\
\text { alone }\end{array}$ & $\begin{array}{l}\text { [143] Reznikov et al. } \\
\text { (2008) }\end{array}$ \\
\hline Rat (Sprague-Dawley) & Juvenile & Adolescent & q & 1 week SI & $\begin{array}{l}\text { Basolateral } \\
\text { Amygdala }\end{array}$ & IHC; WFA stain & $\begin{array}{l}\text { c-Fos + proportion of PV } \\
\text { cells; WFA + proportion of } \\
\text { PV cells; c-Fos + proportion } \\
\text { of WFA + PV cells }\end{array}$ & $\begin{array}{l}\text { decreased WFA }+ \\
\text { proportion; } \\
\text { increased c-Fos }+ \\
\text { proportion of WFA }+ \\
\text { PV cells }\end{array}$ & $\begin{array}{l}{[174]} \\
\text { Vazquez-Sanroman } \\
\text { et al. (2021) }\end{array}$ \\
\hline $\begin{array}{l}\text { Erbin KO Mouse (C57/ } \\
\text { BL6) }\end{array}$ & Adult & Adult & $0^{+}$ & RS $2 \mathrm{~h} /$ day for 3 days & $\begin{array}{l}\text { Basolateral } \\
\text { Amygdala }\end{array}$ & Electrophysiology & $\begin{array}{l}\text { ratio of AMPA:NMDA } \\
\text { currents in PV cells; eIPSC } \\
\text { amplitude in PV neurons; } \\
\text { mEPSC amplitude in PV } \\
\text { neurons; mEPSC frequency } \\
\text { in PV neurons }\end{array}$ & $\begin{array}{l}\text { decreased AMPA: } \\
\text { NMDA ratio and } \\
\text { mEPSC amplitude }\end{array}$ & $\begin{array}{l}\text { [99] Luo et al. } \\
\text { (2020) }\end{array}$ \\
\hline Rat (Wistar) & $\begin{array}{l}\text { Early } \\
\text { postnatal; } \\
\text { adult }\end{array}$ & Adult & o & $\begin{array}{l}\text { Open field stress under bright } \\
\text { light } 15 \mathrm{~min} / \text { day from } \\
\text { P0-P20, then on P90 }\end{array}$ & $\begin{array}{l}\text { Basolateral } \\
\text { Amygdala }\end{array}$ & $\mathrm{IHC}$ & $\mathrm{PV}+/ \mathrm{c}$-Fos + cell density & no change & $\begin{array}{l}\text { [39] Ebertowska } \\
\text { et al. (2020) }\end{array}$ \\
\hline Rat (Sprague-Dawley) & $\begin{array}{l}\text { Juvenile- } \\
\text { Adult }\end{array}$ & Adult & $0^{+}$ & $\begin{array}{l}\text { Forced swim, } 3 \text { 30-min } \\
\text { elevated platform sessions, } 2 \mathrm{~h} \\
\text { RS. } 32 \text { days rest followed by } 4 \\
\text { days of odor exposure } \\
\text { preceding } 45 \mathrm{~s} \text { underwater } \\
\text { restraint trauma. } 4 \text { weeks } \\
\text { later, odor re-exposure then } \\
\text { elevated plus maze before } \\
\text { sacrifice }\end{array}$ & $\begin{array}{l}\text { Basolateral } \\
\text { Amygdala }\end{array}$ & IHC & PV+/c-Fos + cell density & $\begin{array}{l}\text { increased in affected } \\
\text { vs unaffected rats } \\
\text { and control }\end{array}$ & $\begin{array}{l}\text { [142] Regev-Tsur } \\
\text { et al. (2020) }\end{array}$ \\
\hline \multirow[t]{2}{*}{ Rat (Sprague-Dawley) } & Juvenile & Juvenile & $0^{+}$ & RS and LH 2h/day P22-24 & $\begin{array}{l}\text { Basolateral } \\
\text { Amygdala }\end{array}$ & & & no change & $\begin{array}{l}\text { [75] Jiang et al. } \\
\text { (2009) }\end{array}$ \\
\hline & & & & & & & & & continued on next page) \\
\hline
\end{tabular}

of group housing (isolates

G-7142 injection $2 \mathrm{~h}$ before rression in the amygd

using (isolates

to provoke c-Fos

Amygdala

PV cell density; c-Fos

s: WFA + propor

V cells; c-Fos + proport

currents in PV cells; eIPSC

[99] Luo et al.

amplitude in PV neurons

PSC amplitude in PV

RS. 32 days rest followed by

restraint trauma. 4 week

sacrifice 


\begin{tabular}{|c|c|c|c|c|c|c|c|c|c|}
\hline Species & $\begin{array}{l}\text { Age during } \\
\text { manipulation }\end{array}$ & $\begin{array}{l}\text { Age at } \\
\text { measurement }\end{array}$ & Sex & Experimental paradigm & Brain Region & Method & Measure & Outcome & Reference \\
\hline & & & & & & $\begin{array}{l}\text { Electrophysiological } \\
\text { recordings from pyramidal } \\
\text { neurons }\end{array}$ & $\begin{array}{l}\text { Frequency, amplitude, rise } \\
\text { time, and decay time of } \\
\text { sIPSCs }\end{array}$ & & \\
\hline Rat (Sprague-Dawley) & Juvenile & Juvenile & o & RS and LH 2h/day P22-24 & $\begin{array}{l}\text { Basolateral } \\
\text { Amygdala }\end{array}$ & $\begin{array}{l}\text { alpha-methyl-5-HT } \\
\text { application; } \\
\text { electrophysiological } \\
\text { recording from pyramidal } \\
\text { neurons }\end{array}$ & sIPSC frequency & decreased & $\begin{array}{l}\text { [75] Jiang et al. } \\
\text { (2009) }\end{array}$ \\
\hline Rat (Sprague-Dawley) & $\begin{array}{l}\text { Early } \\
\text { postnatal; } \\
\text { adolescent }\end{array}$ & Adolescent & \% & $\begin{array}{l}\text { MS 4h/day from P2-P20; LH } \\
\text { task P41 }\end{array}$ & $\begin{array}{l}\text { Basolateral } \\
\text { Amygdala }\end{array}$ & Western blot & PV protein content & no change & $\begin{array}{l}\text { [97] Lukkes et al. } \\
\text { (2017) }\end{array}$ \\
\hline Rat (Sprague-Dawley) & $\begin{array}{l}\text { Early } \\
\text { postnatal; } \\
\text { adolescent }\end{array}$ & Adolescent & q & $\begin{array}{l}\text { MS 4h/day from P2-P20; LH } \\
\text { task P41; allowed to witness } \\
\text { another rat in task 1d before } \\
\text { they did it. }\end{array}$ & $\begin{array}{l}\text { Basolateral } \\
\text { Amygdala }\end{array}$ & Western blot & PV protein content & decreased & $\begin{array}{l}\text { [97] Lukkes et al. } \\
\text { (2017) }\end{array}$ \\
\hline $\begin{array}{l}\text { PV-Cre Mouse (C57/ } \\
\text { BL6) }\end{array}$ & Adult & Adult & o & $\mathrm{RS} 2 \mathrm{~h} /$ day for 3 days & $\begin{array}{l}\text { Basolateral } \\
\text { Amygdala }\end{array}$ & FACS-qPCR & $\begin{array}{l}\text { PV cell mRNA expression of } \\
\text { fgfr2, fgf13, Nrg1, Narp, } \\
\text { PSD95, Erbin, Erbb2, Erbb4, } \\
\text { GluA1, GluA2 }\end{array}$ & $\begin{array}{l}\text { decreased Erbin } \\
\text { expression }\end{array}$ & $\begin{array}{l}\text { [99] Luo et al. } \\
\text { (2020) }\end{array}$ \\
\hline Rat (Long-Evans) & $\begin{array}{l}\text { Early } \\
\text { postnatal }\end{array}$ & Juvenile & ơ & LB/LN P8-P12 & $\begin{array}{l}\text { Basolateral } \\
\text { Amygdala }\end{array}$ & $\begin{array}{l}\text { EM stains for PV and } \\
\text { excitatory synapse } \\
\text { terminals }\end{array}$ & $\begin{array}{l}\text { Percentage of pyramidal } \\
\text { neuron membrane receiving } \\
\text { contact from PV terminals; } \\
\text { PV terminal number per um } \\
\text { of pyramidal cell } \\
\text { membrane; average length } \\
\text { of PV terminal contacts onto } \\
\text { pyramidal cells }\end{array}$ & decreased (all 3) & $\begin{array}{l}\text { [150] Santiago et al. } \\
\text { (2018) }\end{array}$ \\
\hline Rat (Long-Evans) & $\begin{array}{l}\text { Early } \\
\text { postnatal }\end{array}$ & Juvenile & oㅇ & LB/LN P8-P12 & $\begin{array}{l}\text { Basolateral } \\
\text { Amygdala }\end{array}$ & $\begin{array}{l}\text { EM stains for PV and } \\
\text { excitatory synapse } \\
\text { terminals }\end{array}$ & $\begin{array}{l}\text { Percentage of PV cell } \\
\text { membrane contacted by PV } \\
\text { and excitatory terminals; PV } \\
\text { and excitatory terminal } \\
\text { number/um of PV cell } \\
\text { membrane; excitatory } \\
\text { terminal length onto PV } \\
\text { cells }\end{array}$ & $\begin{array}{l}\text { decreased } \\
\text { percentage of } \\
\text { membrane contact } \\
\text { by PV cells; } \\
\text { decreased PV } \\
\text { terminal number per } \\
\text { um of membrane }\end{array}$ & $\begin{array}{l}\text { [150] Santiago et al. } \\
\text { (2018) }\end{array}$ \\
\hline Rat (Wistar) & $\begin{array}{l}\text { Early } \\
\text { postnatal; } \\
\text { adult }\end{array}$ & Adult & o & $\begin{array}{l}\text { Open field stress under bright } \\
\text { light } 15 \text { min/day from } \\
\text { P0-P20, then on P90 }\end{array}$ & Lateral Amygdala & $\mathrm{IHC}$ & c-Fos $+/ \mathrm{PV}+$ cell density & decreased & $\begin{array}{l}\text { [39] Ebertowska } \\
\text { et al. (2020) }\end{array}$ \\
\hline Rat (Sprague-Dawley) & Adolescent & Adult & \% & $\begin{array}{l}\text { SI from P21-P42, then } 20 \text { days } \\
\text { of group housing (isolates } \\
\text { together, non-isolates } \\
\text { together). On P62, anxiogen } \\
\text { FG-7142 injection } 2 \mathrm{~h} \text { before } \\
\text { sacrifice to provoke c-Fos } \\
\text { expression in the amygdala }\end{array}$ & $\begin{array}{l}\text { Ventrolateral } \\
\text { Lateral Amygdala }\end{array}$ & $\mathrm{IHC}$ & $\begin{array}{l}\text { Total PV cell number; total } \\
\mathrm{PV}+/ \mathrm{c} \text {-Fos + cell number }\end{array}$ & no change & $\begin{array}{l}\text { [97] Lukkes et al. } \\
\text { (2012) }\end{array}$ \\
\hline Rat (Sprague-Dawley) & Adolescent & Adult & \% & $\begin{array}{l}\text { SI from P21-P42, then } 20 \text { days } \\
\text { of group housing (isolates } \\
\text { together, non-isolates } \\
\text { together). On P62, anxiogen } \\
\text { FG-7142 injection } 2 \mathrm{~h} \text { before } \\
\text { sacrifice to provoke c-Fos } \\
\text { expression in the amygdala }\end{array}$ & $\begin{array}{l}\text { Ventromedial } \\
\text { Lateral Amygdala }\end{array}$ & IHC & $\begin{array}{l}\text { Total PV cell number; total } \\
\mathrm{PV}+/ \mathrm{c} \text {-Fos + cell number }\end{array}$ & no change & $\begin{array}{l}\text { [97] Lukkes et al. } \\
\text { (2012) }\end{array}$ \\
\hline Rat (Sprague-Dawley) & Adolescent & Adult & \% & $\begin{array}{l}\text { SI from P21-P42, then } 20 \text { days } \\
\text { of group housing (isolates } \\
\text { together, non-isolates }\end{array}$ & $\begin{array}{l}\text { Dorsolateral } \\
\text { Lateral Amygdala }\end{array}$ & $\mathrm{IHC}$ & $\begin{array}{l}\text { Total PV cell number; total } \\
\mathrm{PV}+/ \mathrm{c} \text {-Fos }+ \text { cell number }\end{array}$ & $\begin{array}{l}\text { decreased } \mathrm{PV}+/ \mathrm{c}- \\
\text { Fos }+ \text { cell number }\end{array}$ & $\begin{array}{l}\text { [97] Lukkes et al. } \\
\text { (2012) }\end{array}$ \\
\hline
\end{tabular}

neuroms

pha-methyl-5-HT

electrophysiologic

ing from pyramid

$\begin{array}{ll}\text { Rat (Sprague-Dawley) } & \begin{array}{l}\text { Early } \\ \text { postnatal; }\end{array} \\ \text { adolescent }\end{array}$

Early

adolescent

PV-Cre Mouse (C57

Early

Juvenile

Basolatera

excitatory synapse

terminals

\section{EM stains for PV an \\ excitatory synapse}

P0-P20, then on P90

SI from P21-P42, then 20 days

of group housing (isolates

of group housing (isolates

G-7142 injection $2 \mathrm{~h}$ befor

expression in the amygda

Lateral Amygdala 


\begin{tabular}{|c|c|c|c|c|c|c|c|c|c|}
\hline Species & $\begin{array}{l}\text { Age during } \\
\text { manipulation }\end{array}$ & $\begin{array}{l}\text { Age at } \\
\text { measurement }\end{array}$ & Sex & Experimental paradigm & Brain Region & Method & Measure & Outcome & Reference \\
\hline & & & & $\begin{array}{l}\text { together). On P62, anxiogen } \\
\text { FG-7142 injection } 2 \mathrm{~h} \text { before } \\
\text { sacrifice to provoke c-Fos } \\
\text { expression in the amygdala }\end{array}$ & & & & & \\
\hline Rat (Sprague-Dawley) & $\begin{array}{l}\text { Juvenile- } \\
\text { Adult }\end{array}$ & Adult & o & $\begin{array}{l}\text { Forced swim, } 3 \text { 30-min } \\
\text { elevated platform sessions, } 2 \mathrm{~h} \\
\text { RS. } 32 \text { days rest followed by } 4 \\
\text { days of odor exposure } \\
\text { preceding } 45 \mathrm{~s} \text { underwater } \\
\text { restraint trauma. } 4 \text { weeks } \\
\text { later, odor re-exposure then } \\
\text { elevated plus maze before } \\
\text { sacrifice }\end{array}$ & Central Amygdala & $\mathrm{IHC}$ & $\mathrm{PV}+/ \mathrm{c}$-Fos + cell density & no change & $\begin{array}{l}\text { [142] Regev-Tsur } \\
\text { et al. (2020) }\end{array}$ \\
\hline Mouse (C57/BL6) & $\begin{array}{l}\text { Adolescent- } \\
\text { adult }\end{array}$ & Adult & o & $\begin{array}{l}\text { CSIS } 7 \text { weeks. After stress, } \\
\text { mice housed individually for } 1 \\
\text { year }\end{array}$ & Central Amygdala & $\mathrm{IHC}$ & PV cell density & no change & $\begin{array}{l}\text { [179] Wang et al. } \\
\text { (2019) }\end{array}$ \\
\hline Rat (Wistar) & $\begin{array}{l}\text { Early } \\
\text { postnatal; } \\
\text { adult }\end{array}$ & Adult & o & $\begin{array}{l}\text { Open field stress under bright } \\
\text { light } 15 \mathrm{~min} / \text { day from } \\
\text { P0-P20, then on P90 }\end{array}$ & $\begin{array}{l}\text { Posterolateral } \\
\text { Cortical Amygdala }\end{array}$ & $\mathrm{IHC}$ & c-Fos $+/ \mathrm{PV}+$ cell density & no change & $\begin{array}{l}\text { [39] Ebertowska } \\
\text { et al. (2020) }\end{array}$ \\
\hline Rat (Sprague-Dawley) & $\begin{array}{l}\text { Early } \\
\text { postnatal; } \\
\text { adolescent }\end{array}$ & Adolescent & \% & $\begin{array}{l}\text { MS 4h/day from P2-P20; LH } \\
\text { tests P40-41 }\end{array}$ & Amygdala & Western blot & PV protein content & $\begin{array}{l}\text { decreased in } \\
\text { anhedonic vs non- } \\
\text { anhedonic }\end{array}$ & $\begin{array}{l}\text { [98] Lukkes et al. } \\
\text { (2018) }\end{array}$ \\
\hline Rat (Sprague-Dawley) & $\begin{array}{l}\text { Juvenile- } \\
\text { adolescent }\end{array}$ & Adolescent & \% & SI 3 weeks & Amygdala & Western blot & $\mathrm{PV}$ protein content & $\begin{array}{l}\text { decreased in } \\
\text { anhedonic vs non- } \\
\text { anhedonic }\end{array}$ & $\begin{array}{l}\text { [98] Lukkes et al. } \\
\text { (2018) }\end{array}$ \\
\hline Mouse (C57/BL6) & $\begin{array}{l}\text { Early } \\
\text { postnatal }\end{array}$ & Adult & 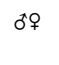 & $\mathrm{LB} / \mathrm{LN}$ & $\begin{array}{l}\text { Orbitofrontal } \\
\text { cortex }\end{array}$ & qPCR & PV mRNA expression & decreased & $\begin{array}{l}\text { [59] Goodwill et al. } \\
\text { (2018) }\end{array}$ \\
\hline Mouse (C57/BL6) & $\begin{array}{l}\text { Early } \\
\text { postnatal }\end{array}$ & Adult & 89 & $\mathrm{LB} / \mathrm{LN}$ & $\begin{array}{l}\text { Ventral } \\
\text { Orbitofrontal } \\
\text { cortex }\end{array}$ & $\mathrm{IHC}$ & PV cell density & decreased in females & $\begin{array}{l}\text { [59] Goodwill et al. } \\
\text { (2018) }\end{array}$ \\
\hline Mouse (C57/BL6) & $\begin{array}{l}\text { Early } \\
\text { postnatal }\end{array}$ & Adult & ơ & $\mathrm{LB} / \mathrm{LN}$ & $\begin{array}{l}\text { Lateral } \\
\text { Orbitofrontal } \\
\text { cortex }\end{array}$ & $\mathrm{IHC}$ & PV cell density & decreased in females & $\begin{array}{l}\text { [59] Goodwill et al. } \\
\text { (2018) }\end{array}$ \\
\hline Rat (Wistar) & Adolescent & Adolescent & o & CMS 4 days & $\begin{array}{l}\text { Dorsolateral } \\
\text { Orbitofrontal } \\
\text { cortex }\end{array}$ & $\mathrm{IHC}$ & PV cell density & no change & $\begin{array}{l}\text { [174] Varga et al. } \\
(2016)\end{array}$ \\
\hline Rat (Wistar) & Adolescent & Adolescent & o & CMS 4 days & $\begin{array}{l}\text { Lateral } \\
\text { Orbitofrontal } \\
\text { cortex }\end{array}$ & $\mathrm{IHC}$ & PV cell density & no change & $\begin{array}{l}\text { [174] Varga et al. } \\
(2016)\end{array}$ \\
\hline Rat (Wistar) & Adolescent & Adolescent & o & CMS 4 days & $\begin{array}{l}\text { Medial } \\
\text { Orbitofrontal } \\
\text { cortex }\end{array}$ & $\mathrm{IHC}$ & PV cell density & no change & $\begin{array}{l}\text { [174] Varga et al. } \\
\text { (2016) }\end{array}$ \\
\hline Rat (Wistar) & Adolescent & Adolescent & o & CMS 4 days & $\begin{array}{l}\text { Ventral } \\
\text { Orbitofrontal } \\
\text { cortex }\end{array}$ & $\mathrm{IHC}$ & PV cell density & no change & $\begin{array}{l}\text { [174] Varga et al. } \\
(2016)\end{array}$ \\
\hline Mouse (C57/BL6) & Adolescent & Adolescent & 89 & RS 2h/day for 7 days & Barrel cortex & $\mathrm{IHC}$ & $\begin{array}{l}\text { PV cell density; c-Fos + } \\
\text { fraction of PV cells }\end{array}$ & $\begin{array}{l}\text { decreased c-Fos }+ \\
\text { fraction of PV cells }\end{array}$ & $\begin{array}{l}\text { [23] Chen et al. } \\
\text { (2018) }\end{array}$ \\
\hline $\begin{array}{l}\text { PV-Cre Mouse (C57/ } \\
\text { BL6) }\end{array}$ & Adolescent & Adolescent & 89 & RS $2 \mathrm{~h} /$ day for 7 days & Barrel cortex & $\begin{array}{l}\text { Optogenetic stimulation of } \\
\text { PV cells; slice } \\
\text { electrophysiology } \\
\text { recording from pyramidal } \\
\text { neurons }\end{array}$ & oIPSC amplitude & no change & $\begin{array}{l}\text { [23] Chen et al. } \\
\text { (2018) }\end{array}$ \\
\hline $\begin{array}{l}\text { PV-Cre Mouse (C57/ } \\
\text { BL6) }\end{array}$ & Adolescent & Adolescent & 80 & $\mathrm{RS} 2 \mathrm{~h} /$ day for 7 days & Barrel cortex & $\begin{array}{l}\text { Current injection to and } \\
\text { electrophysiological } \\
\text { recording from PV cells }\end{array}$ & Firing frequency & $\begin{array}{l}\text { decreased at high } \\
(\geq 300 \mathrm{pA}) \text { but not } \\
\text { low current injection }\end{array}$ & $\begin{array}{l}\text { [23] Chen et al. } \\
\text { (2018) }\end{array}$ \\
\hline
\end{tabular}




\begin{tabular}{|c|c|c|c|c|c|c|c|c|c|}
\hline Species & $\begin{array}{l}\text { Age during } \\
\text { manipulation }\end{array}$ & $\begin{array}{l}\text { Age at } \\
\text { measurement }\end{array}$ & Sex & Experimental paradigm & Brain Region & Method & Measure & Outcome & Reference \\
\hline $\begin{array}{l}\text { PV-Cre Mouse (C57/ } \\
\text { BL6) }\end{array}$ & Adolescent & Adolescent & 6o & $\begin{array}{l}\text { Cre-dependent DREADD } \\
\text { injection to bilateral barrel } \\
\text { cortex; } 7 \text { days of CNO injection } \\
\text { then RS } 2 \mathrm{~h} \text { /day }\end{array}$ & Barrel cortex & $\begin{array}{l}\text { DREADD activation of PV } \\
\text { cells; IHC }\end{array}$ & $\begin{array}{l}\text { Dendritic spine formation } \\
\text { and elimination }\end{array}$ & $\begin{array}{l}\text { decreased } \\
\text { elimination }\end{array}$ & $\begin{array}{l}\text { [23] Chen et al. } \\
\text { (2018) }\end{array}$ \\
\hline Mouse (C57/BL6) & $\begin{array}{l}\text { Early } \\
\text { postnatal }\end{array}$ & Adult & 80 & LB/LN from P4-P11 & $\begin{array}{l}\text { Primary } \\
\text { Somatosensory } \\
\text { cortex }\end{array}$ & qPCR & PV mRNA expression & no change & $\begin{array}{l}\text { [59] Goodwill et al. } \\
\text { (2018) }\end{array}$ \\
\hline $\begin{array}{l}\text { GAD67 }(+/ \text { GFP })(\mathrm{HET}) \\
\text { mouse }\end{array}$ & - & Juvenile & o & $\begin{array}{l}\text { Maternal RS: } 45 \mathrm{~min} 3 \mathrm{x} / \text { day } \\
\text { from E15 to E17.5; BrdU } \\
\text { injection IP once at E12 or E15 }\end{array}$ & $\begin{array}{l}\text { Primary } \\
\text { Somatosensory } \\
\text { cortex - } 10 \text { sagittal } \\
\text { sections }\end{array}$ & $\mathrm{IHC}$ & $\mathrm{PV}+/ \mathrm{GFP}+$ cell density & $\begin{array}{l}\text { decreased in section } \\
4\end{array}$ & $\begin{array}{l}\text { [169] Uchida et al. } \\
\text { (2014) }\end{array}$ \\
\hline Rat (Sprague-Dawley) & Adult & Adult & o & RS $2 \mathrm{~h} /$ day for 3 weeks & $\begin{array}{l}\text { Somatosensory } \\
\text { cortex }\end{array}$ & $\mathrm{IHC}$ & PV cell density & decreased & [90] Lee et al. (2015) \\
\hline Mouse (C57/BL6) & $\begin{array}{l}\text { Juvenile- } \\
\text { adolescent }\end{array}$ & Adolescent & o & SI 5 weeks & $\begin{array}{l}\text { Somatosensory } \\
\text { cortex layers } 2 / 3 \text {, } \\
4 \text {, and } 5 / 6\end{array}$ & IHC and WFA stain & $\begin{array}{l}\text { PV cell density; PNN + } \\
\text { fraction of PV cells; PV } \\
\text { fluorescence intensity; PV } \\
\text { soma area }\end{array}$ & no change & $\begin{array}{l}\text { [170] Ueno et al. } \\
\text { (2017) }\end{array}$ \\
\hline Mouse (C57/BL6) & $\begin{array}{l}\text { Juvenile- } \\
\text { adolescent }\end{array}$ & Adolescent & đ & SI 5 weeks & $\begin{array}{l}\text { Motor cortex } \\
\text { layers } 2 / 3 \text { and } 5 / 6\end{array}$ & IHC and WFA stain & $\begin{array}{l}\text { PV cell density; PNN }+ \\
\text { fraction of PV cells; PV } \\
\text { fluorescence intensity; PV } \\
\text { soma area }\end{array}$ & no change & $\begin{array}{l}\text { [170] Ueno et al. } \\
\text { (2017) }\end{array}$ \\
\hline Mouse (C57/BL6) & $\begin{array}{l}\text { Juvenile; } \\
\text { adult }\end{array}$ & $\begin{array}{l}\text { Adolescent; } \\
\text { adult }\end{array}$ & o & CUS 7 days & $\begin{array}{l}\text { Primary Motor } \\
\text { cortex }\end{array}$ & IHC and WFA stain & $\begin{array}{l}\text { PV cell density; PNN }+ \\
\text { fraction of PV cells; PV }+ \\
\text { fraction of PNNs; PV } \\
\text { fluorescence; PV soma area }\end{array}$ & no change & $\begin{array}{l}\text { [171] Ueno et al. } \\
\text { (2018) }\end{array}$ \\
\hline Rat (Wistar) & Adolescent & Adolescent & o & CMS 4 days & $\begin{array}{l}\text { Primary Motor } \\
\text { cortex }\end{array}$ & IHC & PV cell density & no change & $\begin{array}{l}\text { [174] Varga et al. } \\
(2016)\end{array}$ \\
\hline Mouse (C57/BL6) & Adult & Adult & 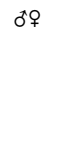 & 3 weeks UCMS & $\begin{array}{l}\text { Nucleus } \\
\text { Accumbens Shell }\end{array}$ & Patch clamp & $\begin{array}{l}100 \mathrm{pA} \text { current injection- } \\
\text { induced PV cell firing } \\
\text { frequency; resting PV cell } \\
\text { membrane potential; PV cell } \\
\text { action potential threshold }\end{array}$ & $\begin{array}{l}\text { increased firing } \\
\text { frequency }\end{array}$ & $\begin{array}{l}\text { [184] Xiao et al. } \\
(2020)\end{array}$ \\
\hline Rat (Sprague-Dawley) & Adult & Adult & $0^{+}$ & RS: $6 \mathrm{~h} /$ day for 10 days & $\begin{array}{l}\text { Thalamic } \\
\text { Reticular Nucleus }\end{array}$ & $\mathrm{IHC}$ & PV stain intensity & increased & $\begin{array}{l}\text { [139] Pesarico et al., } \\
2019\end{array}$ \\
\hline Rat (Sprague-Dawley) & Adult & Adult & o & RS $6 \mathrm{~h} /$ day for 10 days & Habenula & $\mathrm{IHC}$ & PV stain intensity & increased & $\begin{array}{l}\text { [139] Pesarico et al., } \\
2019\end{array}$ \\
\hline Rat (Sprague-Dawley) & $\begin{array}{l}\text { Early } \\
\text { postnatal; } \\
\text { adolescent }\end{array}$ & Adolescent & \% & $\begin{array}{l}\text { MS 4h/day from P2-P20; LH } \\
\text { task P41 }\end{array}$ & $\begin{array}{l}\text { Dorsal Raphe } \\
\text { Nucleus }\end{array}$ & Western blot & PV protein content & decreased & $\begin{array}{l}\text { [97] Lukkes et al. } \\
\text { (2017) }\end{array}$ \\
\hline Rat (Sprague-Dawley) & $\begin{array}{l}\text { Early } \\
\text { postnatal; } \\
\text { adolescent }\end{array}$ & Adolescent & $\%$ & $\begin{array}{l}\text { MS 4h/day from P2-P20; LH } \\
\text { task P41; allowed to witness } \\
\text { another rat in task } 1 \text { day } \\
\text { before they did it. }\end{array}$ & $\begin{array}{l}\text { Dorsal Raphe } \\
\text { Nucleus }\end{array}$ & Western blot & $\mathrm{PV}$ protein content & no change & $\begin{array}{l}\text { [97] Lukkes et al. } \\
\text { (2017) }\end{array}$ \\
\hline Mouse (C57/BL6) & Juvenile-adult & Adolescent & o & SI 5 weeks & $\begin{array}{l}\text { Visual cortex } \\
\text { layers } 2 / 3,4 \text { and } \\
5 / 6\end{array}$ & IHC and WFA stain & $\begin{array}{l}\text { PV cell density; PNN + } \\
\text { fraction of PV cells; PV } \\
\text { fluorescence intensity; PV } \\
\text { soma area }\end{array}$ & $\begin{array}{l}\text { decreased PNN }+ \\
\text { fraction of PV cells in } \\
\text { layer } 2 / 3\end{array}$ & $\begin{array}{l}\text { [170] Ueno et al. } \\
\text { (2017) }\end{array}$ \\
\hline Mouse (C57/BL6) & Juvenile-adult & Adolescent & o & SI 5 weeks & Perirhinal cortex & IHC and WFA stain & $\begin{array}{l}\text { PV cell density; PNN + } \\
\text { fraction of PV cells; PV } \\
\text { fluorescence intensity; PV } \\
\text { soma area }\end{array}$ & $\begin{array}{l}\text { decreased PV } \\
\text { fluorescence } \\
\text { intensity }\end{array}$ & $\begin{array}{l}\text { [170] Ueno et al. } \\
\text { (2017) }\end{array}$ \\
\hline Mouse (C57/BL6) & Juvenile-adult & Adolescent & o & SI 5 weeks & $\begin{array}{l}\text { Dorsintermed } \\
\text { Entorhinal cortex }\end{array}$ & IHC and WFA stain & $\begin{array}{l}\text { PV cell density; PNN + } \\
\text { fraction of PV cells; PV } \\
\text { fluorescence intensity; PV } \\
\text { soma area }\end{array}$ & no change & $\begin{array}{l}\text { [170] Ueno et al. } \\
\text { (2017) }\end{array}$ \\
\hline
\end{tabular}


on offspring c-Fos or NMDA subunit NR1 staining in PV cells (Heslin and Coutellier, 2018) in adulthood. Altogether, these studies differ too widely in timing and type of stressor application and in the outcome assessed to reconcile; in particular, changes in the expression of NMDA receptor subunits on PV neurons do not necessarily indicate electrophysiological changes to PV neurons in the same direction.

Individual studies of PV cell activity, glutamatergic input and oxidative stress markers found no effect of stressors in the IL cortex (Heslin and Coutellier, 2018; Soares et al., 2020). One study of adult rats subjected to CVS found a decrease in PV cells co-expressing glucocorticoid receptors, suggesting that PV cells may be implicated in the loss of a negative feedback loop in the HPA axis in chronic stress (McKlveen et al., 2016).

Studies of the mPFC and whole PFC found increased markers of glutamatergic input onto (Shepard et al., 2016) and activity of (Page et al., 2019) PV cells in rodents stressed as adults, and possible sex differences in intracellular signaling with upregulated ERK activity in stressed females but not males (Shepard and Coutellier, 2017). Conversely, chronic fluoxetine administration to male adults reduced perisomatic PV and synaptophysin puncta on pyramidal neurons, suggesting reduced innervation of these cells (Guirado et al., 2014). A restraint study on adolescents found that 2 days of 6 h' daily restraint increased PV cell dendritic spine formation and elimination rates, whereas 7 days of restraint did not change either metric. This effect was modulated by chemogenetic inhibition and activation of PV cells before daily restraint sessions ( $\mathrm{Ng}$ et al., 2018).

No immediate (Peric et al., 2018) or delayed (Mukhopadhyay et al., 2021) effects of stress have been reported on DG PV cell activity, but early life stress increased PV cell oxidative stress, particularly in females (Schiavone et al., 2013). In a recent study, chronic fluoxetine intake resulted in hyperpolarization and reduced firing frequency of dentate PV cells that may be due to increased potassium channel activity. This effect was eliminated by blockade or PV cell-specific knockout of the inhibitory $5 \mathrm{HT}_{5 \mathrm{~A}}$ receptor (Sagi et al., 2020).

While recent stress increased CA1 sIPSC frequency onto pyramidal neurons in restrained adult male rats (Hu et al., 2010), Riga et al. (2017) found the opposite effect on SDPS-treated male adults 2-3 months after social defeat but with isolation up to that point. On the other hand, one study that exposed mice to a MSEW protocol found no difference in the c-Fos-positive fraction of PV cells in adults, suggesting their activity was unchanged (Murthy et al., 2019). Early life stress further increased PV cell oxidative stress markers in juveniles, particularly females (Soares et al., 2020). A single enrichment study found that acute isoflurane administration at subanesthetic levels increased FosB intensity in PV cells of adults, suggesting more activity (Antila et al., 2017). One study of the dorsal hippocampus found reduced sIPSC frequency on pyramidal neurons in adult rats subjected to SDPS, suggesting decreased PV cell activity, an effect that was eliminated by PNN digestion using chondroitinase ABC a month prior to measurement (Sagi et al., 2020).

Minimal information exists concerning the effects of stress on the generation of theta oscillations by PV neurons. To our knowledge, Hu et al. (2010) is the only report comparing theta power in PV cells of stressed and non-stressed animals; they found increases in relative theta power elicited by the muscarinic receptor agonist carbachol to be unchanged between stressed and unstressed adults, but that increases in theta power due to the cholecystokinin analog CCK8-S were lost in stressed rat CA1 PV neurons. The effects of stress on PV cell theta oscillations, particularly in the HC, represents a gap in our understanding of electrophysiological changes induced by adversity.

Many studies of the BLA described changes in PV cell activity (via cFos expression and electrophysiological parameters) that were stress recency-dependent, however they often conflicted. Stressors produced immediate increases in PV cell activity in some instances (Lukkes et al., 2012; Regev-Tsur et al., 2020; Reznikov et al., 2008) and decreased activity in another account (Guadagno et al., 2020). Similarly, delayed effects of chronic stress produced conflicting effects with some increases 
Animal PV neuron alterations under enrichment paradigms.

\begin{tabular}{|c|c|c|c|c|c|c|c|c|c|}
\hline Species & $\begin{array}{l}\text { Age during } \\
\text { manipulation }\end{array}$ & $\begin{array}{l}\text { Age at } \\
\text { measurement }\end{array}$ & Sex & Experimental paradigm & Brain region & Method & Measure & Outcome & Reference \\
\hline Rat (Sprague-Dawley) & $\begin{array}{l}\text { Early } \\
\text { postnatal; } \\
\text { adolescent }\end{array}$ & Adolescent & o & $\begin{array}{l}\text { MS 4h/day; 500uM TAT2A } \\
\text { microinjection into PFC } \\
\text { every other day from } \\
\text { P31-P39 }\end{array}$ & $\begin{array}{l}\text { Prelimbic } \\
\text { cortex }\end{array}$ & IHC & PV cell density & rescued MS-induced decrease & $\begin{array}{l}\text { [49] Ganguly et al. } \\
\text { (2015) }\end{array}$ \\
\hline Rat (Sprague-Dawley) & $\begin{array}{l}\text { Early } \\
\text { postnatal }\end{array}$ & $\begin{array}{l}\text { Juvenile; } \\
\text { adult }\end{array}$ & o & $\begin{array}{l}\text { Oral FLX } 10 \mathrm{mg} / \mathrm{kg} / \mathrm{d} \text { from } \\
\text { P2-P21 }\end{array}$ & $\begin{array}{l}\text { Prelimbic } \\
\text { cortex }\end{array}$ & IHC; WFA stain & PV cell density & no change & $\begin{array}{l}{[113]} \\
\text { Mukhopadhyay et al. } \\
(2021)\end{array}$ \\
\hline Rat (Wistar) & Adult & Adult & o & EE 2 months & $\begin{array}{l}\text { Prelimbic } \\
\text { cortex }\end{array}$ & $\mathrm{IHC}$ & Total PV cell number & increased & $\begin{array}{l}\text { [149] } \\
\text { Sampedro-Piquero } \\
\text { et al. (2016) }\end{array}$ \\
\hline Rat (Sprague-Dawley) & Adult & Adult & o & $\begin{array}{l}\text { FLX } 10 \mathrm{mg} / \mathrm{kg} \text { twice daily IP } \\
\text { for } 15 \text { days, then brains } \\
\text { collected on day } 35\end{array}$ & $\begin{array}{l}\text { Prelimbic } \\
\text { cortex }\end{array}$ & $\mathrm{IHC}$ & PV cell density & decreased & $\begin{array}{l}\text { [160] Song et al. } \\
(2019)\end{array}$ \\
\hline Rat (Wistar) & Adult & Adult & o & $\begin{array}{l}\text { SI } 21 \text { days; FLX } 15 \mathrm{mg} / \mathrm{kg} / \\
\text { day, CLZ } 20 \mathrm{mg} / \mathrm{kg} / \text { day, or } \\
\text { vehicle IP during stress. }\end{array}$ & $\begin{array}{l}\text { Prelimbic } \\
\text { cortex }\end{array}$ & $\mathrm{IHC}$ & Total PV cell number & $\begin{array}{l}\text { decreased by SI in vehicle but } \\
\text { not CLZ or FLX treatment }\end{array}$ & $\begin{array}{l}\text { [167] Todorovic } \\
\text { et al. (2018) }\end{array}$ \\
\hline Rat (Sprague-Dawley) & Adolescent & Adolescent & o & $\begin{array}{l}\text { R- or S-ketamine } 10 \mathrm{mg} / \mathrm{kg} \\
\text { IP; sacrifice } 30 \mathrm{~min} \text { later }\end{array}$ & $\begin{array}{l}\text { Prelimbic } \\
\text { cortex }\end{array}$ & $\mathrm{IHC}$ & PV cell density & Decreased by S-ketamine & $\begin{array}{l}\text { [186] Yang et al. } \\
\text { (2015) }\end{array}$ \\
\hline Rat (Sprague-Dawley) & $\begin{array}{l}\text { Early } \\
\text { postnatal; } \\
\text { adolescent }\end{array}$ & Adolescent & o & $\begin{array}{l}\text { MS 4h/day P2-P20; IL-10 } \\
\text { intraventricular infusion } \\
\text { from P30-P38. Sacrifice on } \\
\text { P40 }\end{array}$ & $\begin{array}{l}\text { Prelimbic } \\
\text { cortex }\end{array}$ & $\mathrm{IHC}$ & $\begin{array}{l}\text { PV cell density; fraction of PV } \\
\text { cells co-expressing NR2A }\end{array}$ & $\begin{array}{l}\text { density decreased by MS, } \\
\text { rescued by IL-10; fraction } \\
\text { increased by MS, rescued by } \\
\text { IL-10 }\end{array}$ & $\begin{array}{l}\text { [182] Wieck et al. } \\
\text { (2013) }\end{array}$ \\
\hline Rat (Sprague-Dawley) & $\begin{array}{l}\text { Juvenile- } \\
\text { adolescent }\end{array}$ & Adolescent & 809 & EE P21-P36 & $\begin{array}{l}\text { Prelimbic } \\
\text { cortex }\end{array}$ & Western blot & PV protein content & no change & $\begin{array}{l}\text { [35] do Prado et al. } \\
\text { (2015) }\end{array}$ \\
\hline Rat (Sprague-Dawley) & $\begin{array}{l}\text { Early } \\
\text { postnatal- } \\
\text { adolescent }\end{array}$ & Adolescent & 809 & $\begin{array}{l}\text { MS 4h/day from P2-P20; EE } \\
\text { P21-P36 }\end{array}$ & $\begin{array}{l}\text { Prelimbic } \\
\text { cortex }\end{array}$ & Western blot & PV protein content & decreased in males & $\begin{array}{l}\text { [35] do Prado et al. } \\
\text { (2015) }\end{array}$ \\
\hline Rat (Sprague-Dawley) & $\begin{array}{l}\text { Early } \\
\text { postnatal; } \\
\text { adolescent }\end{array}$ & Adolescent & o & $\begin{array}{l}\text { MS 4h/day; 500uM TAT2A } \\
\text { microinjection into PFC } \\
\text { every other day from } \\
\text { P31-P39 }\end{array}$ & $\begin{array}{l}\text { Infralimbic } \\
\text { cortex }\end{array}$ & $\mathrm{IHC}$ & PV cell density & rescued MS-induced decrease & $\begin{array}{l}\text { [49] Ganguly et al. } \\
\text { (2015) }\end{array}$ \\
\hline Rat (Sprague-Dawley) & $\begin{array}{l}\text { Early } \\
\text { postnatal }\end{array}$ & $\begin{array}{l}\text { Juvenile; } \\
\text { adult }\end{array}$ & o & $\begin{array}{l}\text { Oral FLX } 10 \mathrm{mg} / \mathrm{kg} / \mathrm{d} \text { from } \\
\text { P2-P21 }\end{array}$ & $\begin{array}{l}\text { Infralimbic } \\
\text { cortex }\end{array}$ & IHC; WFA stain & PV cell density & no change & $\begin{array}{l}{[113]} \\
\text { Mukhopadhyay et al. } \\
(2021)\end{array}$ \\
\hline Rat (Wistar) & Adult & Adult & o & EE 2 months & $\begin{array}{l}\text { Infralimbic } \\
\text { cortex }\end{array}$ & $\mathrm{IHC}$ & Total PV cell number & no change & $\begin{array}{l}\text { [149] } \\
\text { Sampedro-Piquero } \\
\text { et al. (2016) }\end{array}$ \\
\hline Rat (Sprague-Dawley) & Adult & Adult & o & $\begin{array}{l}\text { FLX } 10 \mathrm{mg} / \mathrm{kg} \text { twice daily IP } \\
\text { for } 15 \text { days, then brains } \\
\text { collected on day } 35\end{array}$ & $\begin{array}{l}\text { Infralimbic } \\
\text { cortex }\end{array}$ & $\mathrm{IHC}$ & PV cell density & decreased & $\begin{array}{l}\text { [160] Song et al. } \\
(2019)\end{array}$ \\
\hline Rat (Wistar) & Adult & Adult & o & $\begin{array}{l}\text { SI } 21 \text { days; FLX } 15 \mathrm{mg} / \mathrm{kg} \text { / } \\
\text { day, CLZ } 20 \mathrm{mg} / \mathrm{kg} / \text { day, or } \\
\text { vehicle IP during stress. }\end{array}$ & $\begin{array}{l}\text { Infralimbic } \\
\text { cortex }\end{array}$ & $\mathrm{IHC}$ & Total PV cell number & $\begin{array}{l}\text { decreased by SI in vehicle but } \\
\text { not CLZ or FLX treatment }\end{array}$ & $\begin{array}{l}\text { [167] Todorovic } \\
\text { et al. (2018) }\end{array}$ \\
\hline Rat (Sprague-Dawley) & Adolescent & Adolescent & o & $\begin{array}{l}\text { R- or S-ketamine } 10 \mathrm{mg} / \mathrm{kg} \\
\text { IP; sacrifice } 30 \text { min later }\end{array}$ & $\begin{array}{l}\text { Infralimbic } \\
\text { cortex }\end{array}$ & IHC & PV cell density & no change & $\begin{array}{l}\text { [186] Yang et al. } \\
(2015)\end{array}$ \\
\hline Mouse (C57/BL6) & Adult & Adult & o & $10 \mathrm{mg} / \mathrm{kg} / \mathrm{d}$ oral FLX 30 days & $\begin{array}{l}\text { Infralimbic } \\
\text { cortex }\end{array}$ & IHC; WFA stain & $\mathrm{PV}+$ fraction of PNN + cells & no change & $\begin{array}{l}\text { [77] Karpova et al. } \\
\text { (2011) }\end{array}$ \\
\hline Rat (Sprague-Dawley) & $\begin{array}{l}\text { Juvenile- } \\
\text { adolescent }\end{array}$ & Adolescent & of & EE P21-P36 & $\begin{array}{l}\text { Infralimbic } \\
\text { cortex }\end{array}$ & Western blot & PV protein content & no change & $\begin{array}{l}\text { [35] do Prado et al. } \\
\text { (2015) }\end{array}$ \\
\hline Rat (Sprague-Dawley) & $\begin{array}{l}\text { Early } \\
\text { postnatal- } \\
\text { adolescent }\end{array}$ & Adolescent & ơ우 & $\begin{array}{l}\text { MS 4h/day from P2-P20; EE } \\
\text { P21-P36 }\end{array}$ & $\begin{array}{l}\text { Infralimbic } \\
\text { cortex }\end{array}$ & Western blot & PV protein content & decreased in males & $\begin{array}{l}\text { [35] do Prado et al. } \\
\text { (2015) }\end{array}$ \\
\hline Rat (Sprague-Dawley) & $\begin{array}{l}\text { Early } \\
\text { postnatal }\end{array}$ & $\begin{array}{l}\text { Juvenile; } \\
\text { adult }\end{array}$ & $0^{\circ}$ & $\begin{array}{l}\text { Oral FLX } 10 \mathrm{mg} / \mathrm{kg} / \mathrm{d} \text { from } \\
\text { P2-P21 }\end{array}$ & $\begin{array}{l}\text { Cingulate } \\
\text { cortex }\end{array}$ & IHC; WFA stain & PV cell density & no change & \\
\hline
\end{tabular}




\begin{tabular}{|c|c|c|c|c|c|c|c|c|c|}
\hline Species & $\begin{array}{l}\text { Age during } \\
\text { manipulation }\end{array}$ & $\begin{array}{l}\text { Age at } \\
\text { measurement }\end{array}$ & Sex & Experimental paradigm & Brain region & Method & Measure & Outcome & Reference \\
\hline & & & & & & & & & $\begin{array}{l}\text { [113] } \\
\text { Mukhopadhyay et al. } \\
\text { (2021) }\end{array}$ \\
\hline Mouse (C57/BL6) & $\begin{array}{l}\text { Adolescent- } \\
\text { adult }\end{array}$ & Adult & o & $\begin{array}{l}\text { Dried bonito broth }(10 \%) \\
\text { intake } 53 \text { days }\end{array}$ & $\begin{array}{l}\text { Medial } \\
\text { Prefrontal } \\
\text { cortex }\end{array}$ & $\mathrm{IHC}$ & PV cell density & increased & $\begin{array}{l}\text { [74] Jargalsaikhan } \\
\text { et al. (2017) }\end{array}$ \\
\hline Rat (Wistar) & Adult & Adult & o & $\begin{array}{l}\mathrm{SI} 21 \text { days; } \mathrm{FLX} 15 \mathrm{mg} / \mathrm{kg} / \\
\text { day, CLZ } 20 \mathrm{mg} / \mathrm{kg} / \mathrm{day} \text {, or } \\
\text { vehicle IP during stress. }\end{array}$ & $\begin{array}{l}\text { Medial } \\
\text { Prefrontal } \\
\text { cortex }\end{array}$ & $\mathrm{IHC}$ & Total PV cell number & $\begin{array}{l}\text { decreased by SI in vehicle but } \\
\text { not CLZ or FLX treatment }\end{array}$ & $\begin{array}{l}\text { [167] Todorovic } \\
\text { et al. (2018) }\end{array}$ \\
\hline Mouse (C57/BL6) & Adult & Adult & o & $\begin{array}{l}\text { FLX } 15 \mathrm{mg} / \mathrm{kg} / \text { day IP for } 3 \\
\text { weeks }\end{array}$ & $\begin{array}{l}\text { Medial Frontal } \\
\text { cortex }\end{array}$ & IHC and WFA stain & $\begin{array}{l}\text { PV cell density; PV+/PNN + } \\
\text { cell density; PNN + fraction of } \\
\text { PV cells }\end{array}$ & decreased (all) & $\begin{array}{l}\text { [125] Ohira et al. } \\
\text { (2013) }\end{array}$ \\
\hline Mouse (GAD-GFP) & Adult & Adult & o & $\begin{array}{l}\text { IP injection of } 20 \mathrm{mg} / \mathrm{kg} \text { FLX } \\
\text { daily for } 2 \text { weeks }\end{array}$ & $\begin{array}{l}\text { Medial } \\
\text { Prefrontal } \\
\text { cortex }\end{array}$ & IHC; WFA stain & $\begin{array}{l}\text { Total PV cell number; total } \\
\text { PV+/PNN + cell number; PV } \\
\text { + fraction of PNN + cells; } \\
\text { perisomatic PV, } \\
\text { synaptophysin, and PV+/ } \\
\text { synaptophysin + puncta } \\
\text { densities on pyramidal cells }\end{array}$ & $\begin{array}{l}\text { decreased } \mathrm{PV}+/ \mathrm{PNN}+\text { cell } \\
\text { number; decreased } \\
\text { perisomatic } \mathrm{PV}+/ \\
\text { synaptophysin + puncta }\end{array}$ & $\begin{array}{l}\text { [63] Guirado et al., } \\
2014\end{array}$ \\
\hline Rat (Wistar) & Juvenile-adult & Adult & 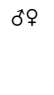 & $\begin{array}{l}\text { SI } 7 \text { weeks with } 5 \mathrm{mg} / \mathrm{kg} / \mathrm{day} \\
\text { oral apocynin }\end{array}$ & $\begin{array}{l}\text { Prefrontal } \\
\text { cortex }\end{array}$ & $\mathrm{IHC}$ & PV immunoreactivity & $\begin{array}{l}\text { decreased by SI alone, no } \\
\text { change in apocynin alone or } \\
\text { SI + apocynin }\end{array}$ & $\begin{array}{l}\text { [151] Schiavone } \\
\text { et al. (2009) }\end{array}$ \\
\hline Rat (Wistar) & Adult & Adult & o & $\begin{array}{l}\text { Ketamine } 10 \mathrm{mg} / \mathrm{kg} \mathrm{IP} \text {; } \\
\text { brains harvested } 0.5 \text { and } 2 \mathrm{~h} \\
\text { after }\end{array}$ & $\begin{array}{l}\text { Prefrontal } \\
\text { cortex }\end{array}$ & $\mathrm{IHC}$ & PV fluorescence intensity & $\begin{array}{l}\text { decreased } 0.5 \mathrm{~h} \text { but not } 2 \mathrm{~h} \\
\text { after ketamine treatment }\end{array}$ & $\begin{array}{l}\text { [190] Zhou et al. } \\
\text { (2014) }\end{array}$ \\
\hline Rat (Wistar) & Adult & Adult & o & $\begin{array}{l}\text { Apocynin } 5 \mathrm{mg} / \mathrm{kg} / \text { day oral } \\
\text { for } 7 \text { days; ketamine } 10 \mathrm{mg} / \\
\mathrm{kg} \text { IP on day } 8 \text {; brains } \\
\text { harvested } 0.5 \text { and } 2 \mathrm{~h} \text { after } \\
\text { ketamine }\end{array}$ & $\begin{array}{l}\text { Prefrontal } \\
\text { cortex }\end{array}$ & $\mathrm{IHC}$ & PV fluorescence intensity & $\begin{array}{l}\text { decreased by ketamine alone } \\
\text { but not apocynin }+ \text { ketamine }\end{array}$ & $\begin{array}{l}\text { [190] Zhou et al. } \\
\text { (2014) }\end{array}$ \\
\hline Rat (Sprague-Dawley) & $\begin{array}{l}\text { Early } \\
\text { postnatal; } \\
\text { adolescent }\end{array}$ & Adolescent & \% & $\begin{array}{l}\text { MS 4h/day; treatment with } \\
\text { COX-2 inhibitor NS-398 } \\
(8 \mathrm{mg} / \mathrm{kg} \text { ) every other day IP } \\
\text { from P30-P38; LH task P41 }\end{array}$ & $\begin{array}{l}\text { Prefrontal } \\
\text { cortex }\end{array}$ & Western blot & PV protein content & increased & $\begin{array}{l}\text { [97] Lukkes et al. } \\
\text { (2017) }\end{array}$ \\
\hline Rat (Sprague-Dawley) & $\begin{array}{l}\text { Early } \\
\text { postnatal; } \\
\text { adolescent }\end{array}$ & Adolescent & \% & $\begin{array}{l}\text { MS 4h/day; treatment with } \\
\text { COX-2 inhibitor NS-398 } \\
\text { ( } 8 \mathrm{mg} / \mathrm{kg} \text { ) every other day IP } \\
\text { from P30-P38; LH P41; } \\
\text { allowed to witness another } \\
\text { rat in task } 1 \text { day before they } \\
\text { did it. }\end{array}$ & $\begin{array}{l}\text { Prefrontal } \\
\text { cortex }\end{array}$ & Western blot & $\mathrm{PV}$ protein content & no change & $\begin{array}{l}\text { [97] Lukkes et al. } \\
\text { (2017) }\end{array}$ \\
\hline Rat (Wistar) & Juvenile-adult & Adult & 우 & $\begin{array}{l}\text { SI } 7 \text { weeks with } 5 \mathrm{mg} / \mathrm{kg} / \mathrm{day} \\
\text { oral apocynin }\end{array}$ & $\begin{array}{l}\text { Prefrontal } \\
\text { cortex }\end{array}$ & Western blot & $\mathrm{PV}$ protein content & $\begin{array}{l}\text { decreased by SI alone, no } \\
\text { change in apocynin alone or } \\
\text { SI + apocynin }\end{array}$ & $\begin{array}{l}\text { [151] Schiavone } \\
\text { et al. (2009) }\end{array}$ \\
\hline Rat (Sprague-Dawley) & Adult & Adult & o & $\begin{array}{l}\text { IFS } 15 \text { min on day } 0 \text {, then EE } \\
2 \text { h/day for } 30 \text { days. Brains } \\
\text { collected on day } 46\end{array}$ & $\begin{array}{l}\text { Prefrontal } \\
\text { cortex }\end{array}$ & Western blot & $\mathrm{PV}$ protein content & $\begin{array}{l}\text { IFS reduced PV protein, EE + } \\
\text { IFS rescued normal amount. } \\
\text { No change for EE alone }\end{array}$ & $\begin{array}{l}\text { [164] Sun et al. } \\
\text { (2016) }\end{array}$ \\
\hline Rat (Wistar) & Adult & Adult & 0 & $\begin{array}{l}\text { Neuregulin- } 1 \text { infusion to } \\
\text { lateral ventricles same time } \\
\text { as ketamine } 10 \mathrm{mg} / \mathrm{kg} \text { IP }\end{array}$ & $\begin{array}{l}\text { Prefrontal } \\
\text { cortex }\end{array}$ & Western blot & PV protein content & $\begin{array}{l}\text { decreased by ketamine but not } \\
\text { ketamine }+ \text { neuregulin- } 1\end{array}$ & $\begin{array}{l}\text { [179] Wang et al. } \\
\text { (2014) }\end{array}$ \\
\hline Rat (Wistar) & Adult & Adult & o & $\begin{array}{l}\text { Ketamine } 10 \mathrm{mg} / \mathrm{kg} \mathrm{IP} \text {; } \\
\text { brains harvested } 0.5 \text { and } 2 \mathrm{~h} \\
\text { after }\end{array}$ & $\begin{array}{l}\text { Prefrontal } \\
\text { cortex }\end{array}$ & Western blot & $\mathrm{PV}$ protein content & $\begin{array}{l}\text { decreased } 0.5 \mathrm{~h} \text { but not } 2 \mathrm{~h} \\
\text { after ketamine treatment }\end{array}$ & $\begin{array}{l}\text { [190] Zhou et al. } \\
\text { (2014) }\end{array}$ \\
\hline \multirow[t]{2}{*}{ Mouse (C57/BL6) } & Adult & Adult & ơ & $\begin{array}{l}10 \mathrm{mg} / \mathrm{kg} \text { ketamine IP; } 1 \\
\text { week rest }\end{array}$ & $\begin{array}{l}\text { Prefrontal } \\
\text { Cortex }\end{array}$ & qPCR & PV mRNA expression & decreased in males & $\begin{array}{l}\text { [127] Okine et al. } \\
(2020)\end{array}$ \\
\hline & & & & & & & & & (continued on next page) \\
\hline
\end{tabular}




\begin{tabular}{|c|c|c|c|c|c|c|c|c|c|}
\hline Species & $\begin{array}{l}\text { Age during } \\
\text { manipulation }\end{array}$ & $\begin{array}{l}\text { Age at } \\
\text { measurement }\end{array}$ & Sex & Experimental paradigm & Brain region & Method & Measure & Outcome & Reference \\
\hline Mouse (C57/BL6) & Adult & Adult & 809 & $\begin{array}{l}10 \mathrm{mg} / \mathrm{kg} \text { ketamine IP; } 1 \\
\text { week rest; } 4 \text { weeks UCMS }\end{array}$ & $\begin{array}{l}\text { Prefrontal } \\
\text { Cortex }\end{array}$ & qPCR & PV mRNA expression & decreased in males & $\begin{array}{l}\text { [127] Okine et al. } \\
(2020)\end{array}$ \\
\hline Rat (Wistar) & Adult & Adult & o & $\begin{array}{l}\text { Lurasidone } 3 \mathrm{mg} / \mathrm{kg} / \text { day } \\
\text { oral for } 5 \text { weeks }\end{array}$ & $\begin{array}{l}\text { Prefrontal } \\
\text { cortex }\end{array}$ & qPCR & PV mRNA expression & no change & $\begin{array}{l}\text { [145] Rossetti et al. } \\
\text { (2018) }\end{array}$ \\
\hline Rat (Wistar) & Adult & Adult & o & $\begin{array}{l}\text { CMS } 7 \text { weeks + lurasidone } 3 \\
\mathrm{mg} / \mathrm{kg} / \text { day oral during last } 5 \\
\text { weeks of CMS }\end{array}$ & $\begin{array}{l}\text { Prefrontal } \\
\text { cortex }\end{array}$ & qPCR & PV mRNA expression & no change & $\begin{array}{l}\text { [145] Rossetti et al. } \\
\text { (2018) }\end{array}$ \\
\hline Mouse (C57/BL6) & Adolescent & Adolescent & 우 & $\begin{array}{l}\text { 10uM ketamine bath } \\
\text { application }\end{array}$ & $\begin{array}{l}\text { Frontal } \\
\text { Association } \\
\text { cortex }\end{array}$ & Electrophysiology & $\begin{array}{l}\text { PV cell firing frequency } 10, \\
30 \text {, and } 50 \text { min after ketamine } \\
\text { infusion }\end{array}$ & $\begin{array}{l}\text { increased after ketamine at } \\
\text { injected currents of } 50,100 \text {, } \\
150,200 \text {, and } 250 \mathrm{pA}\end{array}$ & $\begin{array}{l}{[120] \mathrm{Ng} \text { et al. }} \\
(2018)\end{array}$ \\
\hline $\begin{array}{l}\text { PV-Cre; Ai9-tdTomato } \\
\text { Mice (C57/BL6); } \\
\text { AAV injection of Cre- } \\
\text { GCaMP6f }\end{array}$ & Adolescent & Adolescent & ơ & $\begin{array}{l}8 \mathrm{~h} \mathrm{RS} ; 10 \mathrm{mg} / \mathrm{kg} \text { IP } \\
\text { ketamine at } 4 \text { and } 8 \mathrm{~h} \text { marks }\end{array}$ & $\begin{array}{l}\text { Frontal } \\
\text { Association } \\
\text { cortex layers 2/ } \\
3\end{array}$ & $\begin{array}{l}\text { GCaMP6f signal } \\
\text { recording }\end{array}$ & $\begin{array}{l}\text { PV cell intracellular calcium } \\
\text { (average } \Delta \mathrm{F} / \mathrm{Fo} \text { ) }\end{array}$ & $\begin{array}{l}\text { increased by RS + ketamine vs } \\
\text { RS + saline }\end{array}$ & $\begin{array}{l}\text { [120] Ng et al. } \\
(2018)\end{array}$ \\
\hline Mouse (C57/BL6) & Adolescent & Adolescent & 우 & $\begin{array}{l}10 \mathrm{mg} / \mathrm{kg} \text { IP ketamine or } \\
\text { saline, followed by } 6 \mathrm{~h} \text { RS for } \\
1,2,5 \text {, or } 7 \text { days }\end{array}$ & $\begin{array}{l}\text { Frontal } \\
\text { Association } \\
\text { cortex layers 2/ } \\
3\end{array}$ & $\begin{array}{l}\text { In vivo PV axonal } \\
\text { bouton imaging }\end{array}$ & $\begin{array}{l}\text { PV bouton elimination, } \\
\text { formation, and net change in } \\
\text { PV bouton number }\end{array}$ & $\begin{array}{l}\text { increased elimination at day } 7 \\
\text { RS vs no RS; decreased } \\
\text { formation at day } 5 \text { and day } 7 \\
\text { RS vs RS + ketamine; } \\
\text { decreased net change in PV } \\
\text { bouton number at day } 5 \text { and } 7 \\
\text { RS compared to no RS group. }\end{array}$ & $\begin{array}{l}{[120] \mathrm{Ng} \text { et al. }} \\
(2018)\end{array}$ \\
\hline $\begin{array}{l}\text { PV-Cre; Ai9-tdTomato } \\
\text { Mice (C57/BL6) }\end{array}$ & Adolescent & Adolescent & ơ & $\begin{array}{l}\text { CNO and ketamine } 10 \mathrm{mg} / \mathrm{kg} \\
\text { injection into PV-hM3D or } \\
\text { PV hM4D rats, followed by } \\
6 \mathrm{~h} \mathrm{RS} \text {, for } 2 \text { days }\end{array}$ & $\begin{array}{l}\text { Frontal } \\
\text { Association } \\
\text { cortex layers 2/ } \\
3\end{array}$ & $\begin{array}{l}\text { DREADD activation/ } \\
\text { inhibition of PV cells; } \\
\text { Microscopy }\end{array}$ & $\begin{array}{l}\text { PV cell dendritic spine } \\
\text { elimination rate }\end{array}$ & increased by PV cell inhibition & $\begin{array}{l}{[120] \mathrm{Ng} \text { et al. }} \\
(2018)\end{array}$ \\
\hline $\begin{array}{l}\text { PV-Cre; Ai9-tdTomato } \\
\text { Mice (C57/BL6) }\end{array}$ & Adolescent & Adolescent & 우 & $\begin{array}{l}\mathrm{CNO} \text { and ketamine } 10 \mathrm{mg} / \mathrm{kg} \\
\text { injection into PV-hM3D or } \\
\text { PV hM4D rats, followed by } \\
\text { 6h RS, for } 2 \text { days }\end{array}$ & $\begin{array}{l}\text { Frontal } \\
\text { Association } \\
\text { cortex layers 2/ } \\
3\end{array}$ & $\begin{array}{l}\text { DREADD activation/ } \\
\text { inhibition of PV cells; } \\
\text { Microscopy }\end{array}$ & $\begin{array}{l}\text { PV cell dendritic mushroom, } \\
\text { stubby, and thin spine } \\
\text { elimination rate }\end{array}$ & $\begin{array}{l}\text { increased mushroom spine } \\
\text { elimination in PV-inhibited } \\
\text { mice }\end{array}$ & $\begin{array}{l}{[120] \mathrm{Ng} \text { et al. }} \\
(2018)\end{array}$ \\
\hline Rat (Wistar) & Adult & Adult & o & EE 2 months & $\begin{array}{l}\text { Cingulate } \\
\text { cortex }\end{array}$ & $\mathrm{IHC}$ & Total PV cell number & increased & $\begin{array}{l}\text { [149] } \\
\text { Sampedro-Piquero } \\
\text { et al. (2016) }\end{array}$ \\
\hline Rat (Wistar) & Adult & Adult & o & $\begin{array}{l}\mathrm{SI} 21 \text { days; } \mathrm{FLX} 15 \mathrm{mg} / \mathrm{kg} / \\
\text { day, CLZ } 20 \mathrm{mg} / \mathrm{kg} / \mathrm{day} \text {, or } \\
\text { vehicle IP during stress. }\end{array}$ & $\begin{array}{l}\text { Cingulate } \\
\text { cortex }\end{array}$ & $\mathrm{IHC}$ & Total PV cell number & $\begin{array}{l}\text { decreased by SI, SI + FLX, and } \\
\text { SI + CLZ }\end{array}$ & $\begin{array}{l}\text { [167] Todorovic } \\
\text { et al. (2018) }\end{array}$ \\
\hline Rat (Wistar) & Adult & Adult & o & $\begin{array}{l}\text { SI } 21 \text { days; } \mathrm{FLX} 15 \mathrm{mg} / \mathrm{kg} / \\
\text { day, CLZ } 20 \mathrm{mg} / \mathrm{kg} / \mathrm{day} \text {, or } \\
\text { vehicle IP during stress. }\end{array}$ & $\begin{array}{l}\text { Dorsal } \\
\text { Peduncular } \\
\text { cortex }\end{array}$ & $\mathrm{IHC}$ & Total PV cell number & $\begin{array}{l}\text { decreased by SI in vehicle but } \\
\text { not CLZ or FLX txt; increased } \\
\text { by CLZ alone vs CLZ + SI }\end{array}$ & $\begin{array}{l}\text { [167] Todorovic } \\
\text { et al. (2018) }\end{array}$ \\
\hline $\begin{array}{l}\text { Wnt3a-Cre Mice (C57/ } \\
\text { BL6 * NZB) }\end{array}$ & Not stated & Adolescent & 809 & $\begin{array}{l}\text { EE: running wheel and } \\
\text { Enviro-Dri bedding added } \\
\text { (timeline not stated) }\end{array}$ & Dentate Gyrus & $\mathrm{IHC}$ & PV cell density & no change & $\begin{array}{l}\text { [4] Anstotz et al. } \\
\text { (2018) }\end{array}$ \\
\hline $\begin{array}{l}\text { Tree Shrew (Tupaia } \\
\text { Belangeri) }\end{array}$ & Adult & Adult & o & $\begin{array}{l}5 \text { weeks' daily psychosocial } \\
\text { conflict; FLX ( } 15 \mathrm{mg} / \mathrm{kg} / \\
\text { day) or SLV- } 323(20 \mathrm{mg} / \mathrm{kg} / \\
\text { day) oral treatment daily for } \\
\text { latter } 4 \text { weeks }\end{array}$ & Dentate Gyrus & $\mathrm{IHC}$ & Total PV cell number & $\begin{array}{l}\text { Decreased by stress; rescued } \\
\text { by FLX and by SLV-323 }\end{array}$ & $\begin{array}{l}\text { [31] Czeh et al. } \\
\text { (2005) }\end{array}$ \\
\hline Rat (Wistar) & $\begin{array}{l}\text { Adolescent- } \\
\text { adult }\end{array}$ & Adult & o & $\begin{array}{l}\text { FLX } 15 \mathrm{mg} / \mathrm{kg} / \text { day or CLZ } \\
20 \mathrm{mg} / \mathrm{kg} / \text { day with SI for } 3 \\
\text { weeks }\end{array}$ & Dentate Gyrus & $\mathrm{IHC}$ & Total PV cell number & $\begin{array}{l}\text { decreased by FLX + SI } \\
\text { compared to SI }\end{array}$ & $\begin{array}{l}\text { [44] Filipović et al. } \\
\text { (2017) }\end{array}$ \\
\hline Rat (Wistar) & $\begin{array}{l}\text { Juvenile- } \\
\text { adolescent }\end{array}$ & Adult & o & Physical exercise 40 days & Dentate Gyrus & $\mathrm{IHC}$ & Total PV cell number & no change & $\begin{array}{l}\text { [58] Gomes da Silva } \\
\text { et al., } 2010\end{array}$ \\
\hline Rat (Wistar) & $\begin{array}{l}\text { Adolescent- } \\
\text { adult }\end{array}$ & Adult & o & $\begin{array}{l}\text { CUS } 3 \text { weeks. Anhedonic } \\
\text { subgroup given escitalopram } \\
(5 \mathrm{mg} / \mathrm{kg} / \text { day) or vehicle IP } \\
\text { for } 5 \text { weeks }\end{array}$ & $\begin{array}{l}\text { Dentate gyrus } \\
\text { hilus and } \\
\text { granule cell } \\
\text { layer }\end{array}$ & $\mathrm{IHC}$ & PV cell density & no change & $\begin{array}{l}\text { [69] Holm et al. } \\
\text { (2011) }\end{array}$ \\
\hline
\end{tabular}




\begin{tabular}{|c|c|c|c|c|c|c|c|c|c|}
\hline Species & $\begin{array}{l}\text { Age during } \\
\text { manipulation }\end{array}$ & $\begin{array}{l}\text { Age at } \\
\text { measurement }\end{array}$ & Sex & Experimental paradigm & Brain region & Method & Measure & Outcome & Reference \\
\hline Rat (Long-Evans) & Adult & Adult & o & $\begin{array}{l}\text { Physical exercise } 30 \mathrm{~min} / \text { day } \\
\text { for } 5 \text { weeks }\end{array}$ & Dentate Gyrus & $\mathrm{IHC}$ & Total PV cell number & no change & $\begin{array}{l}\text { [121] Nguyen et al. } \\
\text { (2013) }\end{array}$ \\
\hline Rat (Wistar) & Adult & Adult & o & $\begin{array}{l}\text { SI } 6 \text { weeks with anhedonic } \\
\text { rats given tianeptine } 10 \mathrm{mg} \text { / } \\
\mathrm{kg} / \text { day IP for last } 3 \text { weeks }\end{array}$ & Dentate Gyrus & $\mathrm{IHC}$ & Total PV cell number & $\begin{array}{l}\text { increased by tianeptine }+ \text { SI vs } \\
\text { SI alone }\end{array}$ & $\begin{array}{l}\text { [136] Peric et al. } \\
\text { (2018) }\end{array}$ \\
\hline Rat (Wistar) & Adult & Adult & o & EE 2 months & Dentate Gyrus & $\mathrm{IHC}$ & Total PV cell number & no change & $\begin{array}{l}\text { [149] } \\
\text { Sampedro-Piquero } \\
\text { et al. (2016) }\end{array}$ \\
\hline Rat (Wistar) & Juvenile & Adult & o & EE 40 days & Dentate Gyrus & IHC & PV cell density & no change & $\begin{array}{l}\text { [154] Serra et al. } \\
(2020)\end{array}$ \\
\hline Rat (Wistar) & Juvenile & Adult & o & Exercise 40 days & Dentate Gyrus & IHC & PV cell density & increased & $\begin{array}{l}\text { [154] Serra et al. } \\
(2020)\end{array}$ \\
\hline Rat (Sprague-Dawley) & Adolescent & Adolescent & o & $\begin{array}{l}\text { R- or S-ketamine } 10 \mathrm{mg} / \mathrm{kg} \\
\text { IP; sacrifice } 30 \mathrm{~min} \text { later }\end{array}$ & Dentate Gyrus & $\mathrm{IHC}$ & PV cell density & decreased by S-ketamine & $\begin{array}{l}\text { [186] Yang et al. } \\
\text { (2015) }\end{array}$ \\
\hline Rat (Sprague-Dawley) & $\begin{array}{l}\text { Early } \\
\text { postnatal }\end{array}$ & $\begin{array}{l}\text { Juvenile; } \\
\text { adult }\end{array}$ & o & $\begin{array}{l}\text { Oral FLX } 10 \mathrm{mg} / \mathrm{kg} / \mathrm{d} \text { from } \\
\text { P2-P21 }\end{array}$ & Dentate Gyrus & IHC; WFA stain & $\begin{array}{l}\text { Total PV cell number; PNN + } \\
\text { fraction of PV cells }\end{array}$ & no change & $\begin{array}{l}\text { [113] } \\
\text { Mukhopadhyay et al. } \\
\text { (2021) }\end{array}$ \\
\hline Mouse (C57/BL6) & $\begin{array}{l}\text { Prenatal, } \\
\text { early } \\
\text { postnatal }\end{array}$ & $\begin{array}{l}\text { Early } \\
\text { postnatal; } \\
\text { juvenile }\end{array}$ & 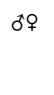 & $\begin{array}{l}\text { Mothers given oral FLX } \\
11.3 \mathrm{mg} / \mathrm{kg} / \mathrm{d} \text { from GD7-P7 }\end{array}$ & Dentate Gyrus & IHC; WHA stain & $\begin{array}{l}\text { Total PV cell number; PV+/ } \\
\text { PNN + cell number; PV } \\
\text { intensity in PV+/PNN + cells }\end{array}$ & no change & $\begin{array}{l}\text { [172] Umemori et al. } \\
\text { (2015) }\end{array}$ \\
\hline $\begin{array}{l}\text { PV-TRAP Mouse (C57/ } \\
\text { BL6) }\end{array}$ & Adult & Adult & 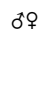 & $\begin{array}{l}18 \text { days oral FLX } 0.167 \mathrm{mg} / \\
\mathrm{ml} \text { in } 1 \% \text { saccharine drinking } \\
\text { water }\end{array}$ & Dentate Gyrus & Electrophysiology & $\begin{array}{l}\text { 5HT-induced change in PV } \\
\text { cell membrane potential }\end{array}$ & decreased (hyperpolarized) & $\begin{array}{l}\text { [146] Sagi et al. } \\
(2020)\end{array}$ \\
\hline $\begin{array}{l}\text { PV-TRAP Mouse (C57/ } \\
\text { BL6) }\end{array}$ & Adult & Adult & ơ & $\begin{array}{l}18 \text { days oral FLX } 0.167 \mathrm{mg} / \\
\text { ml in } 1 \% \text { saccharine drinking } \\
\text { water; } 5 \text { HT5A receptor } \\
\text { antagonist administered }\end{array}$ & Dentate Gyrus & Electrophysiology & $\begin{array}{l}\text { 5HT-induced change in PV } \\
\text { cell membrane potential }\end{array}$ & no change & $\begin{array}{l}\text { [146] Sagi et al. } \\
(2020)\end{array}$ \\
\hline $\begin{array}{l}\text { PV-Cre Mouse (C57/ } \\
\text { BL6) }\end{array}$ & Adult & Adult & ơ우 & $\begin{array}{l}18 \text { days oral FLX } 0.167 \mathrm{mg} \text { / } \\
\text { ml in } 1 \% \text { saccharine drinking } \\
\text { water; } \mathrm{PV} \text { cell-specific } \\
\text { 5HT5A receptor KO }\end{array}$ & Dentate Gyrus & Electrophysiology & $\begin{array}{l}\text { 5HT-induced change in PV } \\
\text { cell membrane potential }\end{array}$ & no change & $\begin{array}{l}\text { [146] Sagi et al. } \\
(2020)\end{array}$ \\
\hline $\begin{array}{l}\text { PV-TRAP Mouse (C57/ } \\
\text { BL6) }\end{array}$ & Adult & Adult & 897 & $\begin{array}{l}18 \text { days oral FLX } 0.167 \mathrm{mg} / \\
\mathrm{ml} \text { in } 1 \% \text { saccharine drinking } \\
\text { water }\end{array}$ & Dentate Gyrus & Electrophysiology & $\begin{array}{l}\text { 5HT-induced PV cell firing } \\
\text { frequency }\end{array}$ & decreased & $\begin{array}{l}\text { [146] Sagi et al. } \\
(2020)\end{array}$ \\
\hline $\begin{array}{l}\text { PV-Cre Mouse (C57/ } \\
\text { BL6) }\end{array}$ & Adult & Adult & ơ우 & $\begin{array}{l}18 \text { days oral FLX } 0.167 \mathrm{mg} \text { / } \\
\text { ml in } 1 \% \text { saccharine drinking } \\
\text { water; PV cell-specific } \\
\text { 5HT5A receptor KO }\end{array}$ & Dentate Gyrus & Electrophysiology & $\begin{array}{l}\text { 5HT-induced PV cell firing } \\
\text { frequency }\end{array}$ & no change & $\begin{array}{l}\text { [146] Sagi et al. } \\
(2020)\end{array}$ \\
\hline $\begin{array}{l}\text { PV-TRAP Mouse (C57/ } \\
\text { BL6) }\end{array}$ & Adult & Adult & 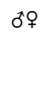 & $\begin{array}{l}18 \text { days oral FLX } 0.167 \mathrm{mg} / \\
\mathrm{ml} \text { in } 1 \% \text { saccharine drinking } \\
\text { water }\end{array}$ & Dentate Gyrus & Electrophysiology & $\begin{array}{l}\text { 5HT-induced PV cell Kv } \\
\text { channel potassium current } \\
\text { amplitude }\end{array}$ & decreased & $\begin{array}{l}\text { [146] Sagi et al. } \\
(2020)\end{array}$ \\
\hline $\begin{array}{l}\text { PV-Cre Mouse (C57/ } \\
\text { BL6) }\end{array}$ & Adult & Adult & 6oㅇ & $\begin{array}{l}18 \text { days oral FLX } 0.167 \mathrm{mg} \text { / } \\
\text { ml in } 1 \% \text { saccharine drinking } \\
\text { water; PV cell-specific } \\
\text { 5HT5A receptor KO }\end{array}$ & Dentate Gyrus & Electrophysiology & $\begin{array}{l}\text { 5HT-induced PV cell Kv } \\
\text { channel potassium current } \\
\text { amplitude }\end{array}$ & no change & $\begin{array}{l}\text { [146] Sagi et al. } \\
(2020)\end{array}$ \\
\hline $\begin{array}{l}\text { PV-TRAP Mouse (C57/ } \\
\text { BL6) }\end{array}$ & Adult & Adult & 80 & $\begin{array}{l}18 \text { days oral FLX } 0.167 \mathrm{mg} / \\
\mathrm{ml} \text { in } 1 \% \text { saccharine drinking } \\
\text { water }\end{array}$ & Dentate Gyrus & Electrophysiology & $\begin{array}{l}\text { Change in PV cell Kv channel } \\
\text { potassium maximum current } \\
\text { amplitude after } 200 \mathrm{nM} \text { PMA } \\
\text { or } 200 \mathrm{nM} \text { PMA+30uM 5HT } \\
\text { bath }\end{array}$ & $\begin{array}{l}\text { decreased in FLX-treated but } \\
\text { not vehicle-treated mice }\end{array}$ & $\begin{array}{l}\text { [146] Sagi et al. } \\
(2020)\end{array}$ \\
\hline $\begin{array}{l}\text { Tree Shrew (Tupaia } \\
\text { Belangeri) }\end{array}$ & Adult & Adult & o & $\begin{array}{l}5 \text { weeks' daily psychosocial } \\
\text { conflict; FLX ( } 15 \mathrm{mg} / \mathrm{kg} / \\
\text { day) or SLV-323 }(20 \mathrm{mg} / \mathrm{kg} / \\
\text { day) oral treatment daily for } \\
\text { latter } 4 \text { weeks }\end{array}$ & CA1 & $\mathrm{IHC}$ & Total PV cell number & no change & $\begin{array}{l}\text { [31] Czeh et al. } \\
\text { (2005) }\end{array}$ \\
\hline
\end{tabular}




\begin{tabular}{|c|c|c|c|c|c|c|c|c|c|}
\hline Species & $\begin{array}{l}\text { Age during } \\
\text { manipulation }\end{array}$ & $\begin{array}{l}\text { Age at } \\
\text { measurement }\end{array}$ & Sex & Experimental paradigm & Brain region & Method & Measure & Outcome & Reference \\
\hline Rat (Wistar) & $\begin{array}{l}\text { Adolescent- } \\
\text { adult }\end{array}$ & Adult & o & $\begin{array}{l}\mathrm{FLX} 15 \mathrm{mg} / \mathrm{kg} / \text { day or CLZ } \\
20 \mathrm{mg} / \mathrm{kg} / \text { day with SI for } 3 \\
\text { weeks }\end{array}$ & CA1 & $\mathrm{IHC}$ & Total PV cell number & $\begin{array}{l}\text { increased by FLX vs vehicle; } \\
\text { decreased by FLX + SI, CLZ, } \\
\text { and CLZ + SI vs vehicle; } \\
\text { decreased by FLX + SI vs FLX }\end{array}$ & $\begin{array}{l}\text { [44] Filipović et al. } \\
\text { (2017) }\end{array}$ \\
\hline Rat (Wistar) & $\begin{array}{l}\text { Juvenile- } \\
\text { adolescent }\end{array}$ & Adult & $0^{\circ}$ & Physical exercise 40 days & CA1 & $\mathrm{IHC}$ & Total PV cell number & increased & $\begin{array}{l}\text { [58] Gomes da Silva } \\
\text { et al., } 2010\end{array}$ \\
\hline Rat (Long-Evans) & Adult & Adult & o & $\begin{array}{l}\text { Physical exercise } 30 \mathrm{~min} / \text { day } \\
\text { for } 5 \text { weeks }\end{array}$ & CA1 & $\mathrm{IHC}$ & Total PV cell number & increased & $\begin{array}{l}\text { [121] Nguyen et al. } \\
\text { (2013) }\end{array}$ \\
\hline Rat (Wistar) & Adult & Adult & o & $\begin{array}{l}\text { SI } 6 \text { weeks with anhedonic } \\
\text { rats given tianeptine } 10 \mathrm{mg} \text { / } \\
\mathrm{kg} / \text { day IP for last } 3 \text { weeks }\end{array}$ & CA1 & $\mathrm{IHC}$ & Total PV cell number & $\begin{array}{l}\text { increased by tianeptine and } \\
\text { tianeptine }+ \text { SI vs their vehicle } \\
\text { controls }\end{array}$ & $\begin{array}{l}\text { [136] Peric et al. } \\
\text { (2018) }\end{array}$ \\
\hline Rat (Wistar) & Adult & Adult & $0^{\circ}$ & EE 2 months & CA1 & $\mathrm{IHC}$ & Total PV cell number & no change & $\begin{array}{l}\text { [149] } \\
\text { Sampedro-Piquero } \\
\text { et al. (2016) }\end{array}$ \\
\hline Rat (Wistar) & Juvenile & Adult & $0^{*}$ & EE 40 days & CA1 & $\mathrm{IHC}$ & PV cell density & no change & $\begin{array}{l}\text { [154] Serra et al. } \\
(2020)\end{array}$ \\
\hline Rat (Wistar) & Juvenile & Adult & $0^{*}$ & Exercise 40 days & CA1 & $\mathrm{IHC}$ & PV cell density & no change & $\begin{array}{l}\text { [154] Serra et al. } \\
(2020)\end{array}$ \\
\hline Rat (Sprague-Dawley) & Adolescent & Adolescent & $0^{\circ}$ & $\begin{array}{l}\text { R- or S-ketamine } 10 \mathrm{mg} / \mathrm{kg} \\
\text { IP; sacrifice } 30 \text { min later }\end{array}$ & CA1 & $\mathrm{IHC}$ & PV cell density & no change & $\begin{array}{l}\text { [186] Yang et al. } \\
\text { (2015) }\end{array}$ \\
\hline Mouse (GAD-GFP) & Adult & Adult & o & $\begin{array}{l}\text { IP injection of } 20 \mathrm{mg} / \mathrm{kg} \text { FLX } \\
\text { daily for } 2 \text { weeks }\end{array}$ & CA1 & IHC; WFA stain & $\begin{array}{l}\text { Total PV cell number; total } \\
\text { PV +/PNN + cell number; PV } \\
+ \text { fraction of PNN }+ \text { cells }\end{array}$ & decreased (all) & $\begin{array}{l}\text { [63] Guirado et al., } \\
2014\end{array}$ \\
\hline Mouse (C57/BL6) & Adult & Adult & $0^{*}$ & $10 \mathrm{mg} / \mathrm{kg} / \mathrm{d}$ oral FLX 30 days & CA1 & IHC; WFA stain & $\mathrm{PV}+$ fraction of PNN + cells & decreased & $\begin{array}{l}\text { [77] Karpova et al. } \\
2011\end{array}$ \\
\hline Rat (Sprague-Dawley) & $\begin{array}{l}\text { Early } \\
\text { postnatal }\end{array}$ & $\begin{array}{l}\text { Juvenile; } \\
\text { adult }\end{array}$ & $0^{*}$ & $\begin{array}{l}\text { Oral FLX } 10 \mathrm{mg} / \mathrm{kg} / \mathrm{d} \text { from } \\
\text { P2-P21 }\end{array}$ & CA1 & IHC; WFA stain & $\begin{array}{l}\text { PNN + fraction of PV cells; } \\
\text { total PV cell number }\end{array}$ & decreased fraction in juveniles & $\begin{array}{l}\text { [113] } \\
\text { Mukhopadhyay et al. } \\
\text { (2021) }\end{array}$ \\
\hline Mouse (C57/BL6) & $\begin{array}{l}\text { Prenatal, } \\
\text { early } \\
\text { postnatal }\end{array}$ & $\begin{array}{l}\text { Early } \\
\text { postnatal; } \\
\text { juvenile }\end{array}$ & 89 & $\begin{array}{l}\text { Mothers given oral FLX } \\
11.3 \mathrm{mg} / \mathrm{kg} / \mathrm{d} \text { from GD7-P7 }\end{array}$ & CA1 & IHC; WHA stain & $\begin{array}{l}\text { Total PV cell number; PV+/ } \\
\text { PNN + cell number; PV } \\
\text { intensity in PV+/PNN + cells }\end{array}$ & no change & $\begin{array}{l}\text { [172] Umemori et al. } \\
\text { (2015) }\end{array}$ \\
\hline Rat (Wistar) & Juvenile-adult & Adult & o & $\begin{array}{l}8 \text { weeks SI starting at P21, } \\
\text { followed by } 3 \text { weeks re- } \\
\text { isolation or pair housing and } \\
\text { oral FLX } 6 \mathrm{mg} / \mathrm{kg} / \mathrm{d} \text { or } \\
\text { vehicle }\end{array}$ & CA1 & $\mathrm{IHC}$ & $\mathrm{PV}+/ \mathrm{PNN}+$ cell number & $\begin{array}{l}\text { decreased by FLX overall (net } \\
\text { effect of re-isolates and pair } \\
\text { housing groups combined) }\end{array}$ & $\begin{array}{l}\text { [109] Mikics et al. } \\
\text { (2018) }\end{array}$ \\
\hline Mouse (C57/BL6) & Adult & Adult & $0^{\circ}$ & $\begin{array}{l}\text { Isoflurane anaesthesia } \\
30 \mathrm{~min}\end{array}$ & CA1 & $\mathrm{IHC}$ & FosB intensity in PV + cells & increased & $\begin{array}{l}\text { [5] Antila et al. } \\
\text { (2017) }\end{array}$ \\
\hline $\begin{array}{l}\text { Tree Shrew (Tupaia } \\
\text { Belangeri) }\end{array}$ & Adult & Adult & o & $\begin{array}{l}5 \text { weeks' daily psychosocial } \\
\text { conflict; FLX }(15 \mathrm{mg} / \mathrm{kg} / \\
\text { day) or SLV- } 323(20 \mathrm{mg} / \mathrm{kg} \text { / } \\
\text { day) oral treatment daily for } \\
\text { latter } 4 \text { weeks }\end{array}$ & CA2 & $\mathrm{IHC}$ & Total PV cell number & $\begin{array}{l}\text { Decreased by stress; rescued } \\
\text { by SLV- } 323\end{array}$ & $\begin{array}{l}\text { [31] Czeh et al. } \\
\text { (2005) }\end{array}$ \\
\hline Rat (Wistar) & $\begin{array}{l}\text { Adolescent- } \\
\text { adult }\end{array}$ & Adult & $0^{\circ}$ & $\begin{array}{l}\text { FLX } 15 \mathrm{mg} / \mathrm{kg} / \text { day or CLZ } \\
20 \mathrm{mg} / \mathrm{kg} / \text { day with SI for } 3 \\
\text { weeks }\end{array}$ & CA2 & $\mathrm{IHC}$ & Total PV cell number & $\begin{array}{l}\text { increased by FLX + SI and } \\
\text { CLZ + SI vs SI alone }\end{array}$ & $\begin{array}{l}\text { [44] Filipović et al. } \\
\text { (2017) }\end{array}$ \\
\hline Rat (Wistar) & Adult & Adult & o & $\begin{array}{l}\text { SI } 6 \text { weeks with anhedonic } \\
\text { rats given tianeptine } 10 \mathrm{mg} \text { / } \\
\mathrm{kg} / \text { day IP for last } 3 \text { weeks }\end{array}$ & CA2 & $\mathrm{IHC}$ & Total PV cell number & $\begin{array}{l}\text { increased by tianeptine and } \\
\text { tianeptine }+ \text { SI vs their vehicle } \\
\text { controls }\end{array}$ & $\begin{array}{l}\text { [136] Peric et al. } \\
\text { (2018) }\end{array}$ \\
\hline Rat (Wistar) & $\begin{array}{l}\text { Juvenile- } \\
\text { adolescent }\end{array}$ & Adult & o & Physical exercise 40 days & $\mathrm{CA} 2 / 3$ & $\mathrm{IHC}$ & Total PV cell number & increased & $\begin{array}{l}\text { [58] Gomes da Silva } \\
\text { et al., } 2010\end{array}$ \\
\hline Rat (Long-Evans) & Adult & Adult & o & $\begin{array}{l}\text { Physical exercise } 30 \mathrm{~min} / \text { day } \\
\text { for } 5 \text { weeks }\end{array}$ & $\mathrm{CA} 2 / 3$ & IHC & Total PV cell number & increased & $\begin{array}{l}\text { [121] Nguyen et al. } \\
\text { (2013) }\end{array}$ \\
\hline \multirow[t]{2}{*}{ Rat (Wistar) } & Juvenile & Adult & o & EE 40 days & $\mathrm{CA} 2 / 3$ & $\mathrm{IHC}$ & PV cell density & no change & $\begin{array}{l}\text { [154] Serra et al. } \\
(2020)\end{array}$ \\
\hline & & & & & & & & & (continued on next page) \\
\hline
\end{tabular}




\begin{tabular}{|c|c|c|c|c|c|c|c|c|c|}
\hline Species & $\begin{array}{l}\text { Age during } \\
\text { manipulation }\end{array}$ & $\begin{array}{l}\text { Age at } \\
\text { measurement }\end{array}$ & Sex & Experimental paradigm & Brain region & Method & Measure & Outcome & Reference \\
\hline Rat (Wistar) & Juvenile & Adult & o & Exercise 40 days & $\mathrm{CA} 2 / 3$ & IHC & PV cell density & increased & $\begin{array}{l}\text { [154] Serra et al. } \\
(2020)\end{array}$ \\
\hline $\begin{array}{l}\text { Tree Shrew (Tupaia } \\
\text { Belangeri) }\end{array}$ & Adult & Adult & o & $\begin{array}{l}5 \text { weeks' daily psychosocial } \\
\text { conflict; FLX ( } 15 \mathrm{mg} / \mathrm{kg} / \\
\text { day) or SLV-323 }(20 \mathrm{mg} / \mathrm{kg} \text { / } \\
\text { day) oral treatment daily for } \\
\text { latter } 4 \text { weeks }\end{array}$ & CA3 & $\mathrm{IHC}$ & Total PV cell number & $\begin{array}{l}\text { Decreased by stress; rescued } \\
\text { by SLV-323 }\end{array}$ & $\begin{array}{l}\text { [31] Czeh et al. } \\
(2005)\end{array}$ \\
\hline PV-Cre mice & Adult & Adult & o & $\mathrm{EE}$ & Dorsal CA3b & IHC & Total PV cell number & no change & $\begin{array}{l}\text { [36] Donato et al. } \\
\text { (2013) }\end{array}$ \\
\hline Rat (Wistar) & $\begin{array}{l}\text { Adolescent- } \\
\text { adult }\end{array}$ & Adult & o & $\begin{array}{l}\text { FLX } 15 \mathrm{mg} / \mathrm{kg} / \text { day or CLZ } \\
20 \mathrm{mg} / \mathrm{kg} / \text { day with SI for } 3 \\
\text { weeks }\end{array}$ & CA3 & $\mathrm{IHC}$ & Total PV cell number & $\begin{array}{l}\text { increased by FLX }+ \text { SI and } \\
\text { CLZ + SI vs SI alone }\end{array}$ & $\begin{array}{l}\text { [44] Filipović et al. } \\
\text { (2017) }\end{array}$ \\
\hline Mouse (C57/BL6) & Adult & Adult & o & $\begin{array}{l}\text { FLX } 10 \mathrm{mg} / \mathrm{kg} / \text { day SC for } 21 \\
\text { days starting at P90 }\end{array}$ & CA3 & $\mathrm{IHC}$ & Total PV cell number & no change & $\begin{array}{l}\text { [56] Godavarthi } \\
\text { et al. (2014) }\end{array}$ \\
\hline Rat (Wistar) & Adult & Adult & o & $\begin{array}{l}\text { SI } 6 \text { weeks with anhedonic } \\
\text { rats given tianeptine } 10 \mathrm{mg} \text { / } \\
\mathrm{kg} / \text { day IP for last } 3 \text { weeks }\end{array}$ & CA3 & $\mathrm{IHC}$ & Total PV cell number & $\begin{array}{l}\text { increased by tianeptine and } \\
\text { tianeptine }+ \text { SI vs their vehicle } \\
\text { controls }\end{array}$ & $\begin{array}{l}\text { [136] Peric et al. } \\
\text { (2018) }\end{array}$ \\
\hline Rat (Wistar) & Adult & Adult & o & EE 2 months & CA3 & $\mathrm{IHC}$ & Total PV cell number & no change & $\begin{array}{l}\text { [149] } \\
\text { Sampedro-Piquero } \\
\text { et al. (2016) }\end{array}$ \\
\hline Rat (Sprague-Dawley) & Adolescent & Adolescent & o & $\begin{array}{l}\text { R- or S-ketamine } 10 \mathrm{mg} / \mathrm{kg} \\
\text { IP; sacrifice } 30 \mathrm{~min} \text { later }\end{array}$ & CA3 & $\mathrm{IHC}$ & PV cell density & no change & $\begin{array}{l}\text { [186] Yang et al. } \\
\text { (2015) }\end{array}$ \\
\hline Rat (Sprague-Dawley) & $\begin{array}{l}\text { Early } \\
\text { postnatal }\end{array}$ & $\begin{array}{l}\text { Juvenile; } \\
\text { adult }\end{array}$ & o & $\begin{array}{l}\text { Oral FLX } 10 \mathrm{mg} / \mathrm{kg} / \mathrm{d} \text { from } \\
\text { P2-P21 }\end{array}$ & CA3 & IHC; WFA stain & $\begin{array}{l}\text { Total PV cell number; PNN + } \\
\text { fraction of PV cells }\end{array}$ & decreased fraction in juveniles & $\begin{array}{l}\text { [113] } \\
\text { Mukhopadhyay et al. } \\
\text { (2021) }\end{array}$ \\
\hline Mouse (C57/BL6) & Adult & Adult & o & $\begin{array}{l}\text { FLX } 15 \mathrm{mg} / \mathrm{kg} / \text { day IP for } 3 \\
\text { weeks }\end{array}$ & CA3 & IHC; WFA stain & $\begin{array}{l}\text { PV cell density; PV+/PNN + } \\
\text { cell density; PNN + fraction of } \\
\text { PV cells }\end{array}$ & $\begin{array}{l}\text { decreased PV cell density and } \\
\mathrm{PV}+/ \mathrm{PNN}+\text { cell density }\end{array}$ & $\begin{array}{l}\text { [125] Ohira et al. } \\
\text { (2013) }\end{array}$ \\
\hline PV-Cre mice & Adult & Adult & o & $\mathrm{EE}$ & Dorsal CA3b & $\mathrm{IHC}$ & $\begin{array}{l}\text { fraction of PV cells expressing } \\
\text { low amounts of PV }\end{array}$ & $\begin{array}{l}\text { increased in basket cells and } \\
\text { PV cells overall (not } \\
\text { chandelier cells) }\end{array}$ & $\begin{array}{l}\text { [36] Donato et al. } \\
\text { (2013) }\end{array}$ \\
\hline PV-Cre mice & Adult & Adult & o & $\mathrm{EE}$ & Dorsal CA3b & $\mathrm{IHC}$ & $\begin{array}{l}\text { Inhibitory puncta densities } \\
\text { onto PV dendrites }\end{array}$ & increased & $\begin{array}{l}\text { [36] Donato et al. } \\
\text { (2013) }\end{array}$ \\
\hline PV-Cre mice & Adult & Adult & o & $\mathrm{EE}$ & Dorsal CA3b & $\begin{array}{l}\text { Chemogenetic } \\
\text { activation of PV cells; } \\
\text { IHC }\end{array}$ & $\begin{array}{l}\text { fraction of PV cells expressing } \\
\text { high amounts of PV }\end{array}$ & increased & $\begin{array}{l}\text { [36] Donato et al. } \\
\text { (2013) }\end{array}$ \\
\hline Rat (Wistar) & Juvenile & Adult & o & EE 40 days & Subiculum & IHC & PV cell density & no change & $\begin{array}{l}\text { [154] Serra et al. } \\
(2020)\end{array}$ \\
\hline Rat (Wistar) & Juvenile & Adult & o & Exercise 40 days & Subiculum & $\mathrm{IHC}$ & PV cell density & increased & $\begin{array}{l}\text { [154] Serra et al. } \\
(2020)\end{array}$ \\
\hline Rat (Wistar) & Juvenile & Adult & o & EE 40 days & Hilus & IHC & PV cell density & no change & $\begin{array}{l}\text { [154] Serra et al. } \\
(2020)\end{array}$ \\
\hline Rat (Wistar) & Juvenile & Adult & o & Exercise 40 days & Hilus & $\mathrm{IHC}$ & PV cell density & no change & $\begin{array}{l}\text { [154] Serra et al. } \\
(2020)\end{array}$ \\
\hline $\begin{array}{l}\text { PV-TRAP Mouse (C57/ } \\
\text { BL6) }\end{array}$ & Adult & Adult & 우 & $\begin{array}{l}18 \text { days oral FLX } 0.167 \mathrm{mg} / \\
\text { ml in } 1 \% \text { saccharine drinking } \\
\text { water }\end{array}$ & $\begin{array}{l}\text { Subgranular } \\
\text { zone }\end{array}$ & $\mathrm{IHC}$ & $5 \mathrm{HT} 5 \mathrm{~A}+$ fraction of PV cells & no change & $\begin{array}{l}\text { [146] Sagi et al. } \\
(2020)\end{array}$ \\
\hline $\begin{array}{l}\text { PV-TRAP Mouse (C57/ } \\
\text { BL6) }\end{array}$ & Adult & Adult & 609 & $\begin{array}{l}18 \text { days oral FLX } 0.167 \mathrm{mg} / \\
\text { ml in } 1 \% \text { saccharine drinking } \\
\text { water }\end{array}$ & $\begin{array}{l}\text { Subgranular } \\
\text { zone }\end{array}$ & $\mathrm{IHC}$ & pKv3.1b + fraction of PV cells & increased & $\begin{array}{l}\text { [146] Sagi et al. } \\
(2020)\end{array}$ \\
\hline $\begin{array}{l}\text { PV-Cre Mouse (C57/ } \\
\text { BL6) }\end{array}$ & Adult & Adult & 우 & $\begin{array}{l}18 \text { days oral FLX } 0.167 \mathrm{mg} / \\
\text { ml in } 1 \% \text { saccharine drinking } \\
\text { water; PV cell-specific } \\
\text { 5HT5A receptor KO }\end{array}$ & $\begin{array}{l}\text { Subgranular } \\
\text { zone }\end{array}$ & $\mathrm{IHC}$ & $\mathrm{pKv} 3.1 \mathrm{~b}+$ fraction of PV cells & no change & $\begin{array}{l}\text { [146] Sagi et al. } \\
(2020)\end{array}$ \\
\hline Mouse (C57/BL6) & & Adult & o & & Hippocampus & $\mathrm{IHC}$ & PV cell density & increased & \\
\hline
\end{tabular}




\begin{tabular}{|c|c|c|c|c|c|c|c|c|c|}
\hline Species & $\begin{array}{l}\text { Age during } \\
\text { manipulation }\end{array}$ & $\begin{array}{l}\text { Age at } \\
\text { measurement }\end{array}$ & Sex & Experimental paradigm & Brain region & Method & Measure & Outcome & Reference \\
\hline & $\begin{array}{l}\text { Adolescent- } \\
\text { adult }\end{array}$ & & & $\begin{array}{l}\text { Dried bonito broth }(10 \%) \\
\text { intake } 53 \text { days }\end{array}$ & & & & & $\begin{array}{l}\text { [74] Jargalsaikhan } \\
\text { et al. (2017) }\end{array}$ \\
\hline Mouse (GAD-GFP) & Adult & Adult & o & $\begin{array}{l}\text { IP injection of } 20 \mathrm{mg} / \mathrm{kg} \mathrm{FLX} \\
\text { daily for } 2 \text { weeks }\end{array}$ & Hippocampus & IHC; WFA stain & $\begin{array}{l}\text { Total PV cell number; total } \\
\text { PV +/PNN + cell number; PV } \\
+ \text { fraction of PNN + cells; } \\
\text { perisomatic PV and } \\
\text { synaptophysin puncta } \\
\text { densities on pyramidal cells }\end{array}$ & $\begin{array}{l}\text { decreased } \mathrm{PV}+/ \mathrm{PNN}+\text { cell } \\
\text { number and } \mathrm{PV}+\text { fraction of } \\
\mathrm{PNN}+\text { cells }\end{array}$ & $\begin{array}{l}\text { [63] Guirado et al., } \\
2014\end{array}$ \\
\hline Rat (Wistar) & Juvenile & Adult & o & EE 40 days & Hippocampus & IHC; Western blot & $\begin{array}{l}\text { PV cell density; PV protein } \\
\text { content }\end{array}$ & no change & $\begin{array}{l}\text { [154] Serra et al. } \\
(2020)\end{array}$ \\
\hline Rat (Wistar) & Juvenile & Adult & o & Exercise 40 days & Hippocampus & IHC; Western blot & $\begin{array}{l}\text { PV cell density; PV protein } \\
\text { content }\end{array}$ & increased protein and density & $\begin{array}{l}\text { [154] Serra et al. } \\
(2020)\end{array}$ \\
\hline Rat (Wistar) & $\begin{array}{l}\text { Juvenile- } \\
\text { adolescent }\end{array}$ & Adult & o & Physical exercise 40 days & Hippocampus & Western blot & PV protein content & increased & $\begin{array}{l}\text { [58] Gomes da Silva } \\
\text { et al., } 2010\end{array}$ \\
\hline Rat (Sprague-Dawley) & $\begin{array}{l}\text { Adolescent- } \\
\text { adult }\end{array}$ & Adult & o & $\begin{array}{l}\text { Paroxetine } 5 \mathrm{mg} / \mathrm{kg} / \mathrm{day} \\
\text { injection for } 12 \text { days }\end{array}$ & Hippocampus & $\begin{array}{l}\text { 2D gel then mass } \\
\text { spectrometry } \\
\text { proteomics on } \\
\text { hippocampus } \\
\text { samples }\end{array}$ & $\mathrm{PV}$ protein content & decreased 1.3-fold & $\begin{array}{l}\text { [104] McHugh et al. } \\
\text { (2009) }\end{array}$ \\
\hline Rat (Sprague-Dawley) & Adult & Adult & o & $\begin{array}{l}\text { IFS } 15 \text { min on day } 0 \text {, then EE } \\
2 \text { h/day for } 30 \text { days. Brains } \\
\text { collected on day } 46\end{array}$ & Hippocampus & Western blot & $\mathrm{PV}$ protein content & $\begin{array}{l}\text { IFS reduced PV protein, EE + } \\
\text { IFS rescued normal amount. } \\
\text { No change for EE alone }\end{array}$ & $\begin{array}{l}\text { [164] Sun et al. } \\
\text { (2016) }\end{array}$ \\
\hline Rat (Wistar) & Adult & Adult & o & $\begin{array}{l}\text { Neuregulin-1 infusion to } \\
\text { lateral ventricles same time } \\
\text { as ketamine } 10 \mathrm{mg} / \mathrm{kg} \text { IP }\end{array}$ & Hippocampus & Western blot & PV protein content & $\begin{array}{l}\text { decreased by ketamine but not } \\
\text { ketamine }+ \text { neuregulin- } 1\end{array}$ & $\begin{array}{l}\text { [177] Wang et al. } \\
\text { (2014) }\end{array}$ \\
\hline Rat (Wistar-Kyoto) & Adolescent & Adolescent & o & $\begin{array}{l}7 \mathrm{~h} / \text { day exposure to roman } \\
\text { chamomile essential oil or a- } \\
\text { pinene vapors for } 14 \text { days }\end{array}$ & Hippocampus & qPCR & PV mRNA expression & $\begin{array}{l}\text { increased by roman } \\
\text { chamomile and a-pinene }\end{array}$ & $\begin{array}{l}\text { [84] Kong et al. } \\
\text { (2017) }\end{array}$ \\
\hline $\begin{array}{l}\text { PV-TRAP Mouse (C57/ } \\
\text { BL6) }\end{array}$ & Adult & Adult & ơ & $\begin{array}{l}18 \text { days oral FLX } 0.167 \mathrm{mg} / \\
\mathrm{ml} \text { in } 1 \% \text { saccharine drinking } \\
\text { water }\end{array}$ & Hippocampus & $\begin{array}{l}\text { Translating ribosome } \\
\text { affinity purification } \\
\text { (TRAP) }\end{array}$ & $\begin{array}{l}\text { PV cell 5HT5A receptor } \\
\text { mRNA }\end{array}$ & no change & $\begin{array}{l}\text { [146] Sagi et al. } \\
(2020)\end{array}$ \\
\hline $\begin{array}{l}\text { PV-TRAP Mouse (C57/ } \\
\text { BL6) }\end{array}$ & Adult & Adult & ơ우 & $\begin{array}{l}18 \text { days oral FLX } 0.167 \mathrm{mg} / \\
\mathrm{ml} \text { in } 1 \% \text { saccharine drinking } \\
\text { water }\end{array}$ & Hippocampus & Western blot & $\begin{array}{l}\text { 5HT5A receptor protein level } \\
\text { in membrane-bound fraction } \\
\text { of hippocampal lysate }\end{array}$ & increased & $\begin{array}{l}\text { [146] Sagi et al. } \\
(2020)\end{array}$ \\
\hline Rat (Wistar) & Adult & Adult & o & $\begin{array}{l}\text { SI } 6 \text { weeks with anhedonic } \\
\text { rats given tianeptine } 10 \mathrm{mg} \text { / } \\
\mathrm{kg} / \text { day IP for last } 3 \text { weeks }\end{array}$ & $\begin{array}{l}\text { Dorsal } \\
\text { Hippocampus }\end{array}$ & IHC & Total PV cell number & $\begin{array}{l}\text { increased by tianeptine and } \\
\text { tianeptine }+ \text { SI vs their vehicle } \\
\text { controls }\end{array}$ & $\begin{array}{l}\text { [136] Peric et al. } \\
\text { (2018) }\end{array}$ \\
\hline Rat (Wistar) & Adult & Adult & o & $\begin{array}{l}\text { Lurasidone } 3 \mathrm{mg} / \mathrm{kg} / \text { day } \\
\text { oral for } 5 \text { weeks }\end{array}$ & $\begin{array}{l}\text { Dorsal } \\
\text { Hippocampus }\end{array}$ & qPCR; Western blot & $\begin{array}{l}\text { PV mRNA expression; PV } \\
\text { protein content }\end{array}$ & decreased mRNA & $\begin{array}{l}\text { [145] Rossetti et al. } \\
\text { (2018) }\end{array}$ \\
\hline Rat (Wistar) & Adult & Adult & o & $\begin{array}{l}\text { CMS } 2 \text { weeks, then } \\
\text { anhedonic rats received } 5 \\
\text { more weeks } \mathrm{CMS}+ \\
\text { lurasidone } 3 \mathrm{mg} / \mathrm{kg} / \text { day oral }\end{array}$ & $\begin{array}{l}\text { Dorsal } \\
\text { Hippocampus }\end{array}$ & qPCR; Western blot & $\begin{array}{l}\text { PV mRNA expression; PV } \\
\text { protein content }\end{array}$ & no change & $\begin{array}{l}\text { [145] Rossetti et al. } \\
\text { (2018) }\end{array}$ \\
\hline Rat (Wistar) & Adult & Adult & o & $\begin{array}{l}\text { Lurasidone } 3 \mathrm{mg} / \mathrm{kg} / \text { day } \\
\text { oral for } 5 \text { weeks }\end{array}$ & $\begin{array}{l}\text { Ventral } \\
\text { Hippocampus }\end{array}$ & qPCR; Western blot & $\begin{array}{l}\text { PV mRNA expression; PV } \\
\text { protein content }\end{array}$ & no change & $\begin{array}{l}\text { [145] Rossetti et al. } \\
\text { (2018) }\end{array}$ \\
\hline Rat (Wistar) & Adult & Adult & o & $\begin{array}{l}\text { CMS } 2 \text { weeks, then } \\
\text { anhedonic rats received } 5 \\
\text { more weeks CMS }+ \\
\text { lurasidone } 3 \mathrm{mg} / \mathrm{kg} / \text { day oral }\end{array}$ & $\begin{array}{l}\text { Ventral } \\
\text { Hippocampus }\end{array}$ & qPCR; Western blot & $\begin{array}{l}\text { PV mRNA expression; PV } \\
\text { protein content }\end{array}$ & no change & $\begin{array}{l}\text { [145] Rossetti et al. } \\
\text { (2018) }\end{array}$ \\
\hline Sprague-Dawley rats & Adult & Adult & o & $\begin{array}{l}\text { Daily FS P65-P74, RS } 1 \mathrm{hr} \text { on } \\
\text { P65, P66, P74; VPA IP } \\
300 \mathrm{mg} / \mathrm{kg} \text { or vehicle P60-74 }\end{array}$ & $\begin{array}{l}\text { Ventral } \\
\text { Hippocampus }\end{array}$ & $\mathrm{IHC}$ & Total PV cell number & $\begin{array}{l}\text { decreased by VPA and VPA + } \\
\text { stress at } 12 \text { weeks old; } \\
\text { decreased by VPA + stress at } \\
16 \text { weeks old }\end{array}$ & $\begin{array}{l}\text { [57] Gomes et al. } \\
\text { (2019) }\end{array}$ \\
\hline Sprague-Dawley rats & Adult & Adult & o & & $\begin{array}{l}\text { Ventral } \\
\text { Hippocampus }\end{array}$ & IHC and WFA stain & Total PV/PNN + cell number & $\begin{array}{l}\text { decreased by VPA and VPA + } \\
\text { stress at } 12 \text { weeks old; }\end{array}$ & $\begin{array}{l}\text { [57] Gomes et al. } \\
\text { (2019) }\end{array}$ \\
\hline
\end{tabular}

y purificatio

IHC

qPCR; Western blot

Pr mRNA exp

PV mRNA expression; PV

protein conten

mRNA expression; $\mathrm{P}$

Total PV cell number

Total PV/PNN + cell number 


\begin{tabular}{|c|c|c|c|c|c|c|c|c|c|}
\hline Species & $\begin{array}{l}\text { Age during } \\
\text { manipulation }\end{array}$ & $\begin{array}{l}\text { Age at } \\
\text { measurement }\end{array}$ & Sex & Experimental paradigm & Brain region & Method & Measure & Outcome & Reference \\
\hline & & & & $\begin{array}{l}\text { Daily FS P65-P74, RS } 1 \mathrm{hr} \text { on } \\
\text { P65, P66, P74; VPA IP } \\
300 \mathrm{mg} / \mathrm{kg} \text { or vehicle P60-74 }\end{array}$ & & & & $\begin{array}{l}\text { decreased by VPA + stress at } \\
16 \text { weeks old }\end{array}$ & \\
\hline Mouse (C57/BL6) & Adult & Adult & $0^{+}$ & $\begin{array}{l}\text { FLX } 10 \text { mg/kg/day SC } 24 \\
\text { days }\end{array}$ & $\begin{array}{l}\text { Basolateral } \\
\text { Amygdala }\end{array}$ & IHC & Total PV cell number & no change & $\begin{array}{l}\text { [56] Godavarthi } \\
\text { et al. (2014) }\end{array}$ \\
\hline Mouse (C57/BL6) & $\begin{array}{l}\text { Adolescent- } \\
\text { adult }\end{array}$ & Adult & o & $\begin{array}{l}\text { Dried bonito broth }(10 \%) \\
\text { intake } 53 \text { days }\end{array}$ & $\begin{array}{l}\text { Basolateral } \\
\text { Amygdala }\end{array}$ & IHC & PV cell density & increased & $\begin{array}{l}\text { [74] Jargalsaikhan } \\
\text { et al. (2017) }\end{array}$ \\
\hline Rat (Wistar) & Adult & Adult & o & EE 2 months & $\begin{array}{l}\text { Basolateral } \\
\text { Amygdala }\end{array}$ & $\mathrm{IHC}$ & Total PV cell number & no change & $\begin{array}{l}\text { [149] } \\
\text { Sampedro-Piquero } \\
\text { et al. (2016) }\end{array}$ \\
\hline Rat (Wistar) & Adolescent & Adult & o & EE 35 days & $\begin{array}{l}\text { Basolateral } \\
\text { Amygdala }\end{array}$ & $\mathrm{IHC}$ & $\begin{array}{l}\text { Total PV cell number; large } \\
\text { and small PV cell number }\end{array}$ & $\begin{array}{l}\text { increased total and small PV } \\
\text { cell number }\end{array}$ & $\begin{array}{l}\text { [173] Urakawa et al. } \\
\text { (2013) }\end{array}$ \\
\hline Mouse (C57/BL6) & $\begin{array}{l}\text { Prenatal, } \\
\text { early } \\
\text { postnatal }\end{array}$ & $\begin{array}{l}\text { Early } \\
\text { postnatal; } \\
\text { juvenile }\end{array}$ & ơo & $\begin{array}{l}\text { Mothers given oral FLX } \\
11.3 \mathrm{mg} / \mathrm{kg} / \mathrm{d} \text { from GD7-P7 }\end{array}$ & $\begin{array}{l}\text { Basolateral } \\
\text { Amygdala }\end{array}$ & IHC; WHA stain & $\begin{array}{l}\text { Total PV cell number; PV+/ } \\
\text { PNN + cell number; PV } \\
\text { intensity in PV+/PNN + cells }\end{array}$ & $\begin{array}{l}\text { decreased PV }+/ \mathrm{PNN}+\text { cell } \\
\text { number at P17 but not P24; } \\
\text { other measures unchanged }\end{array}$ & $\begin{array}{l}\text { [172] Umemori et al. } \\
\text { (2015) }\end{array}$ \\
\hline Mouse (C57/BL6) & Adult & Adult & $0^{+}$ & $10 \mathrm{mg} / \mathrm{kg} / \mathrm{d}$ oral FLX 30 days & $\begin{array}{l}\text { Basolateral } \\
\text { Amygdala }\end{array}$ & IHC; WFA stain & $\mathrm{PV}+$ fraction of PNN + cells & decreased & $\begin{array}{l}\text { [77] Karpova et al. } \\
\text { (2011) }\end{array}$ \\
\hline Rat (Sprague-Dawley) & Juvenile & Adolescent & \% & 1 week EE & $\begin{array}{l}\text { Basolateral } \\
\text { Amygdala }\end{array}$ & IHC; WFA stain & $\begin{array}{l}\text { c-Fos + proportion of PV cells; } \\
\text { WFA + proportion of PV cells; } \\
\text { c-Fos + proportion of WFA + } \\
\text { PV cells }\end{array}$ & $\begin{array}{l}\text { decreased c-Fos + proportion } \\
\text { of PV cells; decreased c-Fos + } \\
\text { proportion of WFA + PV cells }\end{array}$ & $\begin{array}{l}\text { [175] } \\
\text { Vazquez-Sanroman } \\
\text { et al. (2021) }\end{array}$ \\
\hline Rat (Sprague-Dawley) & $\begin{array}{l}\text { Early } \\
\text { postnatal; } \\
\text { adolescent }\end{array}$ & Adolescent & \% & $\begin{array}{l}\text { MS 4h/day from P2-P20; } \\
\text { treatment with COX-2 } \\
\text { inhibitor NS-398 }(8 \mathrm{mg} / \mathrm{kg}) \\
\text { every other day IP from } \\
\text { P30-P38; LH task P41 }\end{array}$ & $\begin{array}{l}\text { Basolateral } \\
\text { Amygdala }\end{array}$ & Western blot & PV protein content & no change & $\begin{array}{l}\text { [97] Lukkes et al. } \\
\text { (2017) }\end{array}$ \\
\hline Rat (Sprague-Dawley) & $\begin{array}{l}\text { Early } \\
\text { postnatal; } \\
\text { adolescent }\end{array}$ & Adolescent & \% & $\begin{array}{l}\text { MS 4h/day from P2-P20; } \\
\text { treatment with COX-2 } \\
\text { inhibitor NS-398 ( } 8 \mathrm{mg} / \mathrm{kg}) \\
\text { every other day IP from } \\
\text { P30-P38; LH task P41; } \\
\text { allowed to witness another } \\
\text { rat in task 1d before they did } \\
\text { it. }\end{array}$ & $\begin{array}{l}\text { Basolateral } \\
\text { Amygdala }\end{array}$ & Western blot & $\mathrm{PV}$ protein content & no change & $\begin{array}{l}\text { [97] Lukkes et al. } \\
\text { (2017) }\end{array}$ \\
\hline Rat (Wistar) & Adolescent & Adult & o & EE 35 days & $\begin{array}{l}\text { Lateral } \\
\text { Amygdala }\end{array}$ & $\mathrm{IHC}$ & $\begin{array}{l}\text { Large and small PV cell } \\
\text { number }\end{array}$ & no change & $\begin{array}{l}\text { [173] Urakawa et al. } \\
\text { (2013) }\end{array}$ \\
\hline Rat (Sprague-Dawley) & Adolescent & Adolescent & o & $\begin{array}{l}\text { R- or S-ketamine } 10 \mathrm{mg} / \mathrm{kg} \\
\text { IP; sacrifice } 30 \mathrm{~min} \text { later }\end{array}$ & $\begin{array}{l}\text { Nucleus } \\
\text { Accumbens }\end{array}$ & $\mathrm{IHC}$ & PV cell density & no change & $\begin{array}{l}\text { [186] Yang et al. } \\
\text { (2015) }\end{array}$ \\
\hline Rat (Wistar) & Juvenile-adult & Adult & 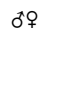 & $\begin{array}{l}\mathrm{SI}+7 \text { weeks with or without } \\
5 \mathrm{mg} / \mathrm{kg} / \text { day oral apocynin }\end{array}$ & $\begin{array}{l}\text { Nucleus } \\
\text { Accumbens }\end{array}$ & $\mathrm{IHC}$ & PV immunoreactivity & $\begin{array}{l}\text { decreased by SI alone, no } \\
\text { change in apocynin alone or } \\
\text { SI + apocynin }\end{array}$ & $\begin{array}{l}\text { [151] Schiavone } \\
\text { et al. (2009) }\end{array}$ \\
\hline Rat (Wistar) & Juvenile-adult & Adult & 6oㅇ & $\begin{array}{l}\mathrm{SI}+7 \text { weeks with or without } \\
5 \mathrm{mg} / \mathrm{kg} / \text { day oral apocynin }\end{array}$ & $\begin{array}{l}\text { Nucleus } \\
\text { Accumbens }\end{array}$ & Western blot & PV protein content & $\begin{array}{l}\text { decreased by SI alone, no } \\
\text { change in apocynin alone or } \\
\text { SI + apocynin }\end{array}$ & $\begin{array}{l}\text { [151] Schiavone } \\
\text { et al. (2009) }\end{array}$ \\
\hline Mouse (C57/BL6) & Adolescent & Adolescent & రㅇำ & $\begin{array}{l}\mathrm{EE} \text { or } \mathrm{EE}+\mathrm{RS} 2 \mathrm{~h} / \mathrm{d} \text { for } 7 \\
\text { days }\end{array}$ & Barrel cortex & $\mathrm{IHC}$ & c-Fos + fraction of PV cells & increased in both & $\begin{array}{l}\text { [23] Chen et al. } \\
\text { (2018) }\end{array}$ \\
\hline Mouse (C57/BL6) & $\begin{array}{l}\text { Early } \\
\text { postnatal }\end{array}$ & $\begin{array}{l}\text { Early } \\
\text { postnatal, } \\
\text { adult }\end{array}$ & ơ우 & $\begin{array}{l}\text { EE from late pregnancy until } \\
\text { P21 }\end{array}$ & $\begin{array}{l}\text { Lateral } \\
\text { Striatum }\end{array}$ & IHC and WFA stain & $\begin{array}{l}\text { High-PV and low-PV cell } \\
\text { density; high-PV and low-PV } \\
\text { PNN + cell density }\end{array}$ & $\begin{array}{l}\text { increased low-PV cell density } \\
\text { and low-PV/PNN }+ \text { cell } \\
\text { density in early postnatal and } \\
\text { adult mice }\end{array}$ & $\begin{array}{l}\text { [124] O'Connor } \\
\text { et al. (2019) }\end{array}$ \\
\hline Mouse (C57/BL6) & $\begin{array}{l}\text { Early } \\
\text { postnatal }\end{array}$ & $\begin{array}{l}\text { Early } \\
\text { postnatal, } \\
\text { adult }\end{array}$ & ơo & $\begin{array}{l}\text { EE from late pregnancy until } \\
\text { P21 }\end{array}$ & $\begin{array}{l}\text { Medial } \\
\text { Striatum }\end{array}$ & IHC and WFA stain & $\begin{array}{l}\text { High-PV and low-PV cell } \\
\text { density; high-PV and low-PV } \\
\text { PNN + cell density }\end{array}$ & $\begin{array}{l}\text { increased low-PV cell density } \\
\text { and low-PV/PNN }+ \text { cell } \\
\text { density in adults }\end{array}$ & $\begin{array}{l}\text { [124] O'Connor } \\
\text { et al. (2019) }\end{array}$ \\
\hline Rat (Sprague-Dawley) & & Adolescent & $\%$ & $\begin{array}{l}\text { MS 4h/day from P2-P20; } \\
\text { treatment with COX-2 }\end{array}$ & $\begin{array}{l}\text { Dorsal Raphe } \\
\text { Nucleus }\end{array}$ & Western blot & $\mathrm{PV}$ protein content & increased & $\begin{array}{l}\text { [97] Lukkes et al. } \\
\text { (2017) }\end{array}$ \\
\hline
\end{tabular}
nhibitor NS-398 (8 mg/kg) P30-P38; LH task P41

IHC

asolater

Basolater

rater

solatera

no change

Accumben

change in apocynin alone or

SI + apocynin

creased by SI alone, no

hange in apocynin alone or

increased low-PV cell density

V/PNN + cell

adult mice

(continued on next page) 


\begin{tabular}{|c|c|c|c|c|c|c|c|c|c|}
\hline Species & $\begin{array}{l}\text { Age during } \\
\text { manipulation }\end{array}$ & $\begin{array}{l}\text { Age at } \\
\text { measurement }\end{array}$ & Sex & Experimental paradigm & Brain region & Method & Measure & Outcome & Reference \\
\hline & $\begin{array}{l}\text { Early } \\
\text { postnatal; } \\
\text { adolescent }\end{array}$ & & & $\begin{array}{l}\text { inhibitor NS-398 }(8 \mathrm{mg} / \mathrm{kg} \text { ) } \\
\text { every other day IP from } \\
\text { P30-P38; LH task P41 }\end{array}$ & & & & & \\
\hline Rat (Sprague-Dawley) & $\begin{array}{l}\text { Early } \\
\text { postnatal; } \\
\text { adolescent }\end{array}$ & Adolescent & \% & $\begin{array}{l}\text { MS 4h/day from P2-P20; } \\
\text { treatment with COX-2 } \\
\text { inhibitor NS-398 ( } 8 \mathrm{mg} / \mathrm{kg}) \\
\text { every other day IP from } \\
\text { P30-P38; LH P41; allowed to } \\
\text { witness another rat in task } 1 \\
\text { day before they did it. }\end{array}$ & $\begin{array}{l}\text { Dorsal Raphe } \\
\text { Nucleus }\end{array}$ & Western blot & PV protein content & no change & $\begin{array}{l}\text { [97] Lukkes et al. } \\
\text { (2017) }\end{array}$ \\
\hline Mouse (C57/BL6) & Adult & Adult & o & $\begin{array}{l}\text { FLX } 15 \text { mg/kg/day IP } 3 \\
\text { weeks }\end{array}$ & $\begin{array}{l}\text { Thalamic } \\
\text { Reticular } \\
\text { Nucleus }\end{array}$ & IHC and WFA stain & $\begin{array}{l}\text { PV cell density; PV+/PNN + } \\
\text { cell density; PNN + fraction of } \\
\text { PV cells }\end{array}$ & no change & $\begin{array}{l}\text { [125] Ohira et al. } \\
\text { (2013) }\end{array}$ \\
\hline Mouse (C57/BL6) & $\begin{array}{l}\text { Adolescent- } \\
\text { adult }\end{array}$ & Adult & o & $\begin{array}{l}\text { Dried bonito broth }(10 \%) \\
\text { intake } 53 \text { days }\end{array}$ & $\begin{array}{l}\text { Superior } \\
\text { Colliculus }\end{array}$ & $\mathrm{IHC}$ & PV cell density & increased & $\begin{array}{l}\text { [74] Jargalsaikhan } \\
\text { et al. (2017) }\end{array}$ \\
\hline Mouse (C57/BL6) & Adult & Adult & o & $\begin{array}{l}\text { CSD } 10 \text { days followed by } \\
20 \mathrm{mg} / \mathrm{kg} / \text { day FLX IP or } \\
\text { vehicle for } 14 \text { days }\end{array}$ & $\begin{array}{l}\text { Ventral } \\
\text { Pallidum }\end{array}$ & Electrophysiology & $\begin{array}{l}\text { Number of spikes elicited by } \\
100 \text { pA current injection in PV } \\
\text { (VP-> LHb) cells; ratio of } \\
\text { excitatory:inhibitory inputs } \\
\text { onto PV(VP- > LHb) cells }\end{array}$ & $\begin{array}{l}\text { CSD alone increased number } \\
\text { of spikes in resilient and } \\
\text { susceptible mice, prevented } \\
\text { by FLX; decreased ratio in } \\
\text { resilient and FLX-treated mice } \\
\text { compared to susceptible }\end{array}$ & $\begin{array}{l}\text { [83] Knowl et al. } \\
\text { (2017) }\end{array}$ \\
\hline Mouse (C57/BL6) & Adult & Adult & to & $\begin{array}{l}\text { CSD } 10 \text { days followed by } \\
20 \mathrm{mg} / \mathrm{kg} / \mathrm{day} \text { FLX IP or } \\
\text { vehicle for } 14 \text { days }\end{array}$ & $\begin{array}{l}\text { Ventral } \\
\text { Pallidum }\end{array}$ & Electrophysiology & $\begin{array}{l}\text { Number of spikes elicited by } \\
100 \text { pA current injection in PV } \\
\text { (VP-> VTA) cells; ratio of } \\
\text { excitatory:inhibitory inputs } \\
\text { onto PV(VP-> VTA) cells }\end{array}$ & $\begin{array}{l}\text { decreased spike number in } \\
\text { resilient and FLX (FLX vs. } \\
\text { susceptible only) mice but not } \\
\text { susceptible; ratio increased in } \\
\text { susceptible mice }\end{array}$ & $\begin{array}{l}\text { [83] Knowl et al. } \\
\text { (2017) }\end{array}$ \\
\hline
\end{tabular}

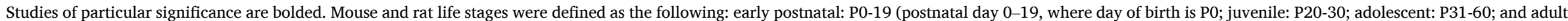

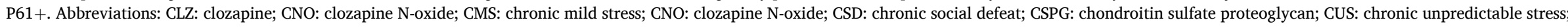

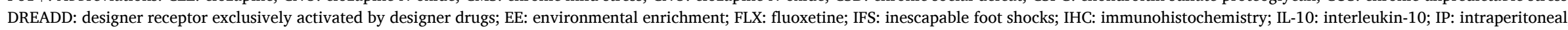

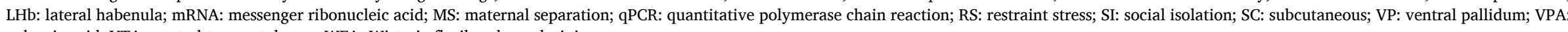
valproic acid; VTA: ventral tegmental area; WFA: Wisteria floribunda agglutinin. 
Table 5

PV neuron alterations in postmortem samples from patients having died with mood disorders.

\begin{tabular}{|c|c|c|c|c|c|c|}
\hline Sex & Disorder & Brain region & Method & Measure & Outcome & Reference \\
\hline $5 \mathrm{M}, 6 \mathrm{~F}$ & MDD & Dorsolateral Prefrontal Cortex & $\begin{array}{l}\text { IHC; WFA } \\
\text { stain }\end{array}$ & $\begin{array}{l}\text { PV cell density; PNN + } \\
\text { fraction of PV cells; PV + } \\
\text { fraction of PNNs }\end{array}$ & no change & $\begin{array}{l}\text { [1] Alcaide et al. } \\
\text { (2019) }\end{array}$ \\
\hline $9 \mathrm{M}, 6 \mathrm{~F}$ & MDD & Dorsolateral Prefrontal Cortex & IHC & PV cell density & no change & $\begin{array}{l}\text { [9] Beasley et al. } \\
(2002)\end{array}$ \\
\hline $4 \mathrm{M}, 7 \mathrm{~F}$ & MDD & $\begin{array}{l}\text { Dorsolateral Prefrontal Cortex } \\
\text { layers 2-6 }\end{array}$ & IHC & PV stain intensity & $\begin{array}{l}\text { decreased in layer } 6 \text {, no change in } \\
\text { other layers }\end{array}$ & $\begin{array}{l}\text { [79] Khundakar } \\
\text { et al. (2010) }\end{array}$ \\
\hline $22 \mathrm{M}, 18 \mathrm{~F}$ & MDD & $\begin{array}{l}\text { Right Dorsolateral Prefrontal } \\
\text { Cortex }\end{array}$ & $\mathrm{qPCR}$ & PV mRNA expression & decreased & $\begin{array}{l}\text { [26] Chung et al. } \\
\text { (2018) }\end{array}$ \\
\hline $10 \mathrm{M}, 9 \mathrm{~F}$ & MDD & Dorsolateral Prefrontal Cortex & $\mathrm{qPCR}$ & PV mRNA expression & no change & $\begin{array}{l}\text { [157] Sibille et al. } \\
\text { (2011) }\end{array}$ \\
\hline $8 \mathrm{M}, 6 \mathrm{~F}$ & MDD & $\begin{array}{l}\text { Orbitofrontal Cortex, } \\
\text { Dorsolateral Prefrontal Cortex }\end{array}$ & IHC & PV cell density & decreased in Orbitofrontal Cortex & $\begin{array}{l}\text { [141] Rajkowska } \\
\text { et al. (2007) }\end{array}$ \\
\hline $9 \mathrm{M}, 6 \mathrm{~F}$ & MDD & Brodmann Area 24 & IHC & $\begin{array}{l}\text { PV cell density in different } \\
\text { layers; PV cell clustering }\end{array}$ & no change & $\begin{array}{l}\text { [29] Cotter et al. } \\
\text { (2002) }\end{array}$ \\
\hline $\begin{array}{l}\text { matched } \\
\text { with } \\
\text { control }\end{array}$ & MDD & $\begin{array}{l}\text { CA1, CA2, CA3, CA4, } \\
\text { Entorhinal Cortex, Subiculum }\end{array}$ & IHC & $\begin{array}{l}\text { Total PV cell number; PV cell } \\
\text { density }\end{array}$ & no change & $\begin{array}{l}\text { [82] Knable et al. } \\
(2004)\end{array}$ \\
\hline $9 \mathrm{M}, 8 \mathrm{~F}$ & MDD & Tpt Auditory Association Cortex & IHC & PV cell size; PV cell density & no change & $\begin{array}{l}\text { [158] Smiley et al. } \\
\text { (2016) }\end{array}$ \\
\hline $9 \mathrm{M}$ & DS-CA & Ventromedial Prefrontal Cortex & $\begin{array}{l}\text { IHC, WFL } \\
\text { stain }\end{array}$ & PNN + fraction of PV cells & $\begin{array}{l}\text { increased vs depressed-suicide and } \\
\text { controls }\end{array}$ & $\begin{array}{l}\text { [166] Tanti et al. } \\
(2020)\end{array}$ \\
\hline $26 \mathrm{M}, 25 \mathrm{~F}$ & MDD & $\begin{array}{l}\text { Subgenual Anterior Cingulate } \\
\text { Cortex, Amygdala }\end{array}$ & qPCR & PV mRNA expression & $\begin{array}{l}\text { decreased in subgenual anterior } \\
\text { cingulate }\end{array}$ & $\begin{array}{l}\text { [168] Tripp et al. } \\
\text { (2012) }\end{array}$ \\
\hline $5 \mathrm{M}, 8 \mathrm{~F}$ & $\mathrm{BD}$ & Dorsolateral Prefrontal Cortex & $\begin{array}{l}\text { IHC; WFA } \\
\text { stain }\end{array}$ & $\begin{array}{l}\text { PV cell density; PNN + } \\
\text { fraction of PV cells; PV + } \\
\text { fraction of PNNs }\end{array}$ & no change & $\begin{array}{l}\text { [1] Alcaide et al. } \\
\text { (2019) }\end{array}$ \\
\hline $9 \mathrm{M}, 6 \mathrm{~F}$ & $\mathrm{BD}$ & Dorsolateral Prefrontal Cortex & IHC & PV cell density & no change & $\begin{array}{l}\text { [9] Beasley et al. } \\
(2002)\end{array}$ \\
\hline $1 \mathrm{M}, 4 \mathrm{~F}$ & BD & Brodmann Area 9 & IHC & PV cell density & no change & $\begin{array}{l}\text { [147] Sakai et al. } \\
\text { (2008) }\end{array}$ \\
\hline $8 \mathrm{M}, 10 \mathrm{~F}$ & $\mathrm{BD}$ & Brodmann Area 9 layers 2-6 & ISH & $\begin{array}{l}\text { Total PV cell number; PV+/ } \\
\text { NR2A + cell density; NR2A } \\
\text { density in PV cells }\end{array}$ & no change & $\begin{array}{l}\text { [13] Bitanihirwe } \\
\text { et al. (2010) }\end{array}$ \\
\hline $22 \mathrm{M}, 18 \mathrm{~F}$ & $\mathrm{BD}$ & $\begin{array}{l}\text { Right Dorsolateral Prefrontal } \\
\text { Cortex }\end{array}$ & qPCR & PV mRNA expression & decreased & $\begin{array}{l}\text { [26] Chung et al. } \\
\text { (2018) }\end{array}$ \\
\hline $10 \mathrm{M}, 9 \mathrm{~F}$ & $\mathrm{BD}$ & Dorsolateral Prefrontal Cortex & $\mathrm{qPCR}$ & PV mRNA expression & $\begin{array}{l}\text { decreased, but unchanged after } \\
\text { exclusion of subject pairs with } \\
\text { potential confounding factors }\end{array}$ & $\begin{array}{l}\text { [157] Sibille et al. } \\
\text { (2011) }\end{array}$ \\
\hline $20 \mathrm{M} / 15 \mathrm{~F}$ & $\begin{array}{l}\text { Low GABA } \\
\text { marker BD* }\end{array}$ & Brodmann Area 9 grey matter & qPCR & PV mRNA expression & $\begin{array}{l}\text { decreased vs controls and non-low } \\
\text { GABA marker subjects }\end{array}$ & $\begin{array}{l}\text { [176] Volk et al. } \\
\text { (2016) }\end{array}$ \\
\hline $20 \mathrm{M} / 15 \mathrm{~F}$ & $\begin{array}{l}\text { Non-low } \\
\text { GABA marker } \\
\text { BD* }\end{array}$ & Brodmann Area 9 grey matter & $\mathrm{qPCR}$ & PV mRNA expression & decreased vs controls & $\begin{array}{l}\text { [176] Volk et al. } \\
\text { (2016) }\end{array}$ \\
\hline $\begin{array}{l}\text { matched } \\
\text { with } \\
\text { control }\end{array}$ & $\mathrm{BD}$ & $\begin{array}{l}\text { Lateral, Basal, Accessory Basal, } \\
\text { and Cortical Nuclei of the } \\
\text { Amygdala }\end{array}$ & IHC & PV cell density & $66 \%$ decrease in Lateral Nucleus & $\begin{array}{l}\text { [11] Berretta et al. } \\
\text { (2003) }\end{array}$ \\
\hline $7 \mathrm{M}, 4 \mathrm{~F}$ & $\mathrm{BD}$ & $\begin{array}{l}\text { Lateral, Basal, Accessory Basal, } \\
\text { and Cortical Nuclei of the } \\
\text { Amygdala }\end{array}$ & IHC & $\begin{array}{l}\text { PV cell density; Total PV cell } \\
\text { number }\end{array}$ & no change & $\begin{array}{l}\text { [135] } \\
\text { Pantazopoulos et al. } \\
(2010)\end{array}$ \\
\hline $9 \mathrm{M}, 6 \mathrm{~F}$ & $\mathrm{BD}$ & Brodmann Area 24 & IHC & $\begin{array}{l}\text { PV cell density in different } \\
\text { layers; PV cell clustering }\end{array}$ & increased clustering & $\begin{array}{l}\text { [29] Cotter et al. } \\
\text { (2002) }\end{array}$ \\
\hline $\begin{array}{l}\text { matched } \\
\text { with } \\
\text { control }\end{array}$ & $\mathrm{BD}$ & $\begin{array}{l}\text { CA1, CA2, CA3, CA4, } \\
\text { Entorhinal Cortex, Subiculum }\end{array}$ & IHC & $\begin{array}{l}\text { Total PV cell number; PV cell } \\
\text { density }\end{array}$ & decreased PV cell number in CA2 & $\begin{array}{l}\text { [82] Knable et al. } \\
(2004)\end{array}$ \\
\hline $5 \mathrm{M}, 9 \mathrm{~F}$ & $\mathrm{BD}$ & $\mathrm{CA} 1, \mathrm{CA} 2 / 3$, and CA4 & IHC & Total PV cell number & decreased in CA1 and CA4 & $\begin{array}{l}\text { [85] Konradi et al. } \\
\text { (2011) }\end{array}$ \\
\hline $6 \mathrm{M}, 4 \mathrm{~F}$ & $\mathrm{BD}$ & Entorhinal Cortex & IHC & $\begin{array}{l}\text { PV soma size; Total PV cell } \\
\text { number; PV cell density }\end{array}$ & decreased PV cell number and density & $\begin{array}{l}{[134]} \\
\text { Pantazopoulos et al. } \\
\text { (2007) }\end{array}$ \\
\hline $4 \mathrm{M}, 9 \mathrm{~F}$ & $\mathrm{BD}$ & $\begin{array}{l}\text { Parasubiculum; Deep } \\
\text { Entorhinal Cortex; Total } \\
\text { Entorhinal Cortex }\end{array}$ & IHC & PV cell density & decreased & $\begin{array}{l}\text { [178] Wang et al. } \\
\text { (2011) }\end{array}$ \\
\hline $4 \mathrm{M}, 9 \mathrm{~F}$ & $\mathrm{BD}$ & $\begin{array}{l}\text { Superficial Entorhinal Cortex; } \\
\text { Subiculum; Pre-subiculum }\end{array}$ & IHC & PV cell density & no change & $\begin{array}{l}\text { [178] Wang et al. } \\
\text { (2011) }\end{array}$ \\
\hline $9 \mathrm{M}, 6 \mathrm{~F}$ & $\mathrm{BD}$ & Thalamic Reticular Nucleus & IHC & Total PV cell number & decreased & $\begin{array}{l}\text { [163] Steullet et al. } \\
\text { (2018) }\end{array}$ \\
\hline
\end{tabular}

All studies were conducted with samples from adults, with a mean age $\geq 35$ years. Studies of particular significance are bolded. Abbreviations: BD: bipolar disorder; DSCA: depressed-suicide + child abuse history; GABA: gamma-amino butyric acid; IHC: immunohistochemistry; ISH: in situ hybridization; MDD: major depressive disorder; qPCR: quantitative polymerase chain reaction. *Low GABA marker and non-low GABA marker BD subjects were divided by quantifying GAD67, PV, SST, and Lxh6 mRNA. 
(Guadagno et al., 2020) and decreases (Reznikov et al., 2008) in activity, and many studies finding little to no change (Ebertowska et al., 2020; Jiang et al., 2009; Lukkes et al., 2012; Varga et al., 2016). No stress-associated changes in PV cell oxidative stress markers were observed (Soares et al., 2020). One interesting study found LB/LN to reduce juveniles' PV cell innervation of both pyramidal neurons and PV cells in the region (Santiago et al., 2018), while the single enrichment study assessing BLA PV cell activity found juvenile environmental enrichment to reduce PV cell activity in adolescent females (Vazquez-Sanroman et al., 2021).

The lateral amygdala was assessed in two studies, one of which found reduced PV-c-Fos colocalization in adults stressed during the early postnatal period (Ebertowska et al., 2020) and the other which found PV-c-Fos colocalization reduced in the dorsolateral but not in the ventrolateral or ventromedial subfields of adults that were isolated during juvenility and adolescence (Lukkes et al., 2012). However, both studies subjected animals to chronic stressors followed by a rest period, then an acute stressor immediately before sacrifice, making it difficult to determine which manipulation was responsible for the outcome.

One study of the barrel cortex found that adolescent chronic restraint decreased PV cell activity and excitability, and that environmental enrichment increased activity (Chen et al., 2018). Finally, an investigation of the nucleus accumbens shell found that PV cell excitability may have been increased by UCMS in adulthood, as measured by firing frequency in response to current injection, although resting membrane potential and action potential threshold remained unchanged (Xiao et al., 2020).

\subsection{Human postmortem studies}

In the brains of MDD patients, PV cells have been most extensively studied in the dorsolateral PFC (dlPFC), with somewhat conflicting findings (Table 5). One study found decreased PV mRNA expression (Chung et al., 2018), while others found no change in PV expression (Song et al., 2019) or in cell number or density (Alcaide et al., 2019; Beasley et al., 2002; Regev-Tsur et al., 2020) in MDD compared to matched controls. Khundakar et al. (2010) found decreased PV staining intensity in the dIPFC layer VI but no such change in layers II-V. Other areas examined in samples from MDD patients include the ACC and subgenual ACC, the HC, the OFC, and the auditory association cortex. While most studies reported no changes in PV cell density or other measures in MDD compared to controls, Rajkowska et al. (2007) found decreased PV cell density in the OFC of MDD patients and Tripp et al. (2012) reported reduced PV mRNA expression in the subgenual ACC in MDD.

The dlPFC/BA9 was also the most extensively studied brain region in people with BD. While PV cell number, density, and NR2A expression in PV cells were not found to be altered (Alcaide et al., 2019; Bitanihirwe et al., 2010; Sakai et al., 2008), there was evidence of reduced PV mRNA expression compared with psychiatrically healthy controls reported in three studies (Chung et al., 2018; Sibille et al., 2011; Volk et al., 2016), although in Sibille et al.'s study this effect was eliminated by the exclusion of case-control pairs with potentially confounding factors. Two investigations of the amygdalar subfields in BD patients have, for the most part, reported no change in PV cell number or density (Berretta et al., 2015; Pantazopoulos et al., 2007). The only discrepancy was in the lateral amygdalar nucleus, where Berretta et al. (2015) reported decreased PV cell density compared to controls, whereas the same team earlier reported no change between groups (Pantazopoulos et al., 2007). In the hippocampal subfields of BD patients, several studies have assessed PV cell number and density with some conflicting results. Findings of decreased PV cell numbers in CA1, CA2, CA4, and the parasubiculum in individual studies have been countered by findings of no change in PV cell numbers across hippocampal subregions (Chu et al., 2016; Knable et al., 2004; Pantazopoulos et al., 2010; Wang et al., 2011). The entorhinal cortex, despite one null report (Kim et al., 2020), had lower PV cell density in two studies (Pantazopoulos et al., 2010; Wang et al., 2011). Individual studies have examined BA24 and the thalamic reticular nucleus (TRN) of BD patients and found increased clustering but unchanged density of PV cells in BA24 (Cotter et al., 2002) and decreased total PV cell number in the TRN of BD patients (Steullet et al., 2018).

Unfortunately, while many studies included the brains of people who died by suicide, cause of death was rarely a subject of analysis. In one of the few studies that did assess the effects of suicide on PV neurons, suicide was not found to associate with changes in PV mRNA in BD (Sibille et al., 2011). One study separating BD subjects into low- and non-low-GABA marker phenotypes based on their mRNA expression of GABAergic markers including PV found that low-GABA marker subjects were less likely to have died by suicide (Volk et al., 2016). This suggests that parvalbumin may be involved in the molecular signature of suicidality.

As of yet, there is little evidence of PNN changes in mood disorders in humans. Two studies have examined PFC subregions (Alcaide et al., 2019; Tanti et al., 2020). Alcaide et al. reported no changes in PNNs in the dIPFC of depressed patients, but reductions in overall PNN densities in the same region in BD. As this increase was not accompanied by a change in the density of PV cells, or in the fractions of PV cells and PNNs colocalized with one another, the reduction in PNNs was likely balanced between PV and non-PV cells. Further, individuals with a past psychotic episode, pooled from people with BD and schizophrenia, also displayed reduced dIPFC PNN density, suggesting that the apparent loss shown in BD may pertain more to psychosis.

Subgroup analysis by Tanti et al. (2020) found PNN increases in the vmPFC of depressed suicides with a history of child abuse compared to depressed suicides and nonpsychiatric controls with no such history. This suggests that PNNs may be lastingly increased by early-life adversity, which is a strong predictor of later depression and suicidality (Felitti et al., 1998). Further cross-sectional studies examining early life stress and neuropsychiatric disorders, and which of these phenomena more faithfully predict changes in PV cells and PNNs in humans, will be useful to elucidate the culprit in the matter.

\section{Discussion}

\subsection{Lower PV cell numbers}

Chronic stress was associated with lower PV cell numbers in subregions of the PFC and HC and higher numbers in the BLA, with some modulation of this effect by animal age, sex, and subregion. Work by the Brenhouse and Coutellier research groups in stressed animals points to several likely interacting culprits explaining lower PV cell numbers or densities: systemic inflammation (Brenhouse and Andersen, 2011; Wieck et al., 2013), local neuroinflammation (Brenhouse and Andersen, 2011; Grassi-Oliveira et al., 2016), increased excitatory input onto (Ganguly et al., 2015; Shepard and Coutellier, 2017; Wieck et al., 2013) and oxidative stress within PV cells (Soares et al., 2020). It should be noted that the apparent PV cell "loss" may not necessarily result from PV cell death but rather from reduced proliferation and maturation of PV cell precursors during postnatal development, or from the reduction (to undetectable levels) of PV protein expression. A combination of these changes may also fully explain the effect. Novel techniques such as single-cell RNA-sequencing may help settle the score by refining our understanding of the transcriptomic signature of PV cell maturation, growth and death and uncovering critical pathways affected by stress exposure.

Reductions in PV cells were matched by losses of PV mRNA and protein expression in the PFC, although these were inconsistent, and the predominant finding was null. Antidepressant treatment during stress, particularly with fluoxetine, showed some efficacy to counteract apparent PV cell loss, suggesting that PV neurons are cellular substrates of both stress-induced depressive-like outcomes and of antidepressants' 
ability to buffer this phenomenon.

\subsection{Enrichment}

Enrichment effects were most consistent in hippocampal areas CA1, CA2, and CA3. Here multiple studies found that enrichment paradigms increased PV cell numbers alone or protected from stress-induced decreases in PV cell density. It should be noted, however, that all enrichment studies in regions CA1-3 assessed adult male animals, except for Yang et al. (2015), which examined adolescent males.

Many other studies found enrichment to produce different effects on PV neurons when administered during a stressor than when given alone. Enrichment often played a buffering role on the impact of stress, preventing changes in PV cell phenotypes. This directionality of effect was rarely maintained when animals were exposed to enrichment in a congenial environment, however.

Enrichment type plays a major role in its effect as well. Fluoxetine administration, considered in this review as a form of enrichment, is the best representative example of the stress buffering effect, at times reducing numbers of PV cells and PNNs in the HC and PFC when administered on its own but typically preventing stress-induced PV cell reductions in these regions. Environmental enrichment and physical exercise regimens were less potent influencers of PV cells, and were not administered concurrently with stressors in any studies in this review (ostensibly due to logistic incompatibilities). Ketamine is in a category of its own as a fast-acting antidepressant, and its unique pharmacology seems to manifest in drastically different effects on PV cells compared to other enrichment paradigms.

\subsection{Sex-specific findings}

Milner et al.'s report (2013) regarding the effect of the estrus cycle on the stress responses and $\mu$-opioid receptor distribution in hilus PV cell dendrites illustrates a further layer of complexity to the study of stress in female animals. The finding of estrus cycle effects on PV neurons represents a field of study that may prove fruitful for understanding ovulation cycle-related changes in stress sensitivity in humans (Olson et al., 2015; Ossewaarde et al., 2013).

While findings in the HC were similar in males and females, reductions in PV cells in the PFC and increases in the BLA were less consistent in female animals. A study by Soares et al. (2020) suggests that juvenile females exhibit more oxidative stress in PV cells after MS than males in the HC and BLA, however it is unclear if this translates to changes in cell numbers or activity, further complicating the question of sex differences.

The preponderance of animal studies showing effects in males calls into question the suitability of current stress paradigms as models of conditions that are more frequent in women. Hopefully, recently developed social stress paradigms adapted for female rodents will provide improved opportunities to study sex-specific neurobiological responses to psychosocial stress (Furman et al., 2019; Takahashi et al., 2017). Further, the recent two-hit model which produced greater phenotypic changes than maternal separation alone in females shows promise as an improved model for interrogating sex-specific neurobiological responses to stress (Gildawie et al., 2021).

\subsection{Why are PV neurons impacted by stress?}

It would seem that due to their fast-spiking electrophysiology and their critical role in gating pyramidal neuron output, PV neurons are particularly sensitive cells, more vulnerable to oxidative stress and excitotoxicity than many other neuronal populations (Cabungcal et al., 2013; Moga et al., 2002). In conditions of chronic stress, involving elevated inflammation in the local microenvironment and oxidative stress within neurons, detection of some PV interneurons is likely lost due to atrophy, apoptosis, or reduced PV expression (possibly as a result of incomplete maturation during postnatal neurodevelopment). Further, given the downregulation of GRs in IL PV cells following stress (McKlveen et al., 2016) points to a possible implication of PV cells in the HPA axis dysregulation found in chronic stress conditions. The crucial roles played by PV cells in microcircuits and gating of excitatory output may make their casualties felt widely in the brain, as evidenced by the many animal studies in this review that found correlations between behavioral changes and altered PV cell phenotypes after stress.

\subsection{Impact of stress severity and duration on PV neurons}

Recent chronic stress studies aimed at studying animal models of mood disorders, such as Spijker group's SDPS model (Koskinen et al., 2019; Riga et al., 2017) and Brenhouse group's recent "two-hit" adversity model involving MS followed by SI (Gildawie et al., 2021), have increased the intensity and/or duration of the stress paradigm. These models have been largely successful at eliciting more pronounced behavioral phenotypes than previously established paradigms. In particular, the two-hit model produced greater effects in females than simple MS, suggesting it to be a viable alternative to other stress models that do not produce changes in female animals as reliably as in males.

\subsection{Functional changes}

The functional changes to PV neurons observed in chronic stress states underscore the likely implication of these interneurons in dysregulated executive function, memory, learning, and emotions commonly found in mood disorders. In this review, we found a wealth of evidence suggesting changes to PV cell E/I balance and other electrophysiological parameters, but often in opposite directions. We are unable to reconcile these disparate findings, and the early hyperexcitability-late hypofunction model proposed by Spijker et al. (2020) was not entirely supported by the reviewed literature. These findings are far from depicting the full picture, which would require a more detailed understanding of how PV cells interact with other neurons and glia, and how such interactions are affected by stress. Direct replications of several studies included in this review (particularly those by the Bath, Brenhouse, Coutellier and Spijker research groups) assessing functional outcomes in key brain regions such as the PFC and BLA with manipulations of pertinent variables like age, sex, and stress recency will be useful to confirm robust effects, and novel experiments that assess neglected factors such as animal species/strain and stressor type and intensity may be promising ventures to elucidate the determinants of observed PV cell changes.

\subsection{PNNs and stress incubation}

The impact of psychopathology and stress on PNNs was included in this review as they seem to influence every aspect of PV neuron physiology and connectivity. The effect of PNN degradation on PV cells is rather hard to decipher, however, as this depends on the connectivity of PV cells with principal cells and their interconnectivity with other inhibitory neurons, is network/region-dependent, and affects a variety of electrophysiological properties. Degrading PNNs though enzymatic digestion or selective $\mathrm{KD} / \mathrm{KO}$ of some of their components have been shown to decrease PV cells' firing rate, increase their spiking variability, and modify their resting membrane potential, input resistance, and excitability, perhaps through changes in both excitatory and inhibitory inputs onto PV cells (Carceller et al., 2020; Christensen et al., 2021) (see review by Wingert and Sorg (2021) for an in-depth description of the diverse functions of PNNs). Some of these changes are likely to contribute to the overall reduction in inhibitory drive onto principal cells observed following PNN removal and the increased firing of pyramidal neurons (Carceller et al., 2020) as well as changes in gamma and theta oscillations (Lensjø et al., 2017).

According to Spijker et al.'s recent review (2020), rodents stressed as 
adolescents show long-term PV cell and PNN reductions (Gomes et al., 2019; Ueno et al., 2017). Animals stressed as adults, however, show an initial apparent loss of PNNs and PV cells which recovers over several weeks to eventually reach greater hippocampal PV and PV $+/ \mathrm{PNN}+$ cell densities compared to non-stressed animals (Koskinen et al., 2019; Riga et al., 2017). These stress recency-dependent changes may serve as an adaptive response to adversity; in the immediate period after the traumatic event, an individual must adapt to novel threats, and PNNs are digested to promote plasticity and learning. After a prolonged period, however, chronic stress takes its toll (ostensibly in the form of neuroinflammation and oxidative stress in the cellular microenvironment); PNN production is increased and PV cells fire less frequently to prevent their own excitotoxicity. There is strong evidence for this pattern in hippocampal area CA1, but it requires validation in the rest of the HC and the PFC as well as further study of its application to female animals as the strongest evidence comes from studies involving male animals only (Koskinen et al., 2019; Riga et al., 2017). Interestingly, studies using fluoxetine reported a similar pattern in CA1, with reductions in PNNs after recent drug administration (Guirado et al., 2014; Karpova et al., 2011; Mukhopadhyay et al., 2021; Umemori et al., 2015) that may disappear long-term (Mukhopadhyay et al., 2021; Umemori et al., 2015). The stress incubation model of PNN changes would be best assessed by experiments involving animals exposed to a variety of stressors at a variety of ages, along with different stressor "incubation" times. Antidepressant administration during stress is also worthy of exploration as a potential buffer of this phenomenon.

We recommend that future studies assessing PNNs report all relevant metrics to make any potentially important information available to other researchers. The numbers of cells staining positively for PV and/or PNNs, the proportions of the former expressing the latter and vice versa, and the staining intensities of each antigen are examples of important information that can be used to glean insight into PV cell and PNN function. Gildawie et al., (2019) and 2021 are examples of such papers with optimal data presentation.

\subsection{Human brains: postmortem studies}

Postmortem studies of brain samples from individuals with mood disorders have revealed replicated PV cell alterations in BD and MDD, although with less consistency for the latter. Our overview suggests that individuals with BD have lower PV mRNA expression in the dlPFC (a region absent in rodents; see the review by Laubach et al. (2018) on anatomical species differences) and reduced PV cell numbers in the entorhinal cortex. Although inconsistent, evidence of decreased numbers of PV cells in hippocampal subfields of BD patients (Knable et al., 2004; Konradi et al., 2011) was somewhat comparable to findings generated in stressed animals.

The association of other psychiatric disorders such as schizophrenia (Kaar et al., 2019) and autism (Lauber et al., 2018) with changes in PV neuron function may reflect the involvement of shared emotional and/or cognitive processing changes among these conditions. Further research linking PV neurons to changes along these dimensions may help illuminate the links between brain disorders and inform the enduring debate over the validity of diagnoses.

The limited translatability of animal studies to human postmortem findings may be explained in part by differences in study design; animal studies mostly compared stressed to non-stressed groups rather than grouping by behavior, whereas humans were grouped into phenotypic classes (psychiatric diagnoses), which inherently vary widely due to heterogeneity in the clinical populations with these disorders. Recent postmortem findings from Tanti et al. (2020) suggest that refining the phenotypic characterization of human subjects by taking into account histories of life (such as early-life adversity) may yield more faithful neurobiological underpinnings. A thorough assessment of child abuse and/or trauma histories will thus be an important consideration for future postmortem studies, as it may be mediating the observed association between mood disorders and PV interneuron changes. Subgroup analysis for other criteria such as suicide or research domain-based criteria (e.g. anhedonia, fatigue) may also elucidate the relationship of PV cells to mood and behavior in humans. For instance, the Bath research group has linked apparent PV cell loss in the OFC with poorer cognitive performance in female mice (Goodwill et al., 2018), a finding that could echo the reduced density of PV cells in the same region of MDD subjects found in a postmortem study (Rajkowska et al., 2007) as cognitive impairments are common in MDD. Refining phenotypic characterizations of subjects beyond diagnosis is therefore crucial, but often impossible in postmortem studies, which limits our ability to reconcile these observations with animal studies.

It is important to highlight the increasing evidence suggesting that there are likely several classes of PV interneurons. Donato et al. (2013) first reported that PV expression in rodent PV cells correlates with their GABA production and found enrichment effects specifically on high-PV-expressing cells. Riga et al. (2017) continued this line of inquiry and described a reduction of low-PV cells and a reciprocal increase in high-PV cells in the CA1 stratum pyramidale after SDPS. Advances in postmortem brain research have recently allowed for the description of PV interneuron subtypes in humans (Nagy et al., 2020). In this study, single-nucleus RNA-seq of dlPFC samples identified two subpopulations differentiated by high and low expression of GABAergic markers, and comparison of samples from depressed-suicides and matched controls revealed a more robust downregulation of genes in the low-GABA cell population in cases. Whether these PV cell subtypes identified in rodent HC and human PFC are of the same nature remains to be determined. Further studies assessing the expression of orthologs in the same brain regions, as well as the electrophysiological characteristics of the subtypes, may be useful to elucidate the relationship and identities of PV interneuron classes. Aside from identifying latent neuronal subpopulations, future postmortem studies combining single-nucleus sequencing with validation approaches such as quantitative in situ hybridization should help to determine the molecular signatures of PV cells in mood disorders as well as potential changes in the way these neurons interact with other cell types.

\subsection{Study limitations}

This study did not assess the possibility of different stress paradigms exerting unique effects on PV cell outcomes, which is highly likely given their differing degrees of construct validity as mood disorder models. With the weight of literature currently available on PV neurons in chronic stress, such an analysis is feasible but would be weak due to other confounding variables such as animal age and sex and stress recency. Another limitation of this review is that it did not assess the effect of a stressor "dose" on PV cells, e.g., comparing different durations of an identical stressor. Again, such an analysis would have very low power; thus, it was omitted in order to limit this review's scope. Furthermore, rats and mice alike (as well as individual studies with degus (Helmeke et al., 2008) and tree shrews (Czeh et al., 2005) were grouped together for analysis and any possible differences between species or strains were ignored, again for the purpose of limiting study scope. Future studies should take these considerations into account and direct comparisons of stress models, stress doses, and species will be useful to elucidate their respective influences on outcomes of interest.

\section{Concluding remarks}

Despite a largely inconsistent literature, mood disorders and chronic stress in rodents were found to affect PV interneurons most frequently in the PFC, HC, and BLA. The impact of stress on PV interneurons and PNNs in humans is sorely lacking compared to rodents and represents a potentially fruitful avenue of future research. In animals, enrichment paradigms showed some evidence of buffering stress effects on PV interneurons, particularly in the HC. Interestingly, it appears that different 
enrichment types exert unique effects on PV cells, and that these may be region- and age-specific. Finally, sex differences in both PV cell alterations and stress responsiveness were evident and will also require further study.

\section{Author credit roles}

George Perlman: Conceptualization, Data curation, Investigation, Methodology, Writing - Original Draft. Arnaud Tanti: Conceptualization, Writing - Review \& Editing. Naguib Mechawar: Conceptualization, Funding acquisition, Methodology, Writing - Review \& Editing.

\section{Funding}

This work was funded by a CIHR Project grant (PJT-173287) to NM. AT was supported by a Young Investigator grant from AFSP.

\section{Declaration of competing interest}

None.

\section{Acknowledgements}

We would like to extend our thanks to Liam O'Leary for creating the graphical abstract.

\section{Appendix A. Supplementary data}

Supplementary data to this article can be found online at https://doi. org/10.1016/j.ynstr.2021.100380.

Studies of particular significance are bolded. Mouse and rat life stages were defined as follows: early postnatal: P0-19 (postnatal day 0-19, where day of birth is P0; juvenile: P20-30; adolescent: P31-60; and adult: P61+. Degus were examined at P45 and P90, which were termed juveniles and adolescents, respectively according to information from Colby et al. (2012). Abbreviations: BrdU: bromodeoxyuridine; CMS: chronic mild stress; CSIS: chronic social instability stress; CUS: chronic unpredictable stress; GAD1/GAD67: glutamate decarboxylase; GD\#: gestational day, where day of fertilization is GD0; HET: heterozygous; IHC: immunohistochemistry; IP: intraperitoneal; LB/LN: limited bedding/limited nesting; LH: learned helplessness; MS: maternal separation; PH: prominent Ih (defined in paper); qPCR: quantitative polymerase chain reaction; RS: restraint stress; SI: social isolation; UCMS: unpredictable chronic mild stress; WFA: Wisteria floribunda agglutinin.

\section{References}

Alcaide, J., Guirado, R., Crespo, C., Blasco-Ibanez, J.M., Varea, E., Sanjuan, J., Nacher, J., 2019. Alterations of perineuronal nets in the dorsolateral prefrontal cortex of neuropsychiatric patients. Int J Bipolar Disord 7 (1), 24.

Altemus, Margaret, et al., 2014. Sex differences in anxiety and depression clinical perspectives. Frontiers in neuroendocrinology 35 (3), 320-330. https://doi.org/ 10.1016/j.yfrne.2014.05.004.

Amilhon, B., Huh, C.Y., Manseau, F., Ducharme, G., Nichol, H., Adamantidis, A., Williams, S., 2015 Jun 3. Parvalbumin interneurons of Hippocampus tune population activity at theta frequency. Neuron 86 (5), 1277-1289. https://doi.org/ 10.1016/j.neuron.2015.05.027. PMID: 26050044.

Anstotz, M., Lee, S.K., Neblett, T.I., Rune, G.M., Maccaferri, G., 2018. Experiencedependent regulation of Cajal-Retzius cell networks in the developing and adult mouse Hippocampus. Cerebr. Cortex 28 (2), 672-687.

Antila, H., Ryazantseva, M., Popova, D., Sipila, P., Guirado, R., Kohtala, S., et al., 2017. Isoflurane produces antidepressant effects and induces TrkB signaling in rodents. Sci. Rep. 7 (1), 7811.

Banasr, M., Lepack, A., Fee, C., Duric, V., Maldonado-Aviles, J., DiLeone, R., Sibille, E. Duman, R.S., Sanacora, G., 2017 Feb. Characterization of GABAergic marker expression in the chronic unpredictable stress model of depression, 2470547017720459 Chronic Stress (Thousand Oaks) 1. https://doi.org/10.1177/ 2470547017720459. Epub 2017 Aug 3. PMID: 28835932; PMCID: PMC5565173.

Bani-Fatemi, A., Tasmim, S., Graff-Guerrero, A., Gerretsen, P., Strauss, J., Kolla, N., Spalletta, G., De Luca, V., 2018 Aug 30. Structural and functional alterations of the suicidal brain: an updated review of neuroimaging studies. Psychiatry Res.
Neuroimaging. 278, 77-91. https://doi.org/10.1016/j.pscychresns.2018.05.008. Epub 2018 May 18. PMID: 29929763.

Bath, K.G., Manzano-Nieves, G., Goodill, H., 2016. Early life stress accelerates behavioral and neural maturation of the hippocampus in male mice. Horm. Behav. 82, 64-71.

Beasley, C.L., Zhang, Z.J., Patten, I., Reynolds, G.P., 2002. Selective deficits in prefrontal cortical GABAergic neurons in schizophrenia defined by the presence of calciumbinding proteins. Biol. Psychiatr. 52 (7), 708-715.

Berretta, S., Pantazopoulos, H., Markota, M., Brown, C., Batzianouli, E.T., 2015. Losing the sugar coating: potential impact of perineuronal net abnormalities on interneurons in schizophrenia. Schizophr. Res. 167 (1-3), 18-27. https://doi.org/ 10.1016/j.schres.2014.12.040.

Berretta, S., Pantazopoulos, H., Heckers, S., Benes, F.M., Walsh, J., 2003. Decreases in volume and parvalbumin-imunoreactive neurons in the amygdala of schizophrenic and bipolar disorder patients. Schizophrenia Research 60 (1), 68-69.

Bicks, L.K., Yamamuro, K., Flanigan, M.E., et al., 2020. Prefrontal parvalbumin interneurons require juvenile social experience to establish adult social behavior. Nat Commun 11, 1003. https://doi.org/10.1038/s41467-020-14740-z.

Bitanihirwe, B.K.Y., Lim, M.P., Woo, T.U.W., 2010. N-methyl-D-aspartate receptor expression in parvalbumin-containing inhibitory neurons in the prefrontal cortex in bipolar disorder. Bipolar Disord. 12 (1), 95-101.

Björkqvist, K., 2001 Jun. Social defeat as a stressor in humans. Physiol. Behav. 73 (3), 435-442. https://doi.org/10.1016/s0031-9384(01)00490-5. PMID: 11438372.

Black, C.N., Bot, M., Scheffer, P.G., Cuijpers, P., Penninx, B.W., 2015 Jan. Is depression associated with increased oxidative stress? A systematic review and meta-analysis. Psychoneuroendocrinology 51, 164-175. https://doi.org/10.1016/j. psyneuen.2014.09.025. Epub 2014 Oct 2. PMID: 25462890.

Boyle, Lara M., Jun. 2013. "A neuroplasticity hypothesis of chronic stress in the basolateral amygdala.". The Yale journal of biology and medicine vol. 86,2 117-25 13.

Bradshaw, K.P., Figueroa Velez, D.X., Habeeb, M., et al., 2018. Precocious deposition of perineuronal nets on Parvalbumin inhibitory neurons transplanted into adult visual cortex. Sci. Rep. 8, 7480. https://doi.org/10.1038/s41598-018-25735-8.

Brannigan, R., Cannon, M., Tanskanen, A., Huttunen, M.O., Leacy, F.P., Clarke, M.C., 2019. The association between subjective maternal stress during pregnancy and offspring clinically diagnosed psychiatric disorders. Acta Psychiatr. Scand. 139 (4), 304-310. https://doi.org/10.1111/acps.12996.

Brenhouse, H.C. Andersen, S.L., 2011. Nonsteroidal anti-inflammatory treatment prevents delayed effects of early life stress in rats. Biol. Psychiatr. 70 (5), 434-440.

Brydges, N.M., Moon, A., Rule, L., Watkin, H., Thomas, K.L., Hall, J., 2018. Sex specific effects of pre-pubertal stress on hippocampal neurogenesis and behaviour. Transl. Psychiatry 8 (1), 271.

Cabungcal, J.H., Steullet, P., Kraftsik, R., Cuenod, M., Do, K.Q., 2013 Mar 15. Early-life insults impair parvalbumin interneurons via oxidative stress: reversal by $\mathrm{N}$ acetylcysteine. Biol. Psychiatr. 73 (6), 574-582. https://doi.org/10.1016/j. biopsych.2012.09.020. Epub 2012 Nov 7. PMID: 23140664.

Carceller, H., Guirado, R., Ripolles-Campos, E., Teruel-Marti, V., Nacher, J., 2020 Jun 24. Perineuronal nets regulate the inhibitory perisomatic input onto parvalbumin interneurons and $\gamma$ activity in the prefrontal cortex. J. Neurosci. 40 (26), 5008-5018. https://doi.org/10.1523/JNEUROSCI.0291-20.2020. Epub 2020 May 26. PMID: 32457072; PMCID: PMC7314408.

Chen, C.C., Lu, J., Yang, R., Ding, J.B., Zuo, Y., 2018. Selective activation of parvalbumin interneurons prevents stress-induced synapse loss and perceptual defects. Mol. Psychiatr. 23 (7), 1614-1625.

Christensen, A.C., Lensjø, K.K., Lepperød, M.E., et al., 2021. Perineuronal nets stabilize the grid cell network. Nat Commun 12, 253. https://doi.org/10.1038/s41467-02020241-w.

Chu, X., Zhou, Y., Hu, Z., Lou, J., Song, W., Li, J., Liang, X., Chen, C., Wang, S., Yang, B., Chen, L., Zhang, X., Song, J., Dong, Y., Chen, S., He, L., Xie, Q., Chen, X., Li, W. 2016. 24-hour-restraint stress induces long-term depressive-like phenotypes in mice. Scientific reports 6 (32935). https://doi.org/10.1038/srep32935.

Chung, D.W., Chung, Y., Bazmi, H.H., Lewis, D.A., 2018. Altered ErbB4 splicing and cortical parvalbumin interneuron dysfunction in schizophrenia and mood disorders. Neuropsychopharmacology 43 (12), 2478-2486.

Clarke, D.J., Chohan, T.W., Kassem, M.S., Smith, K.L., Chesworth, R., Karl, T., Arnold, J. C., 2019. Neuregulin 1 deficiency modulates adolescent stress-induced dendritic spine loss in a brain region-specific manner and increases complement 4 expression in the Hippocampus. Schizophr. Bull. 45 (2), 339-349.

Colby, Lesley F., Rush, Howard G., Mahoney, Megan M., Lee, Theresa M., 2012. Degu. The laboratory Rabbit, Guinea pig, Hamster, and other rodents. American College of Laboratory Animal Medicine 1031-1053.

Cotter, D., au, S., Beasley, C., Stevenson, R., Chana, G., MacMillan, L., Everall, I., 2002. The density and spatial distribution of GABAergic neurons, labelled using calcium binding proteins, in the anterior cingulate cortex in major depressive disorder, bipolar disorder, and schizophrenia. Biol. Psychiatr. 51 (5), 377-386.

Csabai, D., Seress, L., Varga, Z., Abraham, H., Miseta, A., Wiborg, O., Czeh, B., 2017. Electron microscopic analysis of hippocampal axo-somatic synapses in a chronic stress model for depression. Hippocampus 27 (1), 17-27.

Czeh, B., Simon, M., van der Hart, M.G.C., Schmelting, B., Hesselink, M.B., Fuchs, E., 2005. Chronic stress decreases the number of parvalbumin-immunoreactive Interneurons in the hippocampus: prevention by treatment with a substance $\mathrm{P}$ receptor (NK1) antagonist. Neuropsychopharmacology 30 (1), 67-79.

Czeh, B., Varga, Z.K., Henningsen, K., Kovacs, G.L., Miseta, A., Wiborg, O., 2015. Chronic stress reduces the number of GABAergic interneurons in the adult rat hippocampus, dorsal-ventral and region-specific differences. Hippocampus 25 (3), 393-405. 
Czeh, B., Vardya, I., Varga, Z., Febbraro, F., Csabai, D., Martis, L.S., et al., 2018. Longterm stress disrupts the structural and functional integrity of GABAergic neuronal networks in the medial prefrontal cortex of rats. Front Cell Neurosci 12, 148.

Deng, X., Gu, L., Sui, N., Guo, J., Liang, J., 2020. Parvalbumin interneuron in the ventral hippocampus functions as a discriminator in social memory. Proc. Natl. Acad. Sci. U. S. A. 116 (33), 16583-16592. https://doi.org/10.1073/pnas.1819133116.

do Prado, C.H., Narahari, T., Holl, F.H., Lee, H.N., Murthy, S.K., Brenhouse, H.C., 2015. Effects of early adolescent environmental enrichment on cognitive dysfunction, prefrontal cortex development, and inflammatory cytokines after early life stress. Dev. Psychobiol. 58 (4), 482-491.

Donato, F., Rompani, S.B., Caroni, P., 2013. Parvalbumin-expressing basket-cell network plasticity induced by experience regulates adult learning. Nature 504 (7479), 272-276.

Dricks, S., 2016. Effects of neonatal stress on gamma oscillations in hippocampus. Sci. Rep. 6, 29007.

Duman, R., Aghajanian, G., Sanacora, G., et al., 2016. Synaptic plasticity and depression: new insights from stress and rapid-acting antidepressants. Nat. Med. 22, 238-249. https://doi.org/10.1038/nm.4050.

Ebertowska, A., Ludkiewicz, B., Melka, N., Klejbor, I., Morys, J., 2020. The influence of early postnatal chronic mild stress stimulation on the activation of amygdala in adult rat. J Chem Neuroanat 104, 101743.

Favuzzi, E., Marques-Smith, A., Deogracias, R., Winterflood, C.M., Sánchez-Aguilera, A., Mantoan, L., Maeso, P., Fernandes, C., Ewers, H., Rico, B., 2017 Aug 2. Activitydependent gating of parvalbumin interneuron function by the perineuronal net protein Brevican, 639-655.e10 Neuron 95 (3). https://doi.org/10.1016/j. neuron.2017.06.028. Epub 2017 Jul 14. PMID: 28712654.

Felitti, V.J., Anda, R.F., Nordenberg, D., Williamson, D.F., Spitz, A.M., Edwards, V., Koss, M.P., Marks, J.S., 1998 May. Relationship of childhood abuse and household dysfunction to many of the leading causes of death in adults. The Adverse Childhood Experiences (ACE) Study. Am J Prev Med 14 (4), 245-258. https://doi.org/10.1016/ s0749-3797(98)00017-8. PMID: 9635069.

Filipović, D., Zlatković, J., Inta, D., Bjelobaba, I., Stojiljkovic, M., Gass, P., 2011 Sep. Chronic isolation stress predisposes the frontal cortex but not the hippocampus to the potentially detrimental release of cytochrome $\mathrm{c}$ from mitochondria and the activation of caspase-3. J. Neurosci. Res. 89 (9), 1461-1470. https://doi.org/ 10.1002/jnr.22687. Epub 2011 Jun 8. PMID: 21656845.

Filipović, D., Zlatković, J., Gass, P., Inta, D., 2013 Apr 16. The differential effects of acute vs. chronic stress and their combination on hippocampal parvalbumin and inducible heat shock protein 70 expression. Neuroscience 236, 47-54. https://doi.org/ 10.1016/j.neuroscience.2013.01.033. Epub 2013 Jan 25. PMID: 23352936.

Filipović, D., Stanisavljevic, A., Jasnic, N., Bernardi, R.E., Inta, D., Peric, I., Gass, P., 2017. Chronic treatment with fluoxetine or clozapine of socially isolated rats prevents subsector-specific reduction of parvalbumin immunoreactive cells in the Hippocampus. Neuroscience 371, 384-394.

Foscarin, Simona, et al., 2017. Brain ageing changes proteoglycan sulfation, rendering perineuronal nets more inhibitory. Aging 9 (6), 1607-1622. https://doi.org/ 10.18632/aging.101256.

Friedman, A., Homma, D., Bloem, B., Gibb, L.G., Amemori, K.I., Hu, D., et al., 2017. Chronic stress alters striosome-Circuit dynamics, leading to aberrant decisionmaking. Cell 171 (5). https://doi.org/10.1016/j.cell.2017.10.017, 1191-1205 e1128.

Furman, O., Tsoory, M., Chen, A., 2019. Sex differences in chronic social stress models in mice. bioRxiv, 605527. https://doi.org/10.1101/605527.

Galea, L.A., McEwen, B.S., Tanapat, P., Deak, T., Spencer, R.L., Dhabhar, F.S., 1997 Dec. Sex differences in dendritic atrophy of CA3 pyramidal neurons in response to chronic restraint stress. Neuroscience 81 (3), 689-697. https://doi.org/10.1016/s0306-4522 (97)00233-9. PMID: 9316021.

Ganguly, P., Holl, F.H., Brenhouse, H.C., 2015. Functional uncoupling NMDAR NR2A subunit from PSD-95 in the prefrontal cortex: effects on behavioral dysfunction and parvalbumin loss after early-life stress. Neuropsychopharmacology 40 (12), 2666-2675.

Gee, D.G., Casey, B.J., 2015 Jan 1. The impact of developmental timing for stress and Recovery. Neurobiol Stress 1, 184-194. https://doi.org/10.1016/j. ynstr.2015.02.001. PMID: 25798454; PMCID: PMC4363736.

Giachino, C., Canalia, N., Capone, F., Fasolo, A., Alleva, E., Riva, M.A., et al., 2007. Maternal deprivation and early handling affect density of calcium binding proteincontaining neurons in selected brain regions and emotional behavior in periadolescent rats. Neuroscience 145 (2), 568-578. https://doi.org/10.1016/j. neuroscience.2006.12.042

Gildawie, K.R., Honeycutt, J.A., Brenhouse, H.C., 2019. Region-specific effects of maternal separation on perineuronal net and parvalbumin-expressing interneuron formation in male and female rats. Neuroscience 428, 23-37.

Gildawie, K.R., Ryll, L.M., Hexter, J.C., Peterzell, S., Valentine, A.A., Brenhouse, H.C., 2021 Apr. A two-hit adversity model in developing rats reveals sex-specific impacts on prefrontal cortex structure and behavior. Dev Cogn Neurosci 48, 100924. https:// doi.org/10.1016/j.dcn.2021.100924. Epub 2021 Jan 27. PMID: 33515957; PMCID: PMC7847967.

Giovanoli, S., ra Weber, L., Meyer, U., 2014. Single and combined effects of prenatal immune activation and peripubertal stress on parvalbumin and reelin expression in the hippocampal formation. Brain Behav. Immun. 40, 48-54.

Girgenti, M.J., Wohleb, E.S., Mehta, S., et al., 2019. Prefrontal cortex interneurons display dynamic sex-specific stress-induced transcriptomes. Transl. Psychiatry 9 , 292. https://doi.org/10.1038/s41398-019-0642-z.

Godavarthi, S.K., Sharma, A., Jana, N.R., 2014. Reversal of reduced parvalbumin neurons in hippocampus and amygdala of Angelman syndrome model mice by chronic treatment of fluoxetine. J. Neurochem. 130 (3), 444-454.
Gomes, F.V., Zhu, X., Grace, A.A., 2019. The pathophysiological impact of stress on the dopamine system is dependent on the state of the critical period of vulnerability. Mol. Psychiatr. 25, 3278-3291.

Gomes da Silva, S., Dona, F., Fern, d.S., es, M.J., Scorza, F.A., Cavalheiro, E.A., Arida, R. M., 2010. Physical exercise during the adolescent period of life increases hippocampal parvalbumin expression. Brain Dev. 32 (2), 137-142.

Goodwill, H.L., Manzano-Nieves, G., LaChance, P., Teramoto, S., Lin, S., Lopez, C., et al., 2018. Early life stress drives sex-selective impairment in reversal learning by affecting parvalbumin interneurons in orbitofrontal cortex of mice. Cell Rep. 25 (9), 2299-2307 e2294.

Grassi-Oliveira, R., Honeycutt, J.A., Holl, F.H., Ganguly, P., Brenhouse, H.C., 2016. Cognitive impairment effects of early life stress in adolescents can be predicted with early biomarkers: impacts of sex, experience, and cytokines. Psychoneuroendocrinology 71, 19-30.

Greene, J.R.T., Kerkhoff, J.E., Guiver, L., Totterdell, S., 2001. Structural and functional abnormalities of the hippocampal formation in rats with environmentally induced reductions in prepulse inhibition of acoustic startle. Neuroscience 103 (2), 315-323. https://doi.org/10.1016/S0306-4522(00)00560-1. ISSN 0306-4522.

Guadagno, A., Verlezza, S., Long, H., Wong, T., Walker, C., Guadagno, A., et al., 2020. It is all in the Right amygdala: increased synaptic plasticity and perineuronal nets in male, but not female, juvenile rat pups after exposure to early-life stress. J. Neurosci. 40 (43), 8276-8291. Retrieved from. https://www.jneurosci.org/content/40/43/ 8276.long.

Guirado, Ramon, perez-Rando, Marta, sanchez-Matarredona, david, Castrén, Eero, Nacher, juan, October 2014. chronic fluoxetine treatment alters the structure, connectivity and plasticity of cortical interneurons. Int. J. Neuropsychopharmacol. 17 (10) https://doi.org/10.1017/S1461145714000406. Pages 1635-1646.

Hare, B.D., Duman, R.S., 2020. Prefrontal cortex circuits in depression and anxiety: contribution of discrete neuronal populations and target regions. Mol. Psychiatr. 25, 2742-2758. https://doi.org/10.1038/s41380-020-0685-9.

Harte, M.K., Powell, S.B., Swerdlow, N.R., Geyer, M.A., Reynolds, G.P., 2007. Deficits in parvalbumin and calbindin immunoreactive cells in the hippocampus of isolation reared rats. J Neural Transm (Vienna) 114 (7), 893-898. https://doi.org/10.1007/ s00702-007-0627-6.

Helmeke, C., Ovtscharoff Jr., W., Poeggel, G., Braun, K., 2008. Imbalance of immunohistochemically characterized interneuron populations in the adolescent and adult rodent medial prefrontal cortex after repeated exposure to neonatal separation stress. Neuroscience 152 (1), 18-28.

Heslin, K., Coutellier, L., 2018. Npas4 deficiency and prenatal stress interact to affect social recognition in mice. Gene Brain Behav. 17 (5), e12448.

Holl, F.H., Ganguly, P., Potter, D.N., Chartoff, E.H., Brenhouse, H.C., 2014. Early life stress disrupts social behavior and prefrontal cortex parvalbumin interneurons at an earlier time-point in females than in males. Neuroscience letters 566, 131-136.

Holm, M.M., Nieto-Gonzalez, J.L., Vardya, I., Henningsen, K., Jayatissa, M.N. Wiborg, O., Jensen, K., 2011. Hippocampal GABAergic dysfunction in a rat chronic mild stress model of depression. Hippocampus 21 (4), 422-433.

Hu, W., Zhang, M., Czeh, B., Flugge, G., Zhang, W., 2010. Stress impairs GABAergic network function in the hippocampus by activating nongenomic glucocorticoid receptors and affecting the integrity of the parvalbumin-expressing neuronal network. Neuropsychopharmacology 35 (8), 1693-1707. https://doi.org/10.1038/ npp. 2010.31.

Hu, H., Gan, J., Jonas, P., 2014. Interneurons. Fast-spiking, parvalbumin ${ }^{+}$GABAergic interneurons: from cellular design to microcircuit function. Science 345 (6196), 1255263. https://doi.org/10.1126/science.1255263.

Ieraci, A., Mallei, A., Popoli, M., 2016. Social isolation stress induces anxious-depressivelike behavior and alterations of neuroplasticity-related genes in adult male mice. Neural plasticity 2016 (6212983). https://doi.org/10.1155/2016/6212983.

Iñiguez, S.D., Riggs, L.M., Nieto, S.J., Dayrit, G., Zamora, N.N., Shawhan, K.L., Cruz, B., Warren, B.L., 2014. Social defeat stress induces a depression-like phenotype in adolescent male c57BL/6 mice. Stress (Amsterdam, Netherlands) 17 (3), 247-255 https://doi.org/10.3109/10253890.2014.910650.

Jargalsaikhan, U., Nishimaru, H., Matsumoto, J., Takamura, Y., Nakamura, T., Hori, E., et al., 2017. Ingestion of dried-bonito broth (dashi) facilitates PV-parvalbuminimmunoreactive neurons in the brain, and affects emotional behaviors in mice. Nutritional neuroscience 20 (10), 571-586.

Jiang, X., Xing, G., Yang, C., Verma, A., Zhang, L., Li, H., 2009. Stress impairs 5-HT2A receptor-mediated serotonergic facilitation of GABA release in juvenile rat basolateral amygdala. Neuropsychopharmacology 34 (2), 410-423.

Kaar, S.J., Angelescu, I., Marques, T.R., et al., 2019. Pre-frontal parvalbumin interneurons in schizophrenia: a meta-analysis of post-mortem studies. J Neural Transm 126, 1637-1651. https://doi.org/10.1007/s00702-019-02080-2.

Karpova, Nina N., et al., 2011. "Fear erasure in mice requires synergy between antidepressant drugs and extinction training.". Science (New York, N.Y.) 334, 1731-1734. https://doi.org/10.1126/science.1214592, 6063.

Katahira, T., Miyazaki, N., Motoyama, J., 2018. Immediate effects of maternal separation on the development of interneurons derived from medial ganglionic eminence in the neonatal mouse hippocampus. Dev Growth Differ 60 (5), 278-290.

Khundakar, A., Morris, C., Thomas, A.J., 2010. The immunohistochemical examination of GABAergic interneuron markers in the dorsolateral prefrontal cortex of patients with late-life depression. Int Psychogeriatr 23 (4), 644-653.

Kim, H.B., Yoo, J.Y., Yoo, S.Y., Suh, S.W., Lee, S., Park, J.H., Lee, J.H., Baik, T.K., Kim, H. S., Woo, R.S., 2020 Aug 8. Early-life stress induces EAAC1 expression reduction and attention-deficit and depressive behaviors in adolescent rats. Cell Death Dis. 6:73. doi: 10.1038/s41420-020-00308-9. Erratum in: Cell Death Discov. 2020 Nov 10;6 (1):120. PMID: 32818073; PMCID: PMC7415155. 
Kim, Deborah R., et al., 2015. "Prenatal programming of mental illness: current understanding of relationship and mechanisms.". Article 5 (published online; no pages) 17. https://doi.org/10.1007/s11920-014-0546-9.

Knable, M.B., Barci, B.M., Webster, M.J., Meador-Woodruff, J., Torrey, E.F., 2004. Molecular abnormalities of the hippocampus in severe psychiatric illness: postmortem findings from the Stanley Neuropathology Consortium. Mol. Psychiatr. 9 (6), 609-620, 544.

Knowl, D., Lilascharoen, V., Pacia, C.P., Shin, S., Wang, E.H., Lim, B.K., 2017. Distinct ventral pallidal neural populations mediate separate symptoms of depression. Cell 170 (2), 284-297 e218.

Kong, Y., Wang, T., Wang, R., Ma, Y., Song, S., Liu, J., et al., 2017. Inhalation of Roman chamomile essential oil attenuates depressive-like behaviors in Wistar Kyoto rats. Sci China Life Sci 60 (6), 647-655.

Konradi, C., Zimmerman, E.I., Yang, C.K., Lohmann, K.M., Gresch, P., Pantazopoulos, H., et al., 2011. Hippocampal interneurons in bipolar disorder. Arch. Gen. Psychiatr. 68 (4), 340-350.

Koskinen, M.-K., van Mourik, Y., Smit, A.B., Riga, D., Spijker, S., 2019. From stress to depression: development of extracellular matrix-dependent cognitive impairment following social stress. bioRxiv, 806935. https://doi.org/10.1101/806935.

Krugers, H.J., Koolhaas, J.M., Medema, R.M., Korf, J., 1996. Prolonged subordination stress increases Calbindin-D28k immunoreactivity in the rat hippocampal CA1 area. Brain Res. 729 (2), 289-293.

Laubach, Mark, et al., Oct. 2018. What, if anything, is rodent prefrontal cortex? eNeuro vol. 5,5 ENEURO.0315-18.2018 25. https://doi.org/10.1523/ENEURO.031518.2018 .

Lauber, Emanuel, et al., Aug. 2018. "Dysregulation of parvalbumin expression in the Cntnap2-/- mouse model of autism spectrum disorder.". Frontiers in molecular neuroscience vol 11262 (2). https://doi.org/10.3389/fnmol.2018.00262.

Lee, S., Kang, B.M., Shin, M.K., Min, J., Heo, C., Lee, Y., et al., 2015. Chronic stress decreases Cerebrovascular responses during rat Hindlimb electrical stimulation. Front. Neurosci. 9, 462.

Leigh-Hunt, N., Bagguley, D., Bash, K., Turner, V., Turnbull, S., Valtorta, N., Caan, W., 2017 Nov. An overview of systematic reviews on the public health consequences of social isolation and loneliness. Public Health 152, 157-171. https://doi.org/ 10.1016/j.puhe.2017.07.035. Epub 2017 Sep 12. PMID: 28915435.

Lensjø, K.K., Lepperød, M.E., Dick, G., Hafting, T., Fyhn, M., 2017 Feb 1. Removal of perineuronal nets unlocks juvenile plasticity through network mechanisms of decreased inhibition and increased gamma activity. J. Neurosci. 37 (5), 1269-1283. https://doi.org/10.1523/JNEUROSCI.2504-16.2016. Epub 2016 Dec 30. PMID: 28039374; PMCID: PMC6596863.

Leussis, M.P., Freund, N., Brenhouse, H.C., Thompson, B.S., Andersen, S.L., 2012. Depressive-like behavior in adolescents after maternal separation: sex differences, controllability, and GABA. Dev. Neurosci. 34 (2), 210-217.

Liu, Wei, et al., 2017. "The role of neural plasticity in depression: from Hippocampus to prefrontal cortex.”. Neural plasticity 2017, 6871089. https://doi.org/10.1155/ $2017 / 6871089$.

Luine, Victoria, et al., 2017. "Sex differences in chronic stress effects on cognition in rodents.". Pharmacology, biochemistry, and behavior 152, 13-19. https://doi.org/ 10.1016/j.pbb.2016.08.005.

Lukkes, J.L., Burke, A.R., Zelin, N.S., Hale, M.W., Lowry, C.A., 2012. Post-weaning social isolation attenuates c-Fos expression in GABAergic interneurons in the basolateral amygdala of adult female rats. Physiol. Behav. 107 (5), 719-725.

Lukkes, J.L., Meda, S., Thompson, B.S., Freund, N., Andersen, S.L., 2017. Early life stress and later peer distress on depressive behavior in adolescent female rats: effects of a novel intervention on GABA and D2 receptors. Behav. Brain Res. 330, 37-45.

Lukkes, J.L., Meda, S., Norman, K.J., Andersen, S.L., 2018. Anhedonic behavior and gamma-amino butyric acid during a sensitive period in female rats exposed to early adversity. J Psychiatr Res 100, 8-15.

Luo, Z.Y., Huang, L., Lin, S., Yin, Y.N., Jie, W., Hu, N.Y., et al., 2020. Erbin in amygdala parvalbumin-positive neurons modulates anxiety-like behaviors. Biol. Psychiatr. 87 (10), 926-936. https://doi.org/10.1016/j.biopsych.2019.10.021.

Lussier, S.J., Stevens, H.E., 2016. Delays in GABAergic interneuron development and behavioral inhibition after prenatal stress. Dev Neurobiol 76 (10), 1078-1091.

Maćkowiak, M., Latusz, J., Głowacka, U., Bator, E., Bilecki, W., 2019 Feb. Adolescent social isolation affects parvalbumin expression in the medial prefrontal cortex in the MAM-E17 model of schizophrenia. Metab. Brain Dis. 34 (1), 341-352. https://doi. org/10.1007/s11011-018-0359-3. Epub 2018 Dec 5. PMID: 30519836.

Matthews, R.T., Kelly, G.M., Zerillo, C.A., Gray, G., Tiemeyer, M., Hockfield, S., 2002 Sep 1. Aggrecan glycoforms contribute to the molecular heterogeneity of perineuronal nets. J. Neurosci. 22 (17), 7536-7547. https://doi.org/10.1523/JNEUROSCI.22-1707536.2002. PMID: 12196577; PMCID: PMC6757962.

McEwen, B., Nasca, C., Gray, J., 2016. Stress effects on neuronal structure: Hippocampus, amygdala, and prefrontal cortex. Neuropsychopharmacology 41, 3-23. https://doi. org/10.1038/npp.2015.171.

McHugh, P.C., Rogers, G.R., Glubb, D.M., Joyce, P.R., Kennedy, M.A., 2009. Proteomic analysis of rat hippocampus exposed to the antidepressant paroxetine. J Psychopharmacol 24 (8), 1243-1251.

McKlveen, Jessica M., et al., 2016. "Chronic stress increases prefrontal inhibition: a mechanism for stress-induced prefrontal dysfunction.”. Biological psychiatry vol 80 (10), 754-764. https://doi.org/10.1016/j.biopsych.2016.03.2101.

McKlveen, J.M., Moloney, R.D., Scheimann, J.R., Myers, B., Herman, J.P., 2019 Nov 1. Braking" the prefrontal cortex: the role of glucocorticoids and interneurons in stress adaptation and pathology. Biol. Psychiatr. 86 (9), 669-681. https://doi.org/ 10.1016/j.biopsych.2019.04.032. Epub 2019 May 9. PMID: 31326084.
Megahed, T., Hattiangady, B., Shuai, B., Shetty, A.K., 2014. Parvalbumin and neuropeptide Y expressing hippocampal GABA-ergic inhibitory interneuron numbers decline in a model of Gulf War illness. Front Cell Neurosci 8, 447.

Michel, T.M., Pülschen, D., Thome, J., 2012. The role of oxidative stress in depressive disorders. Curr. Pharmaceut. Des. 18 (36), 5890-5899. https://doi.org/10.2174/ 138161212803523554 . PMID: 22681168.

Mikics, É., Guirado, R., Umemori, J., et al., 2018. Social learning requires plasticity enhanced by fluoxetine through prefrontal Bdnf-TrkB signaling to limit aggression induced by post-weaning social isolation. Neuropsychopharmacology 43, 235-245. https://doi.org/10.1038/npp.2017.142.

Milner, T.A., Burstein, S.R., Marrone, G.F., Khalid, S., Gonzalez, A.D., Williams, T.J., et al., 2013. Stress differentially alters Mu opioid receptor density and trafficking in parvalbumin-containing interneurons in the female and male rat Hippocampus. Synapse 67 (11), 757-772.

Moga, D., Hof, P.R., Vissavajjhala, P., Moran, T.M., Morrison, J.H., 2002 May. Parvalbumin-containing interneurons in rat hippocampus have an AMPA receptor profile suggestive of vulnerability to excitotoxicity. J Chem Neuroanat 23 (4), 249-253. https://doi.org/10.1016/s0891-0618(02)00012-1. PMID: 12048108

Moench, K.M., Breach, M.R., Wellman, C.L., 2020. Prior stress followed by a novel stress challenge results in sex-specific deficits in behavioral flexibility and changes in gene expression in rat medial prefrontal cortex. Horm. Behav. 117, 104615.

Mukhopadhyay, S., Chatterjee, A., Tiwari, P., Ghai, U., Vaidya, V.A., 2021 Apr 13. Postnatal fluoxetine treatment alters perineuronal net formation and Maintenance in the Hippocampus. ENEURO.0424-20.2021 eNeuro 8 (2). https://doi.org/10.1523/ ENEURO.0424-20.2021. PMID: 33622703; PMCID: PMC8046023.

Murthy, Sahana, Gould, Elizabeth, Jul. 2018. "Early life stress in rodents: animal models of illness or resilience?.”. Frontiers in behavioral neuroscience vol 12157 (31). https://doi.org/10.3389/fnbeh.2018.00157.

Murthy, S., Gould, E., 2020. How early life adversity influences defensive circuitry. Trends in neurosciences 43 (4), 200-212.

Murthy, S., Kane, G.A., Katchur, N.J., Lara Mejia, P.S., Obiofuma, G., Buschman, T.J., et al., 2019. Perineuronal nets, inhibitory interneurons, and anxiety-related ventral hippocampal neuronal oscillations are altered by early life adversity. Biol. Psychiatr. 85 (12), 1011-1020.

Nagy, C., Maitra, M., Tanti, A., et al., 2020. Single-nucleus transcriptomics of the prefrontal cortex in major depressive disorder implicates oligodendrocyte precursor cells and excitatory neurons. Nat. Neurosci. 23, 771-781. https://doi.org/10.1038/ s41593-020-0621-y.

Nieves, Gabriela Manzano, Bravo, Marilyn, Baskoylu, Saba, Bath, Kevin G., Jul. 2020. "Early life adversity decreases pre-adolescent fear expression by accelerating amygdala PV cell development.". eLife vol. 9 e55263 21. https://doi.org/10.7554/ eLife.55263.

Ng, F., Berk, M., Dean, O., Bush, A.I., 2008 Sep. Oxidative stress in psychiatric disorders: evidence base and therapeutic implications. Int. J. Neuropsychopharmacol. 11 (6), 851-876. https://doi.org/10.1017/S1461145707008401. Epub 2008 Jan 21. PMID: 18205981.

Ng, L.H.L., Huang, Y., Han, L., Chang, R.C.-C., Chan, Y.S., Lai, C.S.W., 2018. Ketamine and selective activation of parvalbumin interneurons inhibit stress-induced dendritic spine elimination. Translational psychiatry 8 (1), 272.

Nguyen, J.C., Killcross, A.S., Jenkins, T.A., 2013. Effect of low-intensity treadmill exercise on behavioural measures and hippocampal parvalbumin immunoreactivity in the rat. Behav. Brain Res. 256, 598-601.

Nieto-Gonzalez, J.L., Holm, M.M., Vardya, I., Christensen, T., Wiborg, O., Jensen, K., 2015. Presynaptic plasticity as a hallmark of rat stress susceptibility and antidepressant response. PloS One 10 (3) e0119993.

Nowak, B., Zadrozna, M., Ossowska, G., Sowa-Kucma, M., Gruca, P., Papp, M., et al., 2010. Alterations in hippocampal calcium-binding neurons induced by stress models of depression: a preliminary assessment. Pharmacol. Rep. 62 (6), 1204-1210.

O'Connor, A.M., Burton, T.J., Mansuri, H., G, R., Leamey, C.A., Sawatari, A., 2019. Environmental enrichment from birth impacts parvalbumin expressing cells and Wisteria floribunda agglutinin labelled peri-neuronal nets within the developing Murine striatum. Front Neuroanat 13, 90.

Ohira, K., Takeuchi, R., Iwanaga, T., Miyakawa, T., 2013. Chronic fluoxetine treatment reduces parvalbumin expression and perineuronal nets in gamma-aminobutyric acidergic interneurons of the frontal cortex in adult mice. Mol. Brain 6, 43.

Ohta, K.I., Suzuki, S., Warita, K., Sumitani, K., Tenkumo, C., Ozawa, T., et al., 2020. The effects of early life stress on the excitatory/inhibitory balance of the medial prefrontal cortex. Behav. Brain Res. 379, 112306. https://doi.org/10.1016/j. bbr.2019.112306.

Okine, Tracy, Shepard, Ryan, Lemanski, Elise, Coutellier, Laurence, Oct. 2020. "Sex differences in the sustained effects of ketamine on resilience to chronic stress.". Frontiers in behavioral neuroscience vol 14581360 (20). https://doi.org/10.3389/ fnbeh.2020.581360.

Olson, K.C., Carroll, H.A., Lustyk, M.K.B., 2015. Psychophysiological stress reactivity relationships across the Menstrual cycle. Journal of Hormones 2015, 631250. https://doi.org/10.1155/2015/631250.

Ossewaarde, Lindsey, et al., 2013. "Menstrual cycle-related changes in amygdala morphology are associated with changes in stress sensitivity.". Human brain mapping vol 34 (5), 1187-1193. https://doi.org/10.1002/hbm.21502.

Page, C.E., Coutellier, L., 2018. Adolescent stress disrupts the maturation of anxietyrelated behaviors and alters the developmental trajectory of the prefrontal cortex in a sex- and age-specific manner. Neuroscience 390, 265-277.

Page, C.E., Alexander, J., Shepard, R., Coutellier, L., 2018. Npas4 deficiency interacts with adolescent stress to disrupt prefrontal GABAergic maturation and adult cognitive flexibility. Gene Brain Behav. 17 (6), e12459. 
Page, C.E., Coutellier, L., 2019 Oct. Prefrontal excitatory/inhibitory balance in stress and emotional disorders: evidence for over-inhibition. Neurosci Biobehav Rev. 105, 39-51. https://doi.org/10.1016/j.neubiorev.2019.07.024. Epub 2019 Aug 1. PMID: 31377218.

Page, C.E., Shepard, R., Heslin, K., Coutellier, L., 2019. Prefrontal parvalbumin cells are sensitive to stress and mediate anxiety-related behaviors in female mice. Sci. Rep. 9 (1), 19772

Pantazopoulos, H., Lange, N., Baldessarini, R.J., Berretta, S., 2007. Parvalbumin neurons in the entorhinal cortex of subjects diagnosed with bipolar disorder or schizophrenia. Biological Psychiatry 61 (5), 640-652.

Pantazopoulos, H., Woo, T.U., Lim, M.P., Lange, N., Berretta, S., 2010. Extracellular matrix-glial abnormalities in the amygdala and entorhinal cortex of subjects diagnosed with schizophrenia. Arch. Gen. Psychiatr. 67 (2), 155-166. https://doi. org/10.1001/archgenpsychiatry.2009.196.

Peric, I., Stanisavljevic, A., Inta, D., Gass, P., Lang, U.E., Borgwardt, S., Filipovic, D., 2018. Tianeptine antagonizes the reduction of PV + and GAD67 cells number in dorsal hippocampus of socially isolated rats. Prog Neuropsychopharmacol Biol Psychiatry 89, 386-399.

Perova, Z., Delevich, K., Li, B., 2015. Depression of excitatory synapses onto parvalbumin interneurons in the medial prefrontal cortex in susceptibility to stress. J. Neurosci. 35 (7), 3201-3206.

Pesarico, A.P., Bueno-Fernandez, C., Guirado, R., Gomez-Climent, M.A., Curto, Y., et al., 2019. Chronic stress modulates interneuronal plasticity: effects on PSA-NCAM and perineuronal nets in cortical and extracortical regions. Front Cell Neurosci 13, 197.

Planchez, B., Surget, A., Belzung, C., 2019 Nov. Animal models of major depression: drawbacks and challenges. J Neural Transm (Vienna) 126 (11), 1383-1408. https:// doi.org/10.1007/s00702-019-02084-y. Epub 2019 Oct 4. PMID: 31584111; PMCID: PMC6815270.

Prévot, T., Sibille, E., 2020. Altered GABA-mediated information processing and cognitive dysfunctions in depression and other brain disorders. Mol. Psychiatr. 26, 151-167. https://doi.org/10.1038/s41380-020-0727-3.

Rajkowska, G., O’Dwyer, G., Teleki, Z., Stockmeier, C.A., Miguel-Hidalgo, J.J., 2007. GABAergic neurons immunoreactive for calcium binding proteins are reduced in the prefrontal cortex in major depression. Neuropsychopharmacology 32 (2), 471-482.

Regev-Tsur, S., Demiray, Y.E., Tripathi, K., Stork, O., Richter-Levin, G., Albrecht, A., 2020 Sep. Region-specific involvement of interneuron subpopulations in traumarelated pathology and resilience. Neurobiol Dis 143, 104974. https://doi.org/ 10.1016/j.nbd.2020.104974. Epub 2020 Jun 17. PMID: 32561495.

Reznikov, L.R., Reagan, L.P., Fadel, J.R., 2008. Activation of phenotypically distinct neuronal subpopulations in the anterior subdivision of the rat basolateral amygdala following acute and repeated stress. J Comp Neurol 508 (3), 458-472.

Riga, D., Kramvis, I., Koskinen, M.K., van Bokhoven, P., van der Harst, J.E., Heistek, T.S., et al., 2017. Hippocampal extracellular matrix alterations contribute to cognitive impairment associated with a chronic depressive-like state in rats. Sci Transl Med 9 (421).

Rossetti, A.C., Paladini, M.S., Colombo, M., Gruca, P., Lason-Tyburkiewicz, M., TotaGlowczyk, K., et al., 2018. Chronic stress exposure reduces parvalbumin expression in the rat Hippocampus through an imbalance of redox mechanisms: Restorative effect of the antipsychotic lurasidone. Int. J. Neuropsychopharmacol. 21 (9), 883-893.

Sagi, Y., Medrihan, L., George, K., et al., 2020. Emergence of 5-HT5A signaling in parvalbumin neurons mediates delayed antidepressant action. Mol. Psychiatr. 25, 1191-1201. https://doi.org/10.1038/s41380-019-0379-3.

Sakai, T., Oshima, A., Nozaki, Y., Ida, I., Haga, C., Akiyama, H., et al., 2008. Changes in density of calcium-binding-protein-immunoreactive GABAergic neurons in prefrontal cortex in schizophrenia and bipolar disorder. Neuropathology 28 (2), 143-150.

Salim, Samina, 2017. "Oxidative stress and the central Nervous system.". The Journal of pharmacology and experimental therapeutics vol 360 (1), 201-205. https://doi.org/ 10.1124/jpet.116.237503.

Sampedro-Piquero, P., Castilla-Ortega, E., Zancada-Menendez, C., Santin, L.J., Begega, A., 2016. Environmental enrichment as a therapeutic avenue for anxiety in aged Wistar rats: effect on cat odor exposition and GABAergic interneurons. Neuroscience $330,17-25$.

Santiago, A.N., Lim, K.Y., Opendak, M., Sullivan, R.M., Aoki, C., 2018. Early life trauma increases threat response of peri-weaning rats, reduction of axo-somatic synapses formed by parvalbumin cells and perineuronal net in the basolateral nucleus of amygdala. J. Comp. Neurol. 526 (16), 2647-2664.

Schiavone, S., Sorce, S., Dubois-Dauphin, M., Jaquet, V., Colaianna, M., Zotti, M., et al. 2009. Involvement of NOX2 in the development of behavioral and pathologic alterations in isolated rats. Biol. Psychiatr. 66 (4), 384-392.

Schiavone, S., Jaquet, V., Sorce, S., Dubois-Dauphin, M., Hultqvist, M., Backdahl, L. et al., 2012. NADPH oxidase elevations in pyramidal neurons drive psychosocial stress-induced neuropathology. Transl. Psychiatry 2, e111.

Schiavone, Stefania, et al., 2013. "Severe life stress and oxidative stress in the brain: from animal models to human pathology.". Antioxidants \& redox signaling vol 18 (12), 1475-1490. https://doi.org/10.1089/ars.2012.4720.

Serra, F.T., Araujo, B.H.S., Placencia, E.V.D., Henrique, J.S., Dona, F., Torres, L.B., Fernandes, M.J.D.S., Arida, R.M., Gomes da Silva, S., 2020 Jul. Enriched environment and exercise effects on parvalbumin expression and distribution in the hippocampal formation of developing rats. Brain Res. Bull. 160, 85-90. https://doi. org/10.1016/j.brainresbull.2020.03.021. Epub 2020 Apr 17. PMID: 32305404.

Shepard, R., Page, C.E., Coutellier, L., 2016. Sensitivity of the prefrontal GABAergic system to chronic stress in male and female mice: Relevance for sex differences in stress-related disorders. Neuroscience 332, 1-12.
Shepard, R., Coutellier, L., 2017. Changes in the prefrontal glutamatergic and parvalbumin systems of mice exposed to unpredictable chronic stress. Molecular Neurobiology 55 (3), 2591-2602.

Sibille, Etienne, et al., 2011. "GABA-related transcripts in the dorsolateral prefrontal cortex in mood disorders. Int. J. Neuropsychopharmacol. 14 (6), 721-734. https:// doi.org/10.1017/S1461145710001616.

Smiley, J.F., Hackett, T.A., Bleiwas, C., Petkova, E., Stankov, A., Mann, J.J., et al., 2016. Reduced GABA neuron density in auditory cerebral cortex of subjects with major depressive disorder. J Chem Neuroanat 76, 108-121.

Soares, A.R., Gildawie, K.R., Honeycutt, J.A., Brenhouse, H.C., 2020 Jun 18. Regionspecific effects of maternal separation on oxidative stress accumulation in parvalbumin neurons of male and female rats. Behav. Brain Res. 388, 112658. https://doi.org/10.1016/j.bbr.2020.112658. Epub 2020 Apr 24. PMID: 32339550.

Song, T., Wu, H., Li, R., Xu, H., Rao, X., Gao, L., et al., 2019. Repeated fluoxetine treatment induces long-lasting neurotrophic changes in the medial prefrontal cortex of adult rats. Behav. Brain Res. 365, 114-124.

Spijker, Sabine, Koskinen, Maija-Kreetta, Riga, Danai, 17 July 2020. "Incubation of depression: ECM assembly and parvalbumin interneurons after stress.". Neuroscience \& Biobehavioral Reviews, Pergamon 118 (65-79).

Steullet, P., Cabungcal, J.H., Coyle, J., et al., 2017. Oxidative stress-driven parvalbumin interneuron impairment as a common mechanism in models of schizophrenia. Mol. Psychiatr. 22, 936-943. https://doi.org/10.1038/mp.2017.47.

Steullet, P., Cabungcal, J.H., Bukhari, S.A., Ardelt, M.I., Pantazopoulos, H., Hamati, F., et al., 2018. The thalamic reticular nucleus in schizophrenia and bipolar disorder: role of parvalbumin-expressing neuron networks and oxidative stress. Molecular Psychiatry 23 (10), 2057-2065.

Sun, X.R., Zhang, H., Zhao, H.T., Ji, M.H., Li, H.H., Wu, J., et al., 2016. Amelioration of oxidative stress-induced phenotype loss of parvalbumin interneurons might contribute to the beneficial effects of environmental enrichment in a rat model of post-traumatic stress disorder. Behavioural Brain Research 312, 84-92.

Takahashi, A., Chung, J., Zhang, S., et al., 2017. Establishment of a repeated social defeat stress model in female mice. Sci. Rep. 7, 12838. https://doi.org/10.1038/s41598017-12811-8.

Tanti, A., Belliveau, C., Nagy, C., Denux, F., Perlman, K., et al., 2020. Child abuse associates with increased recruitment of perineuronal nets in the ventromedial prefrontal cortex: evidence for an implication of oligodendrocyte progenitor cells. bioRxiv. https://doi.org/10.1101/2020.10.19.345355, 2020.2010.2019.345355.

Todorovic, N., Micic, B., Schwirtlich, M., Stevanovic, M., Filipovic, D., 2018. Subregionspecific protective effects of fluoxetine and clozapine on parvalbumin expression in medial prefrontal cortex of Chronically isolated rats. Neuroscience 396, 24-35.

Tripp, Adam, et al., 2012. "Brain-derived neurotrophic factor signaling and subgenual anterior cingulate cortex dysfunction in major depressive disorder.". The American journal of psychiatry vol 169 (11), 1194-1202. https://doi.org/10.1176/appi. ajp.2012.12020248.

Uchida, T., Furukawa, T., Iwata, S., Yanagawa, Y., Fukuda, A., 2014. Selective loss of parvalbumin-positive GABAergic interneurons in the cerebral cortex of maternally stressed Gad1-heterozygous mouse offspring. Transl. Psychiatry 4, e371.

Ueno, H., Suemitsu, S., Murakami, S., Kitamura, N., Wani, K., Okamoto, M., et al., 2017. Region-specific impairments in parvalbumin interneurons in social isolation-reared mice. Neuroscience 359, 196-208.

Ueno, H., Suemitsu, S., Murakami, S., Kitamura, N., Wani, K., Matsumoto, Y., et al., 2018. Juvenile stress induces behavioral change and affects perineuronal net formation in juvenile mice. BMC Neurosci. 19 (1), 41.

Umemori, J., Winkel, F., Castrén, E., Karpova, N.N., 2015 Aug. Distinct effects of perinatal exposure to fluoxetine or methylmercury on parvalbumin and perineuronal nets, the markers of critical periods in brain development. Int J Dev Neurosci 44, 55-64. https://doi.org/10.1016/j.ijdevneu.2015.05.006. Epub 2015 May 19. PMID: 25997908.

Urakawa, S., Takamoto, K., Hori, E., Sakai, N., Ono, T., Nishijo, H., 2013. Rearing in enriched environment increases parvalbumin-positive small neurons in the amygdala and decreases anxiety-like behavior of male rats. BMC Neurosci. 14, 13.

Varga, Z., Csabai, D., Miseta, A., Wiborg, O., Czeh, B., 2016. Chronic stress affects the number of GABAergic neurons in the orbitofrontal cortex of rats. Behav. Brain Res. 316, 104-114.

Vazquez-Sanroman, D.B., Arlington Wilson, G., Bardo, M.T., 2021 Jan. Effects of social isolation on perineuronal nets in the amygdala following a reward omission task in female rats. Mol. Neurobiol. 58 (1), 348-361. https://doi.org/10.1007/s12035-02002125-8. Epub 2020 Sep 17. PMID: 32939692.

Volk, D.W., Sampson, A.R., Zhang, Y., Edelson, J.R., Lewis, D.A., 2016. Cortical GABA markers identify a molecular subtype of psychotic and bipolar disorders. Psychol. Med. 46 (12), 2501-2512.

Wang, N., Zhang, G.-F., Liu, X.-Y., Sun, H.-L., Wang, X.-M., Oiu, L.-L., et al., 2014. Downregulation of neuregulin 1-ErbB4 signaling in parvalbumin interneurons in the rat brain may contribute to the antidepressant properties of ketamine. Journal of molecular neuroscience : MN 54 (2), 211-218.

Wang, A.Y., Lohmann, K.M., Yang, C.K., Zimmerman, E.I., Pantazopoulos, H. Herring, N., et al., 2011. Bipolar disorder type 1 and schizophrenia are accompanied by decreased density of parvalbumin- and somatostatin-positive interneurons in the parahippocampal region. Acta Neuropathol. 122 (5), 615-626.

Wang, H.L., Sun, Y.X., Liu, X., Wang, H., Ma, Y.N., Su, Y.A., et al., 2019. Adolescent stress increases depression-like behaviors and alters the excitatory-inhibitory balance in aged mice. Chin Med J (Engl) 132 (14), 1689-1699.

Wang, T., Sinha, A.S., Akita, T., Yanagawa, Y., Fukuda, A., 2018. Alterations of GABAergic neuron-associated extracellular matrix and synaptic responses in gad1heterozygous mice subjected to prenatal stress. Front Cell Neurosci 12, 284. 
Wen, T.H., Binder, D.K., Ethell, I.M., Razak, K.A., 2018. The perineuronal 'safety' net? Perineuronal net abnormalities in Neurological disorders. Frontiers in molecular neuroscience 11 (270). https://doi.org/10.3389/fnmol.2018.00270.

Wieck, A., Andersen, S.L., Brenhouse, H.C., 2013. Evidence for a neuroinflammatory mechanism in delayed effects of early life adversity in rats: relationship to cortical NMDA receptor expression. Brain Behav Immun 28, 218-226.

Wingert, Jereme C., Sorg, Barbara A., May. 2021. "Impact of perineuronal nets on electrophysiology of parvalbumin interneurons, principal neurons, and brain oscillations: a review.”. Frontiers in synaptic neuroscience vol 13673210 (10). https://doi.org/10.3389/fnsyn.2021.673210.

Xiao, Q., Zhou, X., Wei, P., Xie, L., Han, Y., Wang, J., Cai, A., Xu, F., Tu, J., Wang, L., 2020 Jun 18. A new GABAergic somatostatin projection from the BNST onto accumbal parvalbumin neurons controls anxiety. Mol. Psychiatr. https://doi.org/ 10.1038/s41380-020-0816-3. Epub ahead of print. PMID: 32555286.

Yamamuro, Yoshino, Kazuhiko, Hiroki Ogawa, Yoichi, May. 2020. "Juvenile social isolation enhances the activity of inhibitory neuronal circuits in the medial prefrontal cortex.". Frontiers in cellular neuroscience vol 14105 (12). https://doi. org/10.3389/fncel.2020.00105.

Yang, C., Shirayama, Y., Zhang, J.C., Ren, Q., Yao, W., Ma, M., et al., 2015. R-ketamine: a rapid-onset and sustained antidepressant without psychotomimetic side effects. Transl. Psychiatry 5, e632.
Zadrozna, M., Nowak, B., Lason-Tyburkiewicz, M., Wolak, M., Sowa-Kucma, M., Papp, M., et al., 2011. Different pattern of changes in calcium binding proteins immunoreactivity in the medial prefrontal cortex of rats exposed to stress models of depression. Pharmacol. Rep. 63 (6), 1539-1546.

Zaletel, I., Filipović, D., Puškaš, N., 2016 Jun 1. Chronic stress, hippocampus and parvalbumin-positive interneurons: what do we know so far? Rev. Neurosci. 27 (4), 397-409. https://doi.org/10.1515/revneuro-2015-0042. PMID: 26751865.

Zheng, X., Bi, W., Yang, G., Zhao, J., Wang, J., Li, X., Zhou, X., 2018 Dec 19. Hyperglycemia induced by chronic restraint stress in mice is associated with nucleus tractus solitarius injury and not just the direct effect of glucocorticoids. Front. Neurosci. 12, 983. https://doi.org/10.3389/fnins.2018.00983. PMID: 30618599; PMCID: PMC6305899.

Zhou, Z., Zhang, G., Li, X., Liu, X., Wang, N., Qiu, L., et al., 2014. Loss of phenotype of parvalbumin interneurons in rat prefrontal cortex is involved in antidepressant- and propsychotic-like behaviors following acute and repeated ketamine administration. Mol Neurobiol 51 (2), 808-819.

Zlatković, J., Filipović, D., 2012 Oct 25. Bax and B-cell-lymphoma 2 mediate proapoptotic signaling following chronic isolation stress in rat brain. Neuroscience 223, 238-245. https://doi.org/10.1016/j.neuroscience.2012.08.005. Epub 2012 Aug 9. PMID: 22885231. 